Pontifícia Universidade $C_{\text {atólica }}$

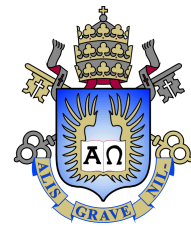

Victor Luis Barroso Nascimento

\title{
Ecumenismo Lógico
}

Dissertação apresentada como requisito parcial para obtenção do grau de Mestre pelo Programa de Pós-graduação em Filosofia do Departamento de Filosofia do Centro de Teologia e Ciências Humanas da PUC-Rio.

Orientador: Prof. Luiz Carlos Pinheiro Dias Pereira 


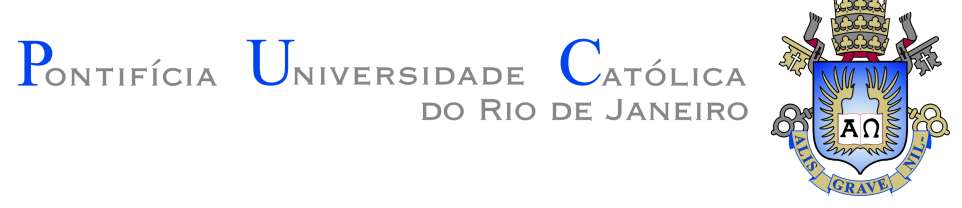

Victor Luis Barroso Nascimento

Ecumenismo Lógico

Dissertação apresentada como requisito parcial para obtenção do grau de Mestre pelo Programa de Pós-graduação em Filosofia do Departamento de Filosofia do Centro de Teologia e Ciências Humanas da PUC-Rio. Aprovada pela Comissão Examinadora abaixo assinada.

\author{
Prof. Luiz Carlos Pinheiro Dias Pereira \\ Orientador \\ Departamento de Filosofia - PUC-Rio
}

Prof. Edward Hermann Haeusler

Departamento de Informática - PUC-Rio

Prof. Bruno Lopes Vieira

Universidade Federal Fluminense - UFF

Prof. Jefferson de Barros Santos

Fundação Getúlio Vargas - FGV

Profa. Monah Winograd

Coordenador Setorial do Centro de Teologia e Ciências

Humanas - PUC-Rio

Rio de Janeiro, 13 de Abril de 2018 
Todos os direitos reservados. É proibida a reprodução total ou parcial do trabalho sem autorização da universidade, do autor e do orientador.

\section{Victor Luis Barroso Nascimento}

Bacharel em Direito pela Universidade do Estado do Rio de Janeiro. Exerce profissão jurídica, mas concentra sua produção acadêmica em outras áreas. Atualmente focado no estudo da Lógica Matemática e da Filosofia.

Ficha Catalográfica

Nascimento, Victor Luis Barroso

Ecumenismo lógico / Victor Luis Barroso Nascimento ; orientador: Luiz Carlos Pinheiro Dias Pereira. - 2018.

97 f. : $30 \mathrm{~cm}$

Dissertação (mestrado) - Pontifícia Universidade Católica do Rio de Janeiro, Departamento de Filosofia , 2018.

Inclui bibliografia

1. Filosofia - Teses. 2. Ecumenismo lógico. 3. Lógica intuicionista. 4. Lógica minimal. 5. Lógica clássica. I. Pereira, Luiz Carlos P. D. II. Pontifícia Universidade Católica do Rio de Janeiro. Departamento de Filosofia . III. Título.

CDD: 100 
Para Patricia Cezar, melhor companheira e maior inspiração. 


\section{Agradecimentos}

Agradeço ao meu orientador, Luiz Carlos Pinheiro Dias Pereira, pela honra e privilégio de ser orientado por uma das poucas pessoas que eu genuinamente admiro, tanto a nível pessoal quanto a nível intelectual.

Agradeço também a meu amigo Guilherme Paulino Passos, por ter me convencido da importância do estudo da lógica e de métodos formais e invertido completamente minhas pretensões acadêmicas, o que me pôs no caminho em que atualmente estou.

Agradeço ao CNPq e à PUC-Rio pelos auxílios concedidos, sem os quais este trabalho não poderia ter sido realizado.

E, por fim, agradeço a Patricia de Carvalho Cezar Siqueira, melhor companheira e maior inspiração, que sempre me auxilia, apoia em meus estudos e, quando necessário, me dá forças para continuar. 


\section{Resumo}

Nascimento, Victor Luis Barroso; Pereira, Luiz Carlos Pinheiro Dias (Orientador). Ecumenismo Lógico. Rio de Janeiro, 2018. 97p. Dissertação de Mestrado - Departamento de Filosofia , Pontifícia Universidade Católica do Rio de Janeiro.

A história recente da Lógica Matemática foi marcada por alguns conflitos entre diferentes correntes filosóficas, cada uma buscando contextualizar a atividade matemática a partir de seu próprio prisma analítico e, por meio disso, tentando conquistar para si mesma o pódio fundacional das Ciências Formais Tais discussões, perenes o bastante para ainda quedarem sem solução, foram fortemente impactadas pela apropriação semântica de alguns resultados técnicos obtidos no campo da teoria da prova, o que redefiniu a relação existente entre as abordagens clássica e intuicionista na matemática. Neste contexto, a presente dissertação tem por finalidade realizar uma descrição da emergente literatura de propostas integrativas entre diferentes sistemas lógicos e matemáticos (apelidadas por Dag Prawitz de "ecumenismo lógico"), além de investigar alguns impactos que mudanças formais poderiam ocasionar nas concepções filosóficas de algumas teorias matemáticas. No capítulo introdutório, traçamos um panorama geral desta nova proposta ecumênica e analisamos com mais atenção o conflito entre as lógicas Clássica, Intuicionista e Minimal, considerado por muitos como um dos mais influentes na literatura contemporânea. No segundo capítulo, este trabalho fornece uma contribuição original para a literatura ao criar uma nova abordagem ecumênica, além de provar algumas equivalências no interior do sistema Clássico-Intuicionista recentemente criado por Prawitz e compará-lo com uma lógica que criamos usando esta nova abordagem. No terceiro capítulo, contribuímos tanto com a abordagem tradicional quanto com nossa abordagem original ao criar e comparar dua lógicas ecumênicas Minimal-Intuicionistas. Por fim, realizamos uma breve revisão do tímido estado da arte no último capítulo, oferecendo um novo esquema conceitual de interpretação dos sistemas ecumênicos e comentando alguns aspectos promissores do campo, que poderão vir a ser melhor trabalhados no futuro.

\section{Palavras-chave}

Ecumenismo lógico; Lógica intuicionista; Lógica minimal; Lógica clássica. 


\section{Abstract}

Nascimento, Victor Luis Barroso; Pereira, Luiz Carlos Pinheiro Dias (Advisor). Logical Ecumenism. Rio de Janeiro, 2018. 97p. Dissertação de Mestrado - Departamento de Filosofia , Pontifícia Universidade Católica do Rio de Janeiro.

The recent history of Mathematical Logic was marked by some conficts between different philosophical positions, each trying to contextualize mathematical activity from its own analytical viewpoint and, with this, trying to conquer the foundational podium of the formal sciences for itself. Such discussions, lasting enough to remain without a solution, were strongly impacted by the semantical appropriation of some technical results obtained in the field of proof theory, which redefined the relation between the classical and intuitionistic approaches to mathematics. In this context, the present dissertation aims to describe the emergent literature about the integration of different logical and mathematical systems (nicknamed "logical ecumenism" by Dag Prawitz), in addition to investigating some impacts that those formal changes could have on the philosophical conceptions of some mathematical theories. In the introductory chapter, we have outlined a general overview of this new ecumenical proposal and analysed in greater depht the conflicts between Classical, Intuitionistic and Minimal logic, considered by many as one of the most influent on the contemporary literature. In the second chapter, this work provides an original contribution to the literature by creating a new ecumenical approach, in addition to proving some equivalencies within Prawitz's recently created Classical-Intuitionist system, and compares it with the logical system we have created using this new approach. In the third chapter, we contribute both to the traditional approach and our original approach by creating and comparing two Minimal-Intuitionist ecumenical logics. Finally, we briefly review the timid state of the art in the last chapter, offering a new conceptual framework for interpreting ecumenical systems, as well as commenting on some promising aspects of the field, which may be better analyzed in the future.

\section{Keywords}

Logical ecumenism; Intuitionistic logic; Minimal logic; Classical logic. 


\section{Sumário}

1 Introdução $\quad 10$

1.1 Monismo e Pluralismo lógico 10

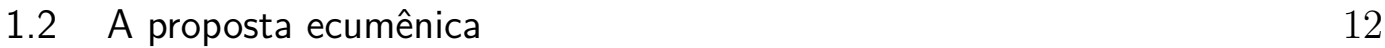

1.2.1 O Argumento de Quine $\quad 15$

$\begin{array}{lll}1.3 & \text { O debate entre clássicos e intuicionistas } & 19\end{array}$

2 Sistemas formais ecumênicos: lógicas clássica e intuicionista $\quad \mathbf{2 5}$

2.1 Definições iniciais 25

2.1.1 Linguagem 25

2.1.2 Elementos estruturais 27

2.1.3 Derivações e operações em derivações 29

2.1.4 Lógicas clássica, intuicionista e minimal 33

2.2 Estudos sobre funções de tradução 34

$\begin{array}{lll}2.3 & \text { Abordagens inferencialista e generalista } & 37\end{array}$

2.3.1 Relações entre ECl e PE 40

2.3.1.1 Uma breve digressão sobre PE: regras alternativas para semântica de provas 44

2.3.2 Normalização, princípio de subfórmula e outros teoremas $\quad 50$

2.3.3 Representação de derivações clássicas $\quad 55$

3 Sistemas formais ecumênicos: lógicas intuicionista e minimal $\quad 58$

3.1 Os sistemas PEM e EMI 58

3.1.1 Representações assimétricas nos sistemas EMI e PEM 61

3.1.2 Normalização e outros teoremas 65

3.1.3 Representação de derivações intuicionistas 66

3.2 Perda e recuperação de alguns resultados no ecumenismo clássicointuicionista-minimal 68

4 Uma reinterpretação ecumênica da Lógica Matemática $\quad 71$

4.1 A significância da diferença entre o ecumenismo inferencialista e o generalista

$\begin{array}{lll}4.2 & \text { Estado da arte } & 73\end{array}$

4.3 Uma nova lógica $\quad 81$

$\begin{array}{lll}4.4 & \text { Possíveis estudos futuros } & 87\end{array}$

$\begin{array}{lll}4.5 & \text { Conclusão } & 88\end{array}$

$\begin{array}{lll}5 & \text { Referências bibliográficas } & 90\end{array}$

$\begin{array}{lll}\text { A Provas adicionais } & 93\end{array}$ 
Once when there was a discussion about the arguments which young people should hear from philosophers in order to master what they are learning, Musonius said that rather than seeking many proofs on each subject, we should seek practical and clear ones. It is not the doctor who brings many drugs to sick people who deserves praise, he said, but rather the one who helps them in a noteworthy manner with the few drugs which he prescribes. The philosopher who teaches his listeners with many proofs is not to be praised either, but rather the one who guides them to where he wants them with a few.

Musonius Rufus, Musonius Rufus: Lectures and Sayings. 


\section{Introdução}

\section{1}

\section{Monismo e Pluralismo lógico}

Desde a fundação da disciplina na antiguidade até pelo menos o final do século passado, todos os estudos sistematizados sobre a lógica se mantiveram focados quase que exclusivamente em único sistema formal, o da contemporaneamente denominada lógica clássica. Durante todo este período, produções acadêmicas do campo eram permeadas pelo objetivo implícito de fornecer subsídios às formas clássicas de raciocínio e representação; sequer fazia sentido utilizar a qualificação "clássica" como elemento de distinção, já que este sistema tendia a ser visto como o único objeto de estudo possível para o campo da lógica.

Esta hegemonia, no entanto, foi recentemente rompida pelo surgimento de propostas que buscavam apontar deficiências ou inadequações no sistema clássico, bem como usar tais falhas para advogar pela necessidade de sua complementação através do uso de outros sistemas formais ou, em alguns casos, até mesmo pela sua completa substituição por novos sistemas formais através de programas "revisionistas" da lógica, normalmente baseados em concepções filosóficas de alguma forma conflitantes com as concepções clássicas. E, em que pese o sistema clássico ainda possa ser considerado o principal da atualidade, estes atos iniciais de afronta deram ensejo a um debate generalizado sobre as finalidades e a natureza do que se estuda no tradicional campo da "Lógica", cuja pretensa unicidade é posta em questão por este novo mundo de sistemas formais múltiplos.

Muito embora a dispersão das críticas dificulte uma análise completa de todos os pontos controvertidos do debate, as diferentes visões defendidas podem, em geral, ser categorizadas em termos de duas posições distintas: a posição monista e a posição pluralista. Os monistas acreditam que há apenas um sistema lógico "correto" ou "apropriado", e defendem que todos os demais sistemas incorrem em algum erro ou são, de alguma forma, inadequados. Por sua vez, os pluralistas defendem a existência de ao menos duas abordagens que encerram alguma forma de mérito e são dignas de reconhecimento, de modo 
que nenhum sistema unitário pode reivindicar para si a totalidade do campo de estudo.

É importante que nos atenhamos à literalidade desta definição para ressaltar que, muito embora o monismo costume ser visualizado com mais frequência em defesas do sistema clássico, não existe nenhuma conexão necessária entre o monismo e esta posição tradicionalista; o monismo consiste na absolutização de qualquer posição no contexto da lógica, e pode ser adotado por qualquer corrente que tente reivindicar para si a totalidade do objeto lógico. A contrario sensu, o pluralismo consiste na rejeição deste absolutismo unitário em favor do relativismo ou, alternativamente, de alguma espécie de absolutismo múltiplo, na qual o valor absoluto passa a ser atribuído a um conjunto seleto de sistemas. Portanto, o pluralismo também não deve ser confundido com o relativismo, que consiste na posição (mais forte) de se negar qualquer espécie de preponderância de qualquer sistema lógico sobre qualquer outro.

Todo defensor do monopólio clássico sobre a verdade é um monista, mas nem todo monista defende que é a lógica clássica que detém este monopólio. Do mesmo modo, todo relativista é um pluralista, mas nem todo pluralista é um relativista; os relativistas se comprometem com uma rejeição completa da hierarquização entre lógicas, enquanto os demais pluralistas, defensores de posições oligopolistas mais ou menos amplas, criam um amplo espectro que separa os extremos monista (heterogêneo, em virtude das diferentes posições monistas) e relativista (homogêneo, já que o niilismo hierárquico é condição necessária e suficiente para que um autor seja incluso na posição).

Como se não bastasse, Roy T. Cook oferece o seguinte esclarecimento no início de seu artigo sobre as diferentes formas de pluralismo lógico, indicando que existem ainda mais nuances nas posições que acabamos de descrever:

"Logical pluralism is the view that there is more than one 'correct', 'best', or 'legitimate' logic, while logical monism is the view that there is only one such logic. Of course, this simple description is of little help until we know what a logic is, what the study of logics is meant to accomplish, and what counts as being 'correct', 'best', or 'legitimate'." (1, pg. 492)

Portanto, além da divergência sobre qual(is) lógica(s) deve(m) ocupar a posição superior nas hierarquias estabelecidas pelo monismo e pelo pluralismo não relativista, o próprio critério usado para efetivar julgamentos de superioridade é alvo de controvérsias, o que cria divisões ainda mais marcantes tanto entre monismo e pluralismo quanto entre diferentes formas de defesa do monismo e do pluralismo. Dois pluralistas podem chegar à conclusão de 
que determinado conjunto de lógicas é o "correto" através de razões completamente distintas e até mesmo autoexcludentes, bastando que adotem diferentes critérios valorativos ou definam de modo distinto o objeto e as finalidades da própria lógica ${ }^{1}$.

É notável a ruptura que o simples surgimento de correntes pluralistas e sistemas lógicos distintos do clássico conseguiram promover na literatura lógica. A nova dispersão de enfoques é evidente, e o número de lógicas sendo estudadas se expandiu e se expande em um ritmo tão rápido que já é praticamente impossível traçar um panorama de absolutamente todas as abordagens que estão sendo desenvolvidas e estudadas. Muito embora a lógica clássica ainda seja amplamente utilizada e retenha boa parte do prestígio de outrora, o interesse crescente por sistemas formais com características peculiares - como, por exemplo, a lógica intuicionista, a lógica de relevância, as lógicas multivaluadas e as lógicas paraconsistentes - obriga as linhas tradicionais de estudo a dividir cada vez mais espaço com as novas tendências.

Diante disto, alguns autores começaram a desenvolver interesse pelo estudo de semelhanças e diferenças entre os diferentes sistemas lógicos e, em um nível mais profundo, pela comparação dos próprios sistemas filosóficos que muitas vezes subjacem e justificam tais sistemas. Com isso, começaram a surgir na literatura abordagens nas quais estas diferentes filosofias e lógicas são mescladas, integradas, comparadas e conjuntamente analisadas das mais variadas formas. E é neste contexto que começou a se delinear a abordagem específica que pretendemos analisar e desenvolver no presente trabalho: o ecumenismo lógico.

\section{2}

\section{A proposta ecumênica}

Antes de explicar o que entendemos por ecumenismo lógico ou abordagem ecumênica da lógica, precisamos fazer uma pequena ressalva sobre o presente status da abordagem na literatura.

Muito embora o termo já tenha sido usado em artigos que explicitamente buscam explorar sistemas ecumênicos ${ }^{2}$, parte significativa dos estudos similares independentemente desenvolvidos, que consideraremos parte integrante da abordagem ecumênica em nossa exposição, não adotam expressamente a nomenclatura aqui utilizada. Como exemplos, podemos citar o artigo de Krauss (5), cujo objetivo manifesto é promover um "refinamento construtivo do cálculo de sequêntes clássico", e o artigo de Dowek, que busca "oferecer definições

\footnotetext{
${ }^{1}$ Uma boa exposição de divergências internas específicas no pluralismo pode ser encontrada em (2)

${ }^{2}$ Vide (3) e, de maneira mais sutil, (4, pg. 30)
} 
construtivas dos conectivos e quantificadores clássicos". Em momento algum os autores utilizam a expressão "ecumenismo" para qualificar suas abordagens.

Por esta razão, o ecumenismo deve ser visualizado não como um descritor de esforços distintos empregados sob um nome comum, tais como as defesas do pluralismo e do intuicionismo em seus diferentes formatos, mas sim como um conceito criado para englobar uma série de trabalhos mais ou menos harmônicos que confluem, direta ou indiretamente, para o estudo de um mesmo objeto. Portanto, artigos devem ser classificados como ecumênicos ou não de acordo com o seu objeto, e não sua filiação filosófica ou finalidade declarada.

Dito isto, podemos definir a abordagem ecumênica como aquela na qual se busca fornecer definições de operadores, fórmulas e/ou outros elementos que integrem determinado sistema formal em outro sistema formal, de modo a permitir tanto que os elementos do primeiro sistema passem a ser incorporados no segundo quanto que os elementos dos dois sistemas possam manter alguma espécie de interação. A partir desta definição, podemos observar claramente como os trabalhos de Krauss e Dowek traçam objetivos que se alinham com o objetivo do ecumenismo lógico, e por conseguinte, devem ser considerados exemplos de abordagens ecumênicas na lógica.

O surgimento do pluralismo lógico e de sistemas formais diversos do clássico, por óbvio, precisaram anteceder o surgimento do ecumenismo lógico, já que não se pode falar de integração entre duas lógicas se não houverem ao menos duas lógicas que possam ser integradas. No entanto, o ecumenismo possui consequências no mínimo curiosas tanto para o pluralismo quanto para o monismo e, se levado a seus extremos, talvez possa até mesmo vir a fazer desaparecer a distinção entre estas duas posições antagônicas.

Caso uma lógica aceita por um monista passe a adotar elementos originalmente pertencentes a lógicas diversas e, o que é mais importante, passe a defini-los em seus próprios termos, o monista será forçado a reconhecer alguma espécie de validade ao sistema "desviante", já que sua própria lógica consegue conferir sentido às constantes, operadores ou inferências do outro sistema. O monista, sob pena de rejeitar sua própria lógica, precisaria aceitar que a diferença entre esta e alguma outra é puramente convencional ou puramente linguística e, a menos que se passe a dizer que as duas lógicas são de fato apenas uma, se verá forçado a reconhecer alguns méritos da visão lógica pluralista.

Por sua vez, posições pluralistas não relativistas colapsarão em uma posição monista sempre que a abordagem ecumênica puder transformar os múltiplos sistemas lógicos tidos como "válidos" por determinada corrente pluralista em um único sistema lógico que possa englobar todos os aspectos desejáveis 
de todos os outros. Caso todos os aspectos desejáveis das múltiplas lógicas estejam contidas nesta nova lógica, o pluralista, sob pena de abandonar o julgamento favorável dispensado aos sistemas originais pelo seu tipo específico de pluralismo, se verá forçado a reconhecer que esta lógica unitária é uma lógica única que se afigura como "correta" para todos os propósitos - o que importa, é claro, na equiparação do pluralismo inicialmente adotado com um novo tipo específico de monismo.

Caso levemos o ecumenismo lógico às suas últimas consequências, é concebível até mesmo que a posição pluralista relativista venha a colapsar em uma posição monista, o que talvez possa ser levado a cabo por meio da criação de alguma espécie de "lógica ecumênica universal" ou, simplesmente, de uma uma "lógica universal". Um framework unificado para todas as lógicas existentes - ou, o que seria ainda mais interessante, para todos os sistemas formais concebíveis - faria com que este "sistema" contivesse todos os outros sistemas formais, e qualquer um que defendesse a "corretude" ou "legitimidade" deste sistema unitário também estaria defendendo que todos os sistemas lógicos existentes (ou concebíveis) também são "corretos" ou "legítimos", o que paradoxalmente poderia ser visto tanto como uma posição monista quanto como uma posição relativista ${ }^{3}$.

${ }^{3}$ No entanto, a própria possibilidade de se promover algo do tipo é posta em questão na literatura. Em uma análise crítica de outras propostas com estas mesmas pretensões, Jean-Yves Béziau (6, pgs. 1-2), defendendo sua própria proposta "universalista", segundo a qual existiria uma teoria geral que engloba todas as lógicas e que não seria em si mesma uma lógica, assevera o seguinte:

"In fact, from the viewpoint of universal logic the existence of one universal logic is not even possible, and this is a result that can easily be shown. One might thus say somehow ironically the following: according to universal logic there is no universal logic.

Some people in some countries have always tried to elaborate a universal system that would account for any sort of reasoning, or reasoning as a whole. Aristotelian logic was depicted itself as a universal one. More recently, first-order classical logic appeared to some as a universal system accounting for mathematical reasoning as well as current one, that is, the one used to buy your bread at the bakery.

But first-order classical logic was also criticized at length, whether concerning its claim to describe mathematical reasoning or physical, computational, current, philosophical ones, and the like. Many new logics were further developed, namely: intuitionistic logic, combinatory logic, linear logic, quantum logic, erotetic logic, modal logic, paraconsistent logic, polar logic, relevant logic and so many others, all the more that each of these is often to be divided into a disparate multiplicity, as in the case of modal logics.

Among advocates of these logics, some forcefully believe that their own logic is the best one, that it explains everything, solves everything, so that their logic is universal, as was formerly the case with Stanislaw Lesniewski or, more recently, with Jean-Yves Girard and its linear logic, Jaakko Hintikka and its IF logic, and, even more explicitly, Ross Brady with its relevant logic he squarely dubbed a "universal logic".

Such a view is not shared by people working in quantum logic, for example; indeed, these only want to account for one particular reasoning related to one particular area, without ever claiming that such is the reasoning we are using or should use whenever we go at the bakery. Now is such a view consistent? Are we entitled to say the following: to each area, to each situation, its own logic, or even to each group of persons, to each individual, its own logic. So there would be a logic of chemistry, logic of clouds, logic of sex, logic of women, 
Do ponto de vista prático, a principal vantagem da abordagem ecumênica decorre de sua aparente capacidade de incutir qualidades específicas de algumas lógicas em outras, o que permite que criemos novos sistemas que contenham as qualidades das lógicas usadas como base para sua criação ou, ainda, que refinemos sistemas já existentes (adicionando novas constantes, por exemplo) para que eles exibam qualidades pertencidas por outro.

No contexto específico da lógica matemática, autores como Prawitz (7), Pereira (8), Krauss (5), Girard (9) e Dowek (10) tentam estender à lógica clássica algumas virtudes das lógicas intuicionista e minimal, que normalmente residem no caráter algorítmico das provas construtivas e na subsequente utilidade destas para as Ciências da Computação. As posições destes autores, assim como as diferenças entre suas abordagens, serão melhor analisadas na exposição do estado da arte, a ser feita no último capítulo (seção 4.2) ${ }^{4}$.

Antes que comecemos a tratar de sistemas ecumênicos específicos, no entanto, é importante que também teçamos considerações sobre algumas críticas dirigidas ao pluralismo em geral, já que a existência de um mínimo de pluralidade na lógica, como apontado anteriormente, pode ser vista como uma condição de possibilidade para o próprio avanço da abordagem ecumênica. Para isto, focaremos especificamente na crítica formulada por Quine contra a possibilidade de revisão e redefinição de sistemas formais na lógica, uma das poucas objeções preeminentes contra as novas tendências da literatura.

\subsection{1}

\section{O Argumento de Quine}

Uma das principais críticas que pode ser levantada contra propostas que impliquem em alguma espécie de revisionismo ou reinterpretação da lógica é aquela formulada por Quine, que afirmava serem as propostas revisionistas

logic of dogs, the logic of Bouvard and the logic of Pécuchet.

Actually, such a relativization of logic is equally absurd as the opposite stance according to which only one logic could explain everything. Obviously, there is also one intermediary situation according to which there are neither only one nor thousand and one logics, but three or four: so is the middle, not to say mediocre position of people who cut the cake into three parts saying that there is the reasoning for formal sciences, on the one hand, the reasoning for empirical sciences, on the other hand, and finally the natural reasoning for daily life. Behind such a stance we see again the old contradistinction between inductive logic and deductive logic.

The view of universal logic is that one plausibly can unify the large kaleidoscopic variety of logics, while preserving their diversity. In the case of universal logic, as opposed to those who support the view of one universal logic, unity is entailed by diversity. Universal logic is not a logic but a general theory of different logics. This general theory is no more a logic itself than is meteorology a cloud."

${ }^{4}$ Como as abordagens que podem ser consideradas ecumênicas ainda estão dispersas na literatura, parece de bom tom que exponhamos melhor o ecumenismo em si, assim como algumas contribuições específicas deste trabalho, antes de comentar e indicar inter-relações entre estes trabalhos. 
sempre fadadas ao fracasso porque, caso atribuamos um novo significado às constantes lógicas contidas em determinado sistema, nós estaremos apenas criando novas constantes lógicas, com sentido completamente diverso do original (ainda que a notação utilizada falsamente nos induza a crer que se tratam das mesmas constantes), e não propriamente revisando o sentido que lhes havia sido atribuído originalmente. Deste modo, toda tentativa de revisão inevitavelmente se tornará uma atividade de criação, o que tornaria o revisionismo algo a priori impossível.

A crítica é formulada no seguinte trecho do livro "Philosophical Logic":

"To turn to a popular extravaganza, what if someone were to reject the law of non-contradication and so accept an occasional sentence and its negation both as true? An answer one hears is that this would vitiate all science. Any conjunction of the form 'p . -p'; logically implies every sentence whatever; therefore acceptance of one sentence and its negation as true would commit us to accepting every sentence as true, and thus forfeiting all distinction between true and false.

In answer to this answer, one hears that such a full-width trivialization could perhaps be staved off by making compensatory adjustments to block this indiscriminate deducibility of all sentences from an inconsistency. Perhaps, it is suggested, we can so rig our new logic that it will isolate its contradictions and contain them.

My view of this dialogue is that neither party knows what he is talking about. They think they are talking about negation,'-', 'not'; but surely the notation ceased to be recognizable as negation when they took to regarding some conjunctions of the form 'p . -p' as true, and stopped regarding such sentences as implying all others. Here evidently, is the deviant logician's predicament: when he tries to deny the doctrine he only changes the subject."(11, pg. 81)

A nosso ver, Quine está correto quando diz que a "revisão" do significado de uma constante lógica, nestes termos, seria equivalente à criação de uma nova constante lógica, necessariamente distinta da anterior. No entanto, o autor também parece estar caracterizando de maneira errônea o debate proposto por revisionistas, monistas não clássicos e pluralistas, o que acaba ocultando o ponto central da discussão.

Quine aparentemente cai em contradição ao indicar que o revisionista, por defender uma impossibilidade lógica, está condenado a ver suas pretensões falharem ("My view of this dialogue is that neither party knows what he is 
talking about [...] Here evidently, is the deviant logician's predicament: when he tries to deny the doctrine he only changes the subject"), muito embora tenha deixado implícito que o revisionista estaria ciente do caráter criativo de sua proposta ("Perhaps, it is suggested, we can so rig our new logic that it will isolate its contradictions and contain them." - grifo nosso). Ora, se o revisionista especifica que sua proposta está dando azo à criação de uma nova lógica (e não simplesmente "ressignificando" uma lógica já existente), seria o retrato de Quine realmente fiel à controvérsia representada? Qual seria a significância prática da observação de que o revisionista, inadvertidamente, estaria criando (e não apenas revisando), conquanto deixasse claro que uma nova lógica estaria sendo criada por esta "revisão"?

Em um trecho posterior do mesmo texto, Quine parece reconhecer brevemente que tais discordâncias extrapolam o campo da lógica, e inclusive concede que algumas objeções levantadas por revisionistas poderiam vir a ser razoáveis:

"By the reasoning of a couple of pages back, whoever denies the law of excluded middle changes the subject. This is not to say that he is wrong in so doing. In repudiating 'p or -p' he is indeed giving up classical negation, or perhaps alternation, or both; and he may have his reasons." (11, pg. 83$)$

Não obstante, ao contrapor a lógica clássica a lógicas trivaluadas, Quine também parece tangenciar nossas considerações ao afirmar que comparações entre operadores similares de duas lógicas diferentes possuem um certo caráter "analógico":

"Sometimes, however, three-valued logic is envisaged as an improved logic. Its three values are called truth, falsity, and something intermediate. A construction called negation carries so-called truths into falsehoods, falsehoods into truths, and intermediates into intermediates. On these terms the law of excluded middle palpably fails. But we must remember, even while honoring this deviant logic as genuine logic, that the terminology 'true', 'false', and 'negation' carries over into it from our logic only by partial analogy. The failure of the law is, insofar, nominal." (11, pg. 84)

A objeção inicial, portanto, só subsistiria caso estivéssemos focando exclusivamente em debates sobre formalismos específicos, onde o ponto de controvérsia seria o "significado" de constantes lógicas já estabelecidas. Este, no entanto, não parece ser o caso; as objeções não questionam o sentido 
atribuído às constantes clássicas no sistema clássico, mas sim sua adequação para o desenvolvimento da atividade lógica, podendo ser críticas gerais ("a lógica clássica não é adequada para a descrição de nenhum fenômeno") ou particulares ("a lógica clássica não é adequada para a descrição de algum fenômeno específico").

De um modo um tanto quanto irônico, podemos dizer que a análise das propostas "desviantes" feita por Quine só pôde chegar à conclusão de que o revisionismo implica em uma mudança de assunto justamente porque Quine mudou de assunto quando começou a descrever as posições "desviantes", atribuindo aos revisionistas um papel que desde o início estes não parecem ter pretendido exercer.

As controvérsias suscitadas por revisionistas, ao que parece, possuem cunho filosófico, e não lógico-formal. Elas não se propõem a discutir o significado estabelecido das constantes lógicas no formalismo clássico, mas sim o quão adequados estes são para a descrição dos objetos não-lógicos que o formalismo se propõe a representar. Um intuicionista, por exemplo, não precisa discordar de um lógico clássico quanto ao significado da disjunção e da implicação verofuncionais clássicas no interior do próprio sistema clássico, e ele não estaria traindo seus princípios caso utilizasse a lógica clássica para descrever um fenômeno não-matemático que considerassem possuir comportamento clássico ${ }^{5}$. A discordância de um intuicionista, por exemplo, se dá exclusivamente no campo da adequação dos raciocínios clássicos ao fenômeno matemático, já que o intuicionista concebe a atividade matemática como uma prática essencialmente construtiva.

Caso realizemos esta delimitação de assunto e identifiquemos que o debate pertence ao campo material-filosófico, teremos em mãos uma genuína discordância que de modo algum poderá ser resolvida no âmbito exclusivo da análise lógica. Não obstante, isto torna claro que o argumento não constitui óbice algum à proposta ecumênica, já que esta busca não promover uma revisão do sentido adotado pelas constantes lógicas em sistemas já estabelecidos, mas sim promover ou a incrementação de sistemas já existentes, sem a realização de modificações nas constantes lógicas já definidas no sistema, ou a criação de novos sistemas que possuam novas constantes lógicas aptas a satisfazer os interesses materiais de todas as correntes de pensamento cujos sistemas formais estão sendo mesclados para a criação de um novo sistema ecumênico.

\footnotetext{
${ }^{5}$ Contanto, é claro, que não restrinjamos o intuicionismo à concepção de Brouwer, que possivelmente defenderia uma extensão do intuicionismo a todos os campos do conhecimento.
} 


\section{3 \\ O debate entre clássicos e intuicionistas}

Historiadores costumam indicar que a lógica clássica remonta pelo menos ao sistema silogístico formulado por Aristóteles ${ }^{6}$, no qual muitos veem as formas de raciocínio clássico expostas em uma de suas versões mais filosoficamente refinadas. No entanto, após um longo período de hegemonia aristotélica, a relativa unicidade da filosofia da lógica foi rompida pelo surgimento de diferentes posições filosóficas que, ao tentar substituir ou incrementar os estudos de Aristóteles, se tornaram incompatíveis entre si, muito embora permanecessem unidas pelo seu reconhecimento monista da supremacia clássica e por sua convergência específica para a lógica clássica após a (relativamente recente) matematização da lógica. Boa parte desta divergência é atribuível às correntes de pensamento pertencentes à tradição analítica da filosofia, que por muito tempo divergiram sem promover alguma espécie de afastamento do monismo.

Tendo em vista esta ampla gama de posições que atualmente orbitam o formalismo clássico, parece que a posição clássica é melhor caracterizada não mais pelas considerações filosóficas que lhe são subjacentes, mas sim por um dos seus mais característicos aspectos formais: a semântica verofuncional bivalente, segundo a qual toda proposição deve possuir ou o valor "verdadeiro" ou o valor "falso".

A semântica bivalente remonta, assim como muitos outros aspectos do sistema clássico, pelo menos até os lógicos estoicos ${ }^{7}$, mas foi drasticamente

\footnotetext{
${ }^{6}$ Muito embora Aristóteles ainda possa ser considerado um dos principais precursores da lógica moderna, a silogística clássica não pode ser confundida com a silogística aristotélica. Sobre o ponto, assim assinala Lukasiewicz: "The difference between the Aristotelian and the traditional syllogism is fundamental. The Aristotelian syllogism as an implication is a proposition, and as a proposition must be either true or false. The traditional syllogism is not a proposition, but a set of propositions which are not unified so as to form one single proposition. [...] It is an inference, or, according to scholastic terminology, a consequence. Inferences and consequences, not being propositions, are neither true nor false, as truth and falsity belong only to propositions. They may be valid or not. The same has to be said of the traditional syllogism. Not being a proposition the traditional syllogism is neither true nor false; it can be valid or invalid. [...] If you find a book or an article where no difference is made between the Aristotelian and the traditional syllogism, you may be sure that the author is either ignorant of logic or has never seen the Greek text of the Organon. [...] When we realize that the difference between a thesis and a rule of inference is from the standpoint of logic a fundamental one, we must agree that an expositions of Aristotelian logic which disregards it cannot be sound. We have to this day no genuine exposition of Aristotelian logic." $(12$, pgs. $21-22)$

${ }^{7}$ Os estóicos anteciparam, por exemplo, as tabelas de verdade e a implicação material (13, pg. 44). Infelizmente, estas contribuições comumente são esquecidas ou erroneamente atribuídas a Aristóteles. Comentando o fato, trazido à tona por Lukasiewicz, Benson Mates assevera o seguinte: "The period of Aristotelian dominance in logic might well have ended sooner if certain ancient texts had been studied more carefully. About fifty years ago, C. S. Peirce noticed that the ancients had been aware of the relation now called "material implication" and had even carried on a great controversy over it. So far as we know, neither Peirce nor anyone else pursued the subject further until 1927, when the eminent Polish
} 
aprofundada e popularizada na lógica matemática após os estudos semânticos de Alfred Tarski (14). De acordo com esta concepção, todas as proposições são ou verdadeiras ou falsas, e esta distribuição de valores independe do nosso conhecimento sobre a veracidade ou falsidade de alguma proposição específica. Deste modo, as afirmações de que toda proposição ou é verdadeira ou é falsa $(A \vee \neg A)$ e de que a afirmação de falsidade de uma alegação de falsidade implica em uma afirmação de verdade $(\neg \neg A \rightarrow A)$ são consideradas tautológicas.

Por sua vez, o sistema formal intuicionista rejeita esta concepção e afirma que, ao menos no campo específico das ideias matemáticas ${ }^{8}$, nosso sistema deve ser construído sobre alicerces mais sólidos: não podemos afirmar que uma proposição é "verdadeira" se não possuirmos um construto matemático que demonstre a verdade desta proposição, e não podemos considerá-la "falsa" se não possuirmos uma construção que demonstre a impossibilidade de sua construção. De igual modo, não podemos afirmar que toda proposição é verdadeira ou falsa $(A \vee \neg A)$ se não possuirmos um método capaz de construir qualquer proposição ou demonstrar sua impossibilidade, assim como não podemos extrair um método para a construção de um objeto a partir da demonstração de sua possibilidade - ou seja, de que sua impossibilidade é impossível $(\neg \neg A \rightarrow A)^{9}$. Com isto, estas duas proposições deixam de ser tautologias e passam a ser proposições contingentes.

Portanto, os conceitos de "verdade" e "falsidade", ao menos como concebidos pelos matemáticos clássicos, são considerados pelos intuicionistas como insuficientes para uma correta caracterização do fenômeno matemático, que

logician Lukasiewicz pointed out that not only material implication but also many other important concepts and methods of modern logic had been anticipated in the writings of the early Stoics. Lukasiewicz showed that Stoic logic had differed essentially from Aristotelian logic, with which it was later confused. The difference lay primarily in two circumstances: (1) Stoic logic was a logic of propositions, while Aristotelian logic was a logic of classes; (2) Stoic logic was a theory of inference schemas, while Aristotelian logic was a theory of logically true matrices. Lukasiewicz showed also that the Stoics had used truth-functional definitions for all the common propositional connectives. He further drew attention to the fact that the Stoics clearly distinguished arguments from the corresponding conditional propositions, and, most important of all, that the Stoics had a kind of calculus of inference-schemas: they took five inference-schemas as valid without proof and rigorously derived other valid schemas from these. Comparing such facts with the extremely adverse and inaccurate characterizations of Stoic logic by Prantl, Zeller, and other "standard" authors, and observing that a similar situation obtained with respect to medieval logic, Lukasiewicz understandably came to the conclusion that the history of logic ought to be rewritten." (13, pgs. 2-3)

${ }^{8}$ "INT. We have spoken about that subject before. The idea that for the description of some kinds of objects another logic may be more adequate than the customary one has sometimes been discussed. But it was Brouwer who fist discovered an object which actually requires a different form of logic, namely the mental mathematical construction [L. E. J. Brouwer 1908]. The reason is that in mathematics from the very beginning we deal with the infinite, whereas ordinary logic is made for reasoning about finite collections." $(15$, pg. 1)

${ }^{9}$ Muito embora a negação dos dois sistemas sejam interpretadas de forma diferente, o seu uso em sistemas formais parece coincidir em diversos aspectos. Sobre o tema, ver as breves considerações feitas por Pereira em (8) 
seria essencialmente ligado à prática matemática e dependeria estritamente da efetiva construção de provas e objetos matemáticos.

Esta mudança de perspectiva possui efeitos interessantes, mas profundamente controversos por suas próprias consequências: na matemática intuicionista (que é um subsistema da matemática clássica), toda prova necessariamente possui natureza algorítmica e é, por conseguinte, "construtiva", o que de pronto elimina do sistema, a contrario sensu, diversos resultados estabelecidos de maneira não construtiva na matemática clássica, bem como todos os resultados derivados a partir deles. Este efeito cascata obriga o intuicionista a rejeitar parte significativa de todos os ramos da matemática contemporânea, o que naturalmente faz com que diversos matemáticos praticantes concluam pela absoluta inviabilidade da condução da matemática nos termos intuicionistas.

Curiosamente, muito embora tanto a diferença de status das proposições $(A \vee \neg A)$ e $(\neg \neg A \rightarrow A)$ quanto as diferenças concretas que isso acarreta na prática matemática sejam bons ponto de partida para a caracterização das diferenças entre as lógicas clássica e intuicionista, os defensores da filosofia intuicionista explicitamente recusam categorizações baseadas tão-somente nos sistemas formais a que os próprios intuicionistas aderem, asseverando que a diferença entre as duas correntes, por ser essencialmente material/filosófica, não pode ser caracterizada apenas pelo ponto de vista formal.

O ponto é ressaltado no seguinte trecho do livro de Heyting, onde o autor expõe sua visão sobre o conflito de forma lúdica através de diálogos:

"FORM. For most mathematicians this value is affected fatally by the fact that you destroy the most precious mathematical results; a valuable method for the foundation of mathematics ought to save as much as possible of its results [D. Hilbert 19221. This might even succeed by constructive methods ; for definitions of constructiveness other than that advocated by the intuitionists are conceivable. For that matter, even the small number of actual intuitionists do not completely agree about the delimination of the constructive. The most striking example is the rejection by Griss of the notion of negation, which other intuitionists accept as perfectly clear [H. Freudenthal 1936A] [G. F. C. Griss 1946, p. 24; 1946A]. It seems probable, on the other hand, that a somewhat more liberal conception of the constructive might lead to the saving of the vital parts of classical mathematics.

INT. As intuitionists speak a non-formalized language, slight divergences of opinion between them can be expected. Though they 
have arisen sooner and in more acute forms than we could foresee, they are in no way alarming, for they all concern minor points and do not affect the fundamental ideas, about which there is complete agreement. Thus it is most unlikely that a wider conception of constructiveness could obtain the support of intuitionists. As to the mutilation of mathematics of which you accuse me, it must be taken as an inevitable consequence of our standpoint. It can also be seen as the excision of noxious ornaments, beautiful in form, but hollow in substance, and it is at least partly compensated for by the charm of subtle distinctions and witty methods by which intuitionists have enriched mathematical thought." (15, pgs. 10-11)

As consequências da adoção de métodos formais intuicionistas, portanto, devem ser vistas como um produto inevitável da adoção da concepção intuicionista da matemática, e não o contrário. Os intuicionistas selecionam sistemas com base nos princípios sobre os quais eles são construídos, e não por suas consequências ou usos práticos. A ruptura intuicionista é de uma natureza profunda; o matemático clássico pode usar a matemática intuicionista esporadicamente quando estiver interessado em algoritmos e resultados de natureza construtiva, mas um matemático intuicionista que usar a matemática clássica estará instantaneamente entrando em contradição com suas próprias concepções filosóficas. O classicismo é disponível para o matemático clássico, mas o intuicionismo é indisponível para os matemáticos intuicionistas.

Isso não quer dizer, é claro, que a posição intuicionista não possua suas nuances; intuicionistas podem divergir sobre aspectos específicos do intuicionismo, contanto que não abandonem os pontos fulcrais e distintivos da concepção construtiva da matemática. Enquanto a adesão a esse núcleo principiológico se mantenha firme, os pontos que lhes unem serão mais fortes que os pontos que lhes separem.

Por conseguinte, um sistema formal construtivo distinto da lógica de Heyting, que se convencionou chamar de "lógica intuicionista", não deveria deixar de ser considerado um sistema intuicionista só por abraçar algumas destas divergências pontuais. Tanto que Heyting explicitamente expõe a posição de um de seus críticos, Johansson, como um "sistema de lógica intuicionista" alternativo, o que nos leva a questionar a adequação do nome "lógica intuicionista", hoje canônico, para denominar o sistema intuicionista específico de Heyting. Tendo em vista que os intuicionistas se recusam a ser definidos por seus formalismos e podem adotar sistemas diferentes, esta escolha de nomenclatura certamente parece infeliz.

Neste sentido, confira-se o trecho que acabamos de comentar: 
"X. $\neg p \rightarrow(p \rightarrow q)[\ldots]$

Axiom X may not seem intuitively clear. As a matter of fact, it adds to the precision of the definition of implication. You remember that $\vdash p \rightarrow q$ can be asserted if and only if we possess a construction which, joined to the construction p, would prove q. Now suppose that $\vdash \neg p$, that is, we have deduced a contradiction from the supposition that $\mathrm{p}$ were carried out. Then, in a sense, this can be considered as a construction, which, joined to a proof of $\mathrm{p}$ (which cannot exist) leads to a proof of $q$. I shall interpret the implication in this wider sense.

A system of intuitionistic logic in which $\rightarrow$ is interpreted in the narrower sense and in which, accordingly, $\mathrm{X}$ is rejected as an axiom, has been developed by Johansson in his "minimal calculus"[I. Johansson 1936]."(15, pgs. 101 e 102).

Deste modo, o sistema minimal criado por Johansson (16) deve ser visualizado como uma variante do sistema intuicionista de Heyting, e as duas lógicas devem ser consideradas partes integrantes do intuicionismo como um todo. A ruptura entre o sistema minimal e o sistema intuicionista é de uma natureza bem menos radical que a destes dois sistemas com o clássico, conforme se pode depreender não só do texto transcrito acima, mas também das extensivas discussões travadas por carta entre os dois autores, parcialmente preservadas e analisadas em um relatório técnico recente (17).

Estabelecidas as diferenças entre esses três sistemas, passaremos agora à parte técnica de nosso trabalho, na qual estudaremos um sistema ecumênico clássico-intuicionista já presente na literatura e o contrastaremos com outras possíveis abordagens ecumênicas, além de expandir a abordagem deste mesmo sistema para a lógica minimal.

Iniciaremos o Capítulo 2 examinando sistemas formais ecumênicos especificamente voltados para a lógica clássica e a lógica intuicionista de Heyting, além de fazer algumas pequenas contribuições para o sistema já estabelecido na literatura. No Capítulo 3, passaremos a realizar uma análise das relações entre a lógica de Heyting e a lógica minimal de Johansson, além de traçar alguns comentários sobre as diferenças técnicas entre o ecumenismo clássicointuicionista e o ecumenismo intuicionista-minimal. Logo após, exploraremos algumas consequências de todas as considerações anteriores para sistemas que objetivem, a um só tempo, mesclar as três lógicas em um único sistema. Por fim, já no Capítulo 4, esclareceremos a relação entre as duas abordagens apontadas no Capítulo 2 e realizaremos uma exposição comentada do estado da 
arte ecumênico, terminando o presente trabalho com a apresentação de um sistema lógico que incorpora todas as ferramentas ecumênicas desenvolvidas nos Capítulos 2 e 3 e alguns comentários sobre trabalhos futuros que poderão vir a ser desenvolvidos de forma a complementar as conclusões do presente estudo. 


\section{Sistemas formais ecumênicos: lógicas clássica e intuicionista}

\section{1}

\section{Definições iniciais}

\subsection{1}

\section{Linguagem}

Nossas definições de linguagem serão feitas da maneira usual e inicialmente seguirão alguns padrões já consagrados pela literatura relevante. Posteriormente, criaremos quatro outras linguagens (derivadas da inicial) que contém alguns elementos essenciais para a criação de fórmulas e operadores ecumênicos.

Nossa linguagem inicial $L$ será composta pelos seguintes elementos:

1. Uma quantidade infinita e enumerável de parâmetros individuais.

Notação: $a, b, c{ }^{1}$

2. Uma quantidade infinita e enumerável de variáveis individuais.

Notação: $x, y, z$.

3. Para todo $n \in \mathbb{N}$, uma quantidade infinita e enumerável de parâmetros predicativos com aridade " $n$ ". A aridade de cada parâmetro predicativo utilizado ficará implícita na quantidade de variáveis ou parâmetros que o seguirem, e será adotada uma notação simplificada para os casos onde $n=0$.

Notação $(n=0): \mathrm{P}, \mathrm{Q}, \mathrm{R}$.

4. Uma quantidade infinita e enumerável de metavariáveis, que ocuparam o lugar de fórmulas quaisquer nos esquemas conceituais.

Notação: A, B, C.

Em alguns contextos específicos, as metavariáveis ocuparão o lugar de sequências de $n$ parâmetros individuais ou parâmetros e variáveis individuais, antecedidas por um predicado n-ário. Nos dois casos, indicaremos

${ }^{1}$ Os trechos marcados como "Notação" são meramente exemplificativos, não integrando a definição formal propriamente dita 
explicitamente que o uso está sendo feito neste sentido, além de escrever predicados antes das metavariáveis (nos dois casos) e quantificadores antes dos predicados (no segundo caso).

5. Constantes lógicas: $\wedge, \vee, \rightarrow, \neg, \perp, \forall, \exists$.

6. Sinais auxiliares: parênteses, vírgulas, colchetes e chaves, que serão utilizados com liberalidade para melhorar a legibilidade de algumas fórmulas e/ou evitar ambiguidades.

Como mencionado, esta linguagem não é suficiente para a criação de sistemas ecumênicos. Por isso, criaremos quatro novas linguagens, $L_{C} 1, L_{C} 2$, $L_{I} 1$ e $L_{I} 2$, que contém todos os elementos de $L$ e mais os que listaremos a seguir.

I - Adições que precisam ser feitas a $\boldsymbol{L}$ para a obtenção de $L_{C} 1$ :

7. Constantes ecumênicas clássicas: $\rightarrow_{c}, \vee_{c}, \exists_{c}$.

8. Para todo $n \in \mathbb{N}$, uma quantidade infinita e enumerável de parâmetros predicativos clássicos com aridade " $n$ ". A aridade de cada parâmetro predicativo clássico utilizado ficará implícita na quantidade de variáveis ou parâmetros que o seguirem, e será adotada uma notação simplificada para os casos onde $n=0$.

Notação $(n=0): P_{c}, Q_{c}, R_{c}$.

Notação $(n>0): P_{c} a(n=1), P_{c} a b(n=2), P_{c} a b x(n=3)$, etc.

\section{II - Adições a $\boldsymbol{L}$ para a obtenção de $L_{C} 2$ :}

7. Constante ecumênica clássica: "C", usado como subscrito em fórmulas e metavariáveis ${ }^{2}$.

Notação: $P_{c} a, A \wedge_{c} B,\left(A_{c} \rightarrow_{c} B_{c}\right)$.

\section{III - Adições a $\boldsymbol{L}$ para a obtenção de $L_{I} 1$ :}

7. Constantes ecumênicas intuicionistas: $\rightarrow_{i}, \forall_{i}$.

${ }^{2}$ É importante notar que o conceito de fórmula, a ser definido posteriormente, permitirá a criação de fórmulas e metavariáveis com mais de um subscrito, tais como $Q_{c c}$ e $P \wedge_{c} Q$ 


\section{IV - Adições a $\boldsymbol{L}$ para a obtenção de $L_{I} 2$ :}

7. Constante ecumênica intuicionista: "I", usado como subscrito em fórmulas e metavariáveis ${ }^{3}$.

Notação: $P_{i} a, A \wedge_{i} B,\left(A_{i} \rightarrow_{i} B_{i}\right)$.

\subsection{2 \\ Elementos estruturais}

Delimitados os elementos linguísticos dos nossos sistemas, procederemos à definição de seus elementos estruturais mais básicos. Nossas definições usarão metavariáveis, que deverão ser compreendidas como simples placeholders para os demais elementos linguísticos. Posteriormente, os parênteses de todas as definições poderão ser omitidos quando não houver risco de ambiguidade ou confusão.

1. $A$ é um átomo se e somente se $A$ for igual a $\perp$ ou for composto por um parâmetro predicativo seguido de $n$ parâmetros individuais $(n \in \mathbb{N})$.

2.1. Se $A$ é um átomo, então $A$ é uma fórmula, além de ser uma fórmula atômica.

2.2. Se $A$ e $B$ são fórmulas, então $(A \wedge B),(A \vee B),(A \rightarrow B)$ e $(\neg A)$ são fórmulas.

2.3. Se $A$ é uma fórmula e contém ao menos um parâmetro individual em sua formação, então $\left(\forall x A^{\prime}\right)$ e $\left(\exists x A^{\prime}\right)$, além de serem fórmulas quantificadas, são fórmulas, onde $x$ é uma variável individual e $A^{\prime}$ é obtido a partir de $A$ por meio da substituição de todas as ocorrências de algum parâmetro individual específico em $A$ pela variável individual $x$.

Convenção: em alguns casos, por razões de simplicidade, usaremos apenas predicados unários em nossas derivações. No entanto, todos os resultados que provaremos são válidos para predicados com qualquer aridade.

2.4. Se $A$ é uma fórmula composta ou quantificada obtida através da fórmula $B$ ou das fórmulas $B$ e $C$, então seu conectivo principal é a constante lógica introduzida antes da fórmula $B$ (no caso da negação; $\neg B$ ) ou entre as fórmulas $B$ e $C$ para a obtenção de $A$ (no caso dos demais conectivos; $A \wedge B, A \rightarrow B$, etc).

${ }^{3}$ As informações do rodapé anterior também se aplicam a essa definição 
4. Se $A$ e $B$ são fórmulas em um sistema que utiliza a linguagem $L_{c} 1$, então $\left(A \rightarrow_{c} B\right),\left(A \vee_{c} B\right),\left(\exists_{c} x A^{\prime}\right)$ (onde $x$ é uma variável individual e $A^{\prime}$ é obtido a partir de $A$ por meio da substituição de todas as ocorrências de algum parâmetro individual específico em $A$ por uma variável individual $x$ ) e $A^{\prime}$ (onde $A^{\prime}$ é obtido a partir de $A$ por meio da substituição de todas as ocorrências de ao menos um parâmetro predicativo com aridade " $n$ " por um parâmetro predicativo clássico com a mesma aridade) também são fórmulas no mesmo sistema, além de serem fórmulas ecumênicas neste sistema.

4.1. Em fórmulas criadas por este procedimento, a constante ecumênica introduzida será considerada o conectivo principal.

5. Se $A$ é uma fórmula em um sistema que utiliza a linguagem $L_{c} 2$, então $A^{\prime}$ é tanto uma fórmula quanto uma fórmula ecumênica no mesmo sistema, onde $A^{\prime}$ é obtido a partir de $A$ por meio da aposição de $C$ como subscrito ${ }^{4}$. Para facilitar a legibilidade destas novas fórmulas, escreveremos o subscrito junto ao predicado de $A$ (caso $A$ seja atômico), da constante lógica central de $A$ (caso $A$ seja composto) ou de outro subscrito $C$ já presente na constante lógica central de $A$ sempre que as fórmulas precisarem ser representadas graficamente, mas usaremos a definição formal em novas definições posteriores. Exemplos: $P a_{c},(P a \wedge P b)_{c}, \neg\left(P a_{c}\right),(\neg P a)_{c}$ e $P a_{c c}$ serão representadas, respectivamente, como $P_{c} a,\left(P a \wedge_{c} P b\right), \neg P_{c} a, \neg_{c} P a$ e $P_{c c} a$.

5.1. Caso seja aposto o subscrito $C$ a alguma fórmula para a obtenção de uma nova fórmula, o próprio subscrito será considerado o conectivo principal desta última.

6. Se $A$ e $B$ são fórmulas em um sistema que utiliza a linguagem $L_{i} 1$, então $\left(A \rightarrow_{i} B\right)$, e $\left(\forall_{i} x^{\prime} A^{\prime}\right)$ (onde $x^{\prime}$ é uma variável individual e $A^{\prime}$ é obtido a partir de $A$ por meio da substituição de todas as ocorrências de algum parâmetro individual específico em $A$ por uma variável individual x') também são fórmulas no mesmo sistema, além de serem fórmulas ecumênicas neste sistema.

6.1. Em fórmulas criadas por este procedimento, a constante ecumênica introduzida será considerada o conectivo principal.

${ }^{4} \mathrm{~A}$ rigor, a adição à linguagem de fórmulas ecumênicas baseadas nas constantes lógicas $\perp$ e $\neg$ não seria realmente necessária, mas a omissão destas nos forçaria a abandonar a uniformidade da abordagem e a considerar casos especiais em algumas provas que virão a ser apresentadas. O mesmo acontece no caso intuicionista, que será apresentado a seguir. Portanto, apesar de trivial, estas adições estão sendo feitas por razões de economia. 
7. Se $A$ é uma fórmula em um sistema que utiliza a linguagem $L_{i} 2$, então $A^{\prime}$ é tanto uma fórmula quanto uma fórmula ecumênica no mesmo sistema, onde $A^{\prime}$ é obtido a partir de $A$ por meio da aposição de $I$ como subscrito. Adotaremos a mesma convenção estabelecida no ponto 5 com relação ao local de posicionamento do subscrito.

7.1. Caso seja aposto o subscrito $I$ a alguma fórmula para a obtenção de uma nova fórmula, o próprio subscrito será considerado o conectivo principal desta última.

8 Substituições: $A[x / a]$ é a fórmula obtida a partir da substituição de todas as ocorrências da variável $x$ em "A" pelo parâmetro individual $a$. A definição também é válida para substituição de parâmetros individuais por variáveis individuais, parâmetros individuais por parâmetros individuais e variáveis individuais por variáveis individuais (Ex: $A[a / x], A[a / b]$, $A[x / y]$.

\subsection{3}

\section{Derivações e operações em derivações}

Nosso sistema para derivações deve ser considerado como uma versão alternativa do utilizado por Prawitz (18) em seu clássico estudo de sistemas de Dedução Natural. Deixaremos de realizar algumas definições que eram úteis para as finalidades de Prawitz mas não o são para as do presente trabalho, mas os sistemas ainda devem ser vistos como essencialmente iguais.

1. Uma inferência é representada por um traço horizontal que separa uma ou mais fórmulas, escritas acima do traço, de uma única fórmula, escrita abaixo do traço, contendo ou não números entre chaves (Ex: $\{1\})$ à sua direita.

Exemplos ${ }^{5}$ :

$$
\frac{P a \quad P b}{P c} \quad \frac{P d}{P e}\{1\}
$$

2. Uma composição é uma representação gráfica contendo uma única inferência ou superposições de inferências. Neste último caso, dizemos que duas ou mais inferências são superpostas quando a fórmula única abaixo de uma ou mais inferências é uma das fórmulas imediatamente acima de outra inferência.

Exemplo:

${ }^{5}$ Assim como no caso da exposição de notações, os exemplos são meramente ilustrativos e não fazem parte da definição formal. 


$$
\frac{P a P b}{P d}+\frac{P d}{P e} \Rightarrow \frac{P a P b}{\frac{P d}{P e}}
$$

3. A conclusão de uma composição é a única fórmula que não está acima de nenhum traço horizontal.

4. Uma hipótese é uma fórmula que não está abaixo de nenhum traço horizontal na composição.

4.1. Em uma composição, cada hipótese deve ser marcada com um sobrescrito, e todas as fórmulas com o mesmo formato ${ }^{6}$ que ocorrerem como hipóteses antes da aplicação de uma regra que descarte as hipóteses com este sobrescrito deverão ter o mesmo sobrescrito. Além disso, fórmulas com formatos diferentes e fórmulas com o mesmo formato que não obedeçam à condição anterior não poderão receber o mesmo sobrescrito.'

Em outras palavras: nossas hipóteses serão numeradas $\left(A^{1}, B^{2}\right.$, etc), e usaremos a mesma numeração toda vez que "reutilizarmos" a mesma hipótese antes de descartá-la. A parte final da definição nos proíbe de usar o mesmo número para hipóteses distintas, além de proibir a "reutilização" de uma hipótese já descartada (que precisará receber um novo número).

4.2. Uma hipótese (ou grupo de hipóteses) é (são) descartada(s) em um traço horizontal de uma composição se e somente se seu sobrescrito estiver entre chaves e à direita de alguns traços.

Exemplos para os pontos 4, 4.1 e 4.2:

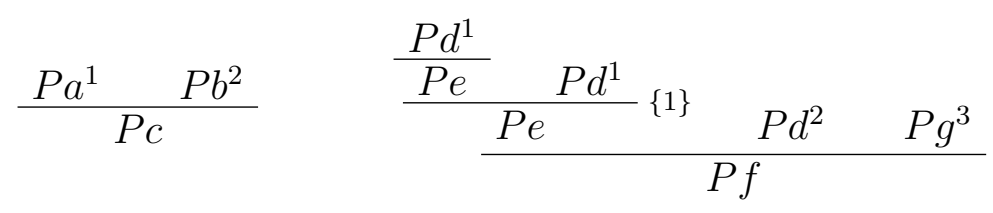

5. Dizemos que uma fórmula depende ou é dependente de uma hipótese ou grupo de hipóteses se e somente se a fórmula e as hipóteses estiverem acima do mesmo traço horizontal ou, alternativamente, ao menos uma das fórmulas imediatamente acima desta fórmula for dependente destas hipóteses e estas hipóteses não houverem sido descartadas nos traços horizontais acima da fórmula.

Exemplo:

${ }^{6} \mathrm{Ou}$ seja: compostas pelos mesmos parâmetros predicativos, clássicos ou comuns, e pelas mesmas variáveis individuais, parâmetros individuais e constantes lógicas, ecumênicas ou comuns, devendo ser observada, inclusive, a ordem de composição 


$$
\begin{aligned}
& \frac{P a^{1} \quad P a^{1}}{\frac{P b}{P c}}\{1\} \quad P e^{2} \quad P f^{3} \\
& \frac{P d}{P d}\{2\},\{3\}
\end{aligned}
$$

$P a$ depende de $P a ; P b$ depende de $P a ; P c$ depende de $P a ; P d$ depende de $P e$ e $P f$, assim como $P e$ e $P f ; P g$ não depende de nenhuma hipótese.

6. Um conjunto de fórmulas com o mesmo formato que tenha sobrescrito " $n$ " é descartado em uma inferência se e somente se o sobrescrito destas fórmulas estiver escrito entre chaves à direita do traço horizontal.

Para facilitar a rápida identificação de fórmulas descartadas, passaremos a colocá-las entre colchetes (Ex: $[P a])$.

7. Uma inferência possui o formato de uma regra aceita por um sistema de derivações se e somente se pudermos obter uma das regras do sistema substituindo as fórmulas superiores, as hipóteses das quais elas dependem, o número à direita da inferência e as fórmulas que compõem a fórmula inferior, excluindo o conectivo principal, por metavariáveis, bem como substituindo por variáveis (no caso de regras que descartam hipóteses) ou eliminando (no caso de regras que não descartam) eventuais subscritos das fórmulas superiores ${ }^{7}$.

Exemplos:

$$
\frac{P a \quad P b}{P a \wedge P b} \Rightarrow \begin{gathered}
A \quad B \\
A \wedge B
\end{gathered} \wedge \begin{gathered}
{\left[P a^{3}\right]} \\
\vdots \\
\frac{P b}{P a \rightarrow P b}\{3\}, I \rightarrow
\end{gathered} \Rightarrow \begin{gathered}
{\left[A^{n}\right]} \\
\vdots \\
A \rightarrow B
\end{gathered}\{n\}
$$

8. Uma derivação em um sistema de derivações "S" é uma composição finita na qual todas as inferências possuem o formato de uma regra aceita por "S".

De acordo com esta definição, a superposição de duas ou mais derivações de um sistema também é uma derivação neste sistema, de modo que podemos definir procedimentos de criação de novas derivações a partir de um conjunto de derivações base.

9. Uma transformação é um procedimento que superposiciona duas ou mais derivações para obter uma nova derivação, possivelmente modificando o número à direita de traços horizontais para conformá-los com a regra 4.1,

${ }^{7}$ É interessante descartar que, por esta definição, todas as 
eliminando sobrescritos de fórmulas que deixam de ser hipóteses e adicionando sobrescritos a fórmulas que passam a ser hipóteses. Usaremos $\Pi$ para denotar derivações, e sobrescritos $\Pi^{1}$ para diferenciar diferentes derivações que aparecerem em um mesmo contexto ${ }^{8}$.

Exemplo:

$$
\frac{\Pi^{1}}{A}+\frac{B^{1}}{\Pi^{3}}+\frac{\frac{A^{2}}{\Pi^{2}}}{B} \Rightarrow \frac{\frac{\Pi^{1}}{A}}{\frac{\Pi^{2}}{B}}
$$

É importante ressaltar que estas conversões mudam as relações de dependência da nova derivação. Neste exemplo, a conclusão de $\Pi^{3}$ deixa de ser dependente de $B$, mas passa a depender de quaisquer hipóteses não descartadas presentes em $\Pi^{1}$ e $\Pi^{2}$

9.1. Convenção: em todo procedimento de transformação, as variáveis individuais usadas em regras que obedeçam a determinadas restrições (ex: $I \forall, E \exists)$ devem ser substituídas de modo a fazer com que as restrições também sejam satisfeitas na derivação final ${ }^{9}$.

10. Duas regras - digamos, "R1"e "R2-, do mesmo sistema ou não, são ditas equivalentes no interior de determinado sistema - digamos, "S- se e somente se for possível converter uma inferência "R1" em uma derivação em $S+R 2$ (ou seja: as regras do sistema "S" mais a regra $\mathrm{R} 2$ ), bem como for possível converter uma inferência "R2" em uma derivação em $S+R 1$, sem modificar as relações originais de dependência em nenhum dos casos. Exemplo:

$$
{\frac{\Pi^{1}}{B}}_{R 1} \Rightarrow \frac{\frac{\Pi^{1}}{A}}{\frac{\Pi_{S+R 2}^{1}}{B}}
$$

Muito embora $\Pi^{1}$ também possa conter aplicações de $R 1$, o fato de todas as derivações serem finitas por definição faz com que possamos aplicar o mesmo procedimento a todas as demais instâncias de $R 1$ em $\Pi^{1}$, de modo a obter, após uma quantidade finita de novas transformações, uma derivação com o seguinte formato:

${ }^{8}$ Deve-se atentar para a diferença entre sobrescritos de hipóteses e derivações; hipóteses podem ser descartadas, derivações não. Pressuporemos que a utilização dos mesmos números para algumas hipóteses e derivações não é capaz de gerar confusão no leitor.

${ }^{9}$ Sobre a possibilidade desta substituição, originalmente pensada em termos de parâmetros "próprios" e "puros", ver (18, pg. 29) 


$$
\frac{\frac{\Pi_{S+R 2}^{1}}{A}}{\frac{\Pi_{S+R 2}^{2}}{B}}
$$

11. Usaremos $A, B, \ldots, C \vdash D$ para declarar que há uma derivação de $D$ dependendo das hipóteses $(A, B, \ldots, C)$. Do mesmo modo, $\vdash A$ é usado para declarar que há uma derivação de $A$ na qual $A$ não depende de nenhuma fórmula.

\subsection{4}

\section{Lógicas clássica, intuicionista e minimal}

A lógica clássica pode ser definida como o sistema que utiliza a linguagem inicial $L$ e aceita todas as regras a seguir:

$$
\begin{aligned}
& \frac{A \quad B}{A \wedge B} \mathrm{I} \wedge \quad \frac{A \wedge B}{A} \mathrm{E} \wedge_{e} \quad \frac{A \wedge B}{B} \mathrm{E} \wedge_{d}
\end{aligned}
$$

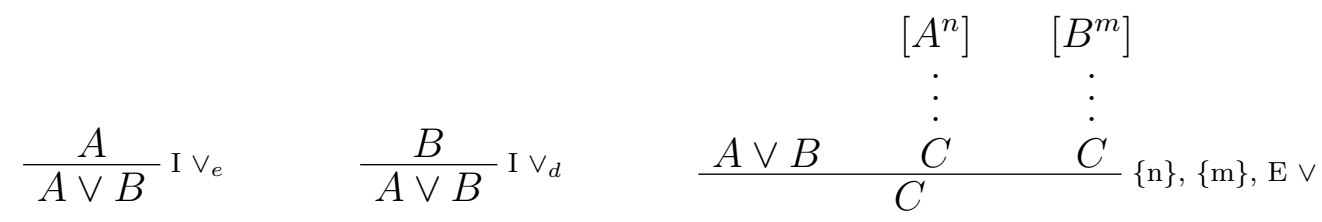

$$
\begin{aligned}
& {\left[A^{n}\right] \quad\left[\neg A^{n}\right]} \\
& \frac{\dot{B}}{A \rightarrow B}\{\mathrm{n}\}, \mathrm{I} \rightarrow \quad \frac{A \rightarrow B \quad A}{B} \mathrm{E} \rightarrow \quad \frac{\perp}{A} \mathrm{I} \perp \quad \frac{\perp}{A}\{\mathrm{n}\}, \mathrm{C} \perp \\
& {\left[A[x / a]^{n}\right]} \\
& \frac{A}{\forall x A[a / x]} \mathrm{I} \forall \quad \frac{\forall x A}{A[x / a]} \mathrm{E} \forall \quad \frac{A}{\exists x A[a / x]} \mathrm{I} \exists \quad \frac{\exists x A}{B}\{\mathrm{n}\}, \mathrm{E} \exists
\end{aligned}
$$

Restrições sobre a regra I $\forall$ : o parâmetro individual "a" não ocorre em nenhuma hipótese da qual "A" depende.

Restrições sobre a regra $\mathrm{E} \exists$ : o parâmetro individual "a" não ocorre em $\exists x A$, em $B$ e nem em nenhuma hipótese da qual $A[x / a]$ dependa, com exceção da própria fórmula $A[x / a]$.

A lógica intuicionista aceita todas estas regras, com exceção de $C \perp$. A lógica minimal aceita todas estas regras, com exceção de $C \perp$ e $I \perp$.

Por razões de economia, passaremos a ocultar o superscrito de regras envolvendo descarte, já que o emprego de colchetes já basta para indicar o formato inferencial adotado em cada caso. 


\section{2}

\section{Estudos sobre funções de tradução}

Do ponto de vista sintático, o ecumenismo está intimamente ligado à possibilidade de se definir funções de tradução entre duas ou mais lógicas, já que tais funções nos permitem analisar em que termos as derivações de determinado sistema podem ser tidas como aceitáveis para outro e, com isto, em se tratando de lógicas de algum modo conflitantes, sob quais condições seria possível criar um ambiente compartilhado de sentido no qual a convivência mútua fosse possível. Deste modo, antes de investigarmos sistemas ecumênicos sintáticos envolvendo as lógicas clássica, minimal e intuicionista, é importante que procedamos a uma breve revisão dos principais resultados envolvendo traduções entre estas lógicas.

Em relação às lógicas clássica e intuicionista, os resultados mais importantes do campo são aqueles envolvendo incorporações da primeira na segunda com o auxílio das chamadas "traduções por dupla negação"10. Estas funções utilizam semelhanças conhecidas entre o comportamento de fórmulas negadas no interior dos dois sistemas para estabelecer relações mais gerais entre as duas lógicas.

A primeira destas semelhanças já havia sido descoberta pelo próprio Brouwer ${ }^{11}$ e é expressa pela equivalência $\neg A \Longleftrightarrow \neg \neg \neg A$, válida tanto clássica quanto intuicionistamente. Muito embora o procedimento de eliminação da dupla negação (que consiste na inferência $\neg \neg A \vdash A$ ) não seja válido em geral para fórmulas intuicionistas, as propriedades da negação intuicionista não só permitem que realizemos esta inferência para fórmulas que tenham a negação como conectivo principal como também faz com que o comportamento de

\footnotetext{
${ }^{10}$ Tradução livre de "Double-negation translations"

11 "Let us consider a 'subordinating' sequence of $n$ predicates of absurdity: absurdity of absurdity ... of absurdity, or in a shortened form, abs abs ... abs. The classical point of view admits the principle of reciprocity of complementarity, and thus allows this sequence to be reduced, by repeated cancellation of pairs of successive predicates, either to truth or to absurdity. One might expect that from the intuitionistic point of view such cancellations are strictly excluded, so that unequal sequences of this kind would have to be treated as inequivalent. But, surprisingly, this is not the case; cancellations of the kind mentioned are admissable, provided that they leave the first predicate of the sequence untouched, as follows from the following intuitionistic
}

THEOREM. Absurdity of absurdity of absurdity is equivalent to absurdity.

PROOF. Firstly, since implication of the assertion $y$ by the assertion $x$ implies implication of absurdity of $x$ by absurdity of $y$, the implication of absurdity of absurdity by truth (which is an established fact) implies the implication of absurdity of truth, that is to say of absurdity, by absurdity of absurdity of absurdity. Secondly, since truth of an assertion implies absurdity of its absurdity, in particular truth of absurdity implies absurdity of absurdity of absurdity.

From the theorem thus proved it follows that in intuitionistic mathematics every subordinating sequence of $n>2$ predicates of absurdity can be reduced either to absurdity or to absurdity of absurdity."(19, pgs. 11 e 12) 
fórmulas negadas intuicionistas seja idêntico ao comportamento de fórmulas negadas clássicas, o que termina por equiparar os dois sistemas no fragmento negativo $^{12}$ da linguagem.

A esse respeito, os seguintes resultados já foram estabelecidos na literatura:

- Teorema 1. Se A não contém $\vee$ ou $\exists$ e todos os átomos em $A$ exceto $\perp$ estiverem negados, então $\vdash_{i} \neg \neg A \leftrightarrow A$ (20, pg. 161).

- Teorema 2. A lógica de predicados/proposicional clássica é conservativa sobre a lógica de predicados/proposicional intuicionista com respeito a fórmulas compartilhadas, definidas como aquelas contendo apenas os conectivos $\wedge, \rightarrow, \forall$ e $\perp$ e nas quais toda fórmula atômica é precedida por uma negação: $\vdash_{i} A \Longleftrightarrow \vdash_{c} A$, para A compartilhado (20, pg. 163).

No nível proposicional, nós temos os chamados teoremas de Glivenko (21), segundo os quais uma proposição qualquer $A$ é um teorema na lógica proposicional clássica se e somente se $\neg \neg A$ for um teorema na lógica proposicional intuicionista, e uma proposição $\neg A$ é um teorema intuicionista se e somente se for um teorema clássico. Estes resultados, no entanto, não são válidos para a lógica de predicados, para a qual podemos estabelecer apenas resultado mais fraco:

- Teorema 3.1 (Kuroda). Se A não contém nenhum quantificador universal, então $\vdash_{i} \neg \neg A \Longleftrightarrow \vdash_{c} A$ (22, pg. 22).

- Teorema 3.2 (Glivenko). Se A não contém nenhum quantificador universal, então $\vdash_{i} \neg A \Longleftrightarrow \vdash_{c} \neg A$ (22, pg. 22).

Existem diversas traduções por dupla negação entre as lógicas clássica e intuicionista, sendo especialmente prevalentes na literatura aquelas definidas por Gödel, Gentzen, Kolmogorov, Kuroda e Krivine. Recentemente, um estudo comparativo (22) estabeleceu que as traduções de Kuroda e Krivine podem ser obtidas através de sucessivas simplificações das definições iniciais de Kolmogorov, em um procedimento que utiliza equivalências intuicionistas para progressivamente eliminar fórmulas negadas das definições iniciais e produzir novas traduções que, apesar de equivalentes à primeira, utilizam menos símbolos de negação em suas definições. Este mesmo estudo indica que, no tocante à quantidade de negações desnecessárias utilizadas nas definições, as traduções de Gödel e Gentzen são intermediárias em relação à tradução de Kolmogorov e

\footnotetext{
${ }^{12} \mathrm{Ou}$ seja, o fragmento da linguagem no qual todas as fórmulas possuem como conectivo principal a negação.
} 
às traduções de Kuroda e Krivine, sendo que estas últimas não podem ser simplificadas ainda mais por novas iterações do mesmo procedimento. Portanto, as traduções de Kuroda e Krivine são "mínimas" com respeito à quantidade bruta de fórmulas negadas utilizadas em definições.

Por sua vez, traduções da lógica intuicionista na lógica minimal se ocupam primariamente de possibilitar a introdução de fórmulas arbitrárias no sistema sempre que a constante $\perp$ for derivável, o que costuma envolver manipulação dos operadores $\rightarrow$ e $\perp$. Em um estudo sobre o tema, Prawitz e Malmnäs estabeleceram que a interpretação pode ser realizada substituindo todas as fórmulas e subfórmulas do tipo $B$ usadas em uma inferência minimalmente válida $\Gamma \vdash_{m} A$ por $B \vee \perp(4$, pg. 219) ou, alternativamente, substituindo uniformemente todas as fórmulas (e subfórmulas) do tipo $A \rightarrow B$ por fórmulas do tipo $A \rightarrow(B \vee \perp)$ e todas as fórmulas/subfórmulas do tipo $\forall x A$ por fórmulas do tipo $\forall x(A \vee \perp)$ (4).

Estes resultados são particularmente interessantes porque, ao conversarem sobre suas divergências filosóficas por correspondência, Johansson e Heyting pareciam discordar precisamente sobre qual seria a correta interpretação construtiva do operador condicional na presença de uma prova da impossibilidade do antecedente. Heyting interpretava fórmulas do tipo $A \rightarrow B$ como "Existe uma redução da solução de B à solução de A, ou A é impossível", enquanto Johansson rejeitava a possibilidade de se concluir pela validade do condicional na hipótese de A ser impossível (17, pg. 7). Johansson insistia que o condicional deveria ser utilizado em sua versão estrita, significando apenas "Existe uma redução da solução de B à solução de A", apesar de concordar que sua lógica seria equivalente à de Heyting caso nenhuma inconsistência seja derivada ou utilizada nas derivações ${ }^{13}$. Ao tentar expressar para Heyting sua discordância em termos formais, Johansson usou especificamente as equivalên$\operatorname{cias}\left(A \rightarrow B \Longleftrightarrow A \rightarrow_{m}(B \vee \perp)\right)$ e $\left(A \rightarrow B \Longleftrightarrow\left(A \rightarrow_{m} B\right) \vee \neg A\right)(17$, pg. 8) (onde $\rightarrow$ seria o condicional intuicionista e $\rightarrow_{m}$ seria o condicional minimal) para tentar caracterizar a implicação intuicionista e indicar alguns dos erros ou extrapolações que Heyting poderia estar cometendo em sua interpretação das fórmulas condicionais, tendo a segunda codificação se mostrado mais adequada para a representação do conectivo nos moldes intuicionistas.

Esta divergência se reflete de maneira clara na caracterização axiomática das lógicas intuicionista e minimal, onde podemos obter a segunda a partir da primeira simplesmente removendo o axioma $\neg A \rightarrow(A \rightarrow B)$. E, em relação à possibilidade de justificação intuitiva deste axioma, os apontamentos

\footnotetext{
13 "In short, my position presently is as follows: derivations according to the rules of usual intiutionistic logic gives us the sentences that will be valid as soon as the consistency is proved."(17, pg. 10)
} 
de Johansson sobre o caráter contra-intuitivo das inferências por ele autorizadas parecem ter sido parcialmente acatados por Heyting, que menciona a divergência em sua principal publicação sobre o tema, conforme visto na seção 1.3 .

Com isso, enquanto o principal fator de aproximação existente entre as lógicas clássica e intuicionista é o fragmento da linguagem composto por fórmulas que tenham a negação como sinal principal (ou seja, fórmulas do tipo $A \rightarrow \perp$ ), as lógicas intuicionista e minimal possuem o fragmento da linguagem que não contém $\perp$ como ponto unificador, o que parece sugerir uma especial importância da constante $\perp$ (usada tanto nas definições construtivas de negação quanto nas de inconsistência) ou de fórmulas equivalentes (tais como $A \wedge \neg A$ ) para o estabelecimento de um ponto de contato entre as três lógicas.

Os resultados apresentados nesta seção do trabalho devem ser usados não só como subsídio para a definição de operadores ecumênicos, mas também para orientar nossa intuição sobre as diferenças entre os três sistemas, bem como sobre a melhor forma de interpretar os elementos distintivos de uma das lógicas na outra. Portanto, estabelecido este arcabouço formal e informal preliminar, passaremos agora a analisar e definir alguns sistemas formais propriamente ecumênicos.

\section{3}

\section{Abordagens inferencialista e generalista}

Ao menos duas estratégias podem ser adotadas durante a caracterização de um sistema ecumênico, cada uma possuindo vantagens e desvantagens próprias. A primeira abordagem, que chamaremos de inferencialista, é usada tanto por Prawitz em sua definição de conectivos clássicos para a lógica intuicionista (7) quanto por Krauss em seu refinamento construtivo do cálculo de sequentes clássico (5). A segunda, que chamaremos de generalista, é uma contribuição original deste trabalho e, conforme veremos, permite a criação de sistemas com algumas características bem interessantes, o que parece lhe tornar digna de estudo.

A abordagem inferencialista consiste, basicamente, em adicionar regras de introdução e eliminação para operadores ecumênicos ao sistema, que são definidos utilizando fórmulas já contidas na linguagem da lógica utilizada como base. As regras ecumênicas de Prawitz, por exemplo, utilizam as seguintes definições para permitir a introdução de disjunções, implicações e existenciais clássicos em um sistema que usa a linguagem $L_{c} 1$ e também aceita todas as inferências intuicionistas: 


$$
\begin{aligned}
& {[(A),(\neg B)]}
\end{aligned}
$$

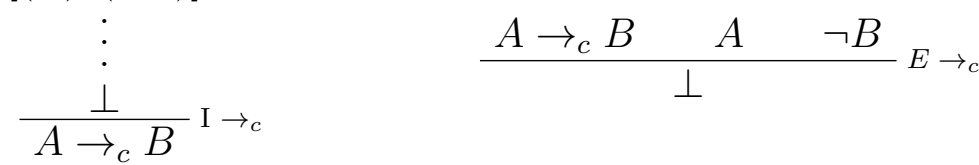

$$
\begin{aligned}
& {[(\neg A),(\neg B)]}
\end{aligned}
$$

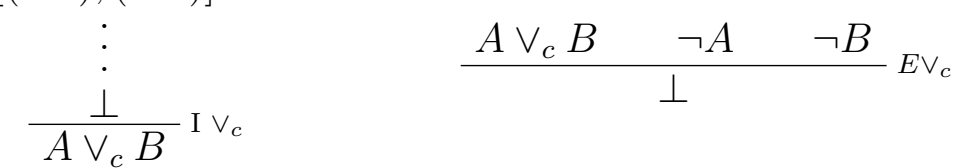

$$
\begin{aligned}
& \begin{array}{ll}
{[(\forall x \neg A)]} & \\
\vdots & \frac{\exists_{c} x A \quad \forall x \neg A}{\perp} E \exists_{c} \\
\frac{\perp}{\exists_{c} x A} \mathrm{I} \exists_{c} & \perp
\end{array} \\
& {[\neg P(A)]^{*}} \\
& \frac{\dot{\perp}}{P_{c}(A)} \text { I } P_{c}
\end{aligned}
$$

* Onde "A"é uma sequência de parâmetros individuais; vide definição 4 da seção 2.1.1..

Uma prova do teorema de normalização para o fragmento proposicional desta nova lógica poderá ser encontrada em um trabalho recentemente publicado por Pereira e Rodriguez (3), bem como provas de soundness e completude com relação à semântica de Kripke para a lógica intuicionista. No entanto, os mesmos resultados ainda não foram estabelecidos para a regra do existencial clássico.

Por sua vez, a abordagem generalista consiste em adicionar ao sistema regras mais gerais para a introdução de fórmulas ecumênicas (que podem, inclusive, ser atômicas). Deste modo, ao invés de definir diretamente condições de asserção para conectivos ecumênicos, a abordagem generalista busca definir condições de asserção para fórmulas ecumênicas em geral, de modo que possamos introduzir os demais operadores ecumênicos como casos particulares da mesma regra. A caracterização das lógicas clássica e intuicionista em sistemas de dedução natural feita por Prawitz, por exemplo, sugere um sistema ecumênico generalista bem simples para as lógicas intuicionista e clássica, que consiste em um sistema que use a linguagem $L_{c} 2$, aceite todas as inferências intuicionistas e, ainda, aceite a seguinte regra de inferência: 


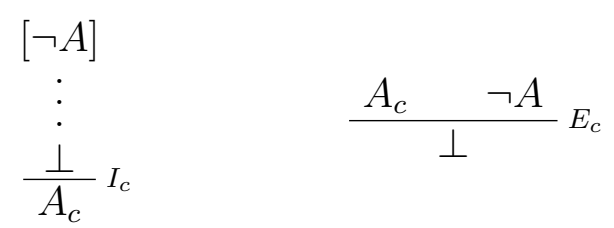

Onde "A" pode ser qualquer fórmula do sistema.

Diferentemente do que ocorre com os predicados clássicos de Prawitz, este subscrito é melhor interpretado como uma constante lógica autônoma, e não como um qualificador de constantes lógicas ou de elementos não-lógicos. O subscrito é usado para indicar a aplicação da inferência clássica a uma fórmula qualquer: $A_{c}$ deve ser visualizada como uma fórmula $A$ à qual foi aplicada a inferência reductio ad absurdum, assim como $\neg A$ é visualizada como a introdução de uma implicação com antecedente $A$ e consequente $\perp$. Caso a regra do reductio seja aplicada a uma fórmula que já comportou uma aplicação do reductio, por exemplo, usaremos a notação $A_{c c}$, que não faria sentido nas definições de Prawitz, onde o subscrito só pode ser usado uma vez em predicados, disjunções, implicações e existenciais.

A distinção indica que, nesta lógica, o uso de subscritos em diferentes contextos decorre de semelhanças presentes no nível estrutural das definições. Na lógica de Prawitz, o uso de subscrito na disjunção e na implicação são meras comodidades notacionais; seria igualmente válido definir $\vee_{c}$ como $\curlyvee \mathrm{e} \rightarrow_{c}$ como $\supset$, duas constantes lógicas distintas que não compartilham elementos gráficos guardam nenhuma relação mais forte. Neste sistema, no entanto, $\vee_{c}$ e $\rightarrow_{c}$ representam a aplicação de uma mesma operação a duas fórmulas diferentes, assim como $\neg(A \wedge B)$ e $\neg(A \rightarrow B)$ representam a possibilidade de se obter derivações de $\perp$ a partir de derivações destas duas fórmulas distintas.

Para tornar a notação mais econômica e visualmente agradável, passaremos a escrever o subscrito logo após o átomo ou conectivo ao qual ele é aplicado. Deste modo, fórmulas como $(A \vee B)_{c}$ e $(A \rightarrow B)_{c}$ serão substituídas, respectivamente, por $A \rightarrow_{c} B$ e $A \rightarrow_{c} B$, enquanto fórmulas como $\neg(B)_{c}$ e $\left((A)_{c} \wedge(B)_{c}\right)_{c}$ passarão a ser escritas, respectivamente, como $\neg B_{c}$ e $A_{c} \wedge_{c} B_{c}$.

Este sistema (que passaremos a chamar de ECI, abreviação de "Ecumenismo Clássico-Intuicionista") possui algumas propriedades bastante interessantes que, ao que parece, podem ser estendidas de maneira simples à lógica ecumênica de Prawitz (que passaremos a denominar PE, abreviação de "Prawitz Ecumênica"), conforme demonstraremos no próximo tópico. 


\subsection{1}

\section{Relações entre ECI e PE}

Antes de analisar pontos de contato entre as duas lógicas, precisamos estabelecer algumas definições que nos ajudarão a lidar com as diferenças na linguagem utilizada pelos dois sistemas.

\section{- Definições - ECI}

1. Se $A_{c}$ é uma subfórmula de $B$, então $A$ é uma subfórmula de $B$.

2. Se $A_{c}$ é uma subfórmula de $B$, então $A_{c}$ é uma subfórmula clássica de $B$.

$2.1 \mathrm{Se}\left(A \vee_{c} B\right),\left(A \rightarrow_{c} B\right)$ ou $\left(\exists_{c} x A\right)$ são subfórmulas de $C$, então, respectivamente em cada um destes casos, chamaremos $\left(A \vee_{c} B\right),\left(A \rightarrow_{c}\right.$ $B),\left(\exists_{c} x A\right)$ de PE-subfórmulas de $C$.

2.1.1. Uma derivação em ECI é PE-aceitável se e somente se toda subfórmula clássica de qualquer fórmula que ocorra na derivação também for uma PE-subfórmula.

A noção de derivações PE-aceitáveis nos permite considerar derivações em ECI que lidem apenas com os conectivos tratados por PE, nos permitindo afastar problemas relacionados à linguagem limitada desta última, que não contém versões clássicas de todos os operadores. Com isto, nós podemos estabelecer o seguinte resultado:

- Teorema 4. Existe uma derivação $\Gamma \vdash A$ em PE se e somente se existir uma derivação PE-aceitável $\Gamma \vdash A$ em ECI.

Prova:

Como as únicas regras não compartilhadas pelos dois sistemas são as regras de introdução e eliminação para operadores clássicos, podemos restringir nossas considerações a derivações que as apliquem.

$(\Rightarrow)$. Toda aplicação de uma regra clássica em PE pode ser transformada em uma aplicação das regras de introdução e eliminação para fórmulas clássicas em ECI, de acordo com os seguintes esquemas:

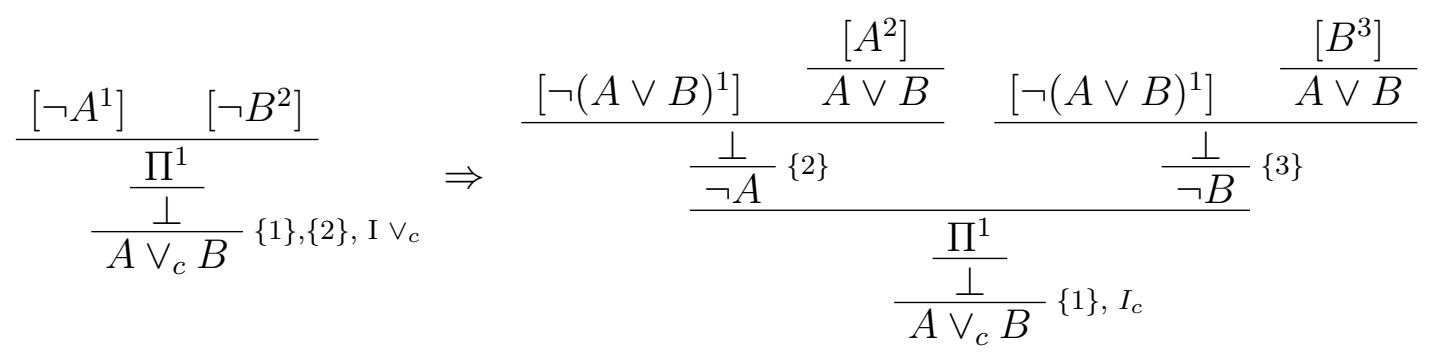




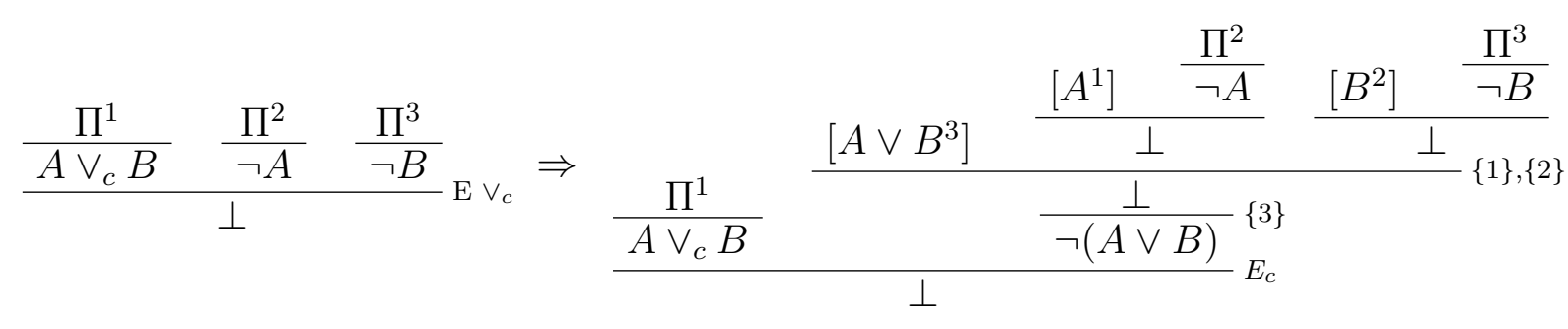

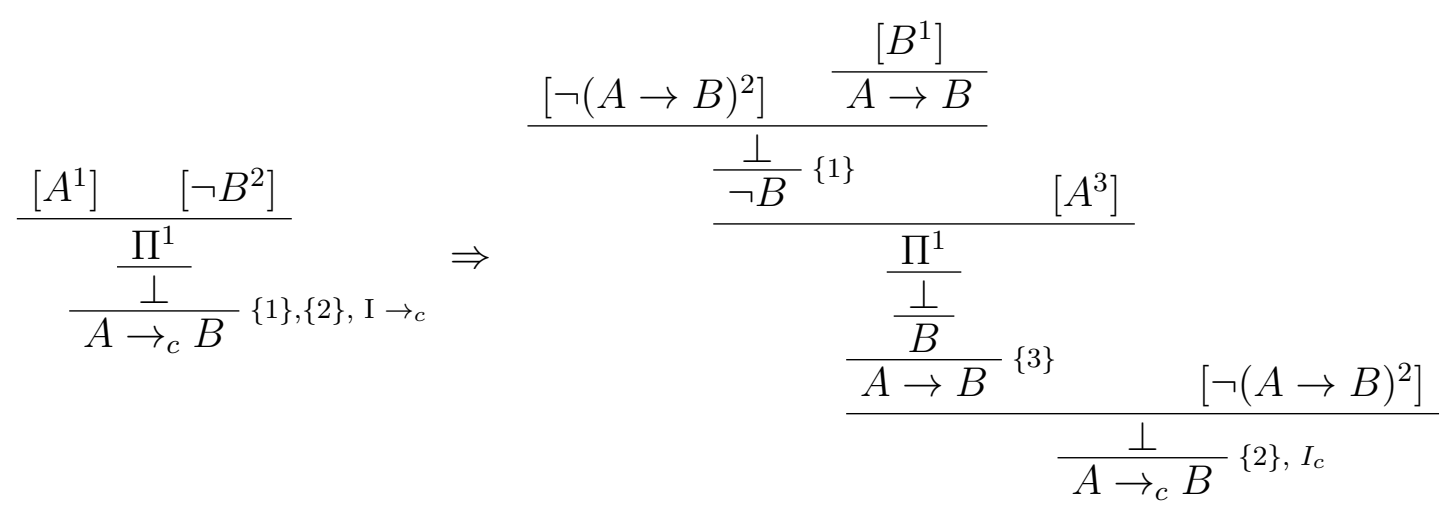

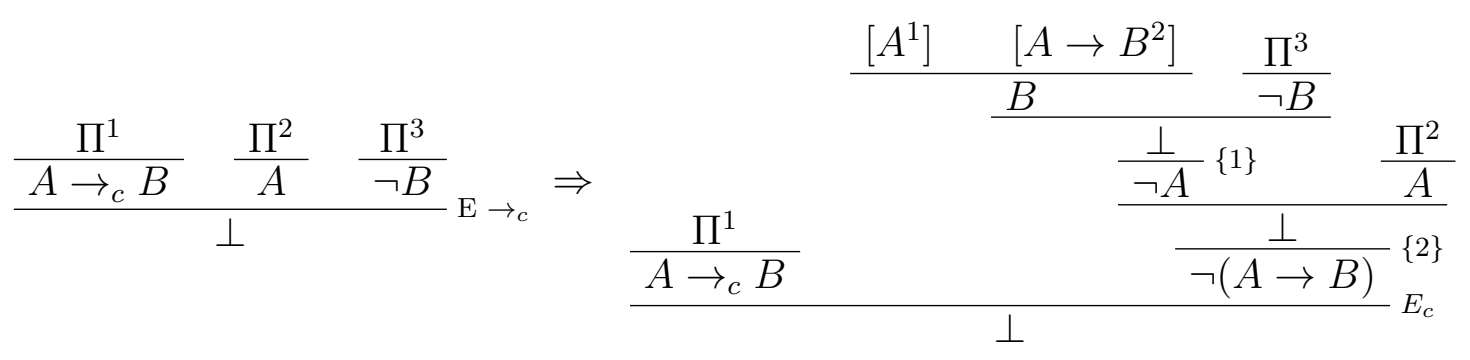

$$
\frac{\left[\forall x \neg P x^{1}\right]}{\frac{\frac{\Pi^{1}}{\perp}}{\exists_{c} x P x} \mathrm{I} \exists_{c},\{1\}} \Rightarrow \frac{\frac{\left[P a^{1}\right]}{\exists x P x} \quad\left[\neg \exists x P x^{2}\right]}{\frac{\frac{\perp}{\forall x \neg P}\{1\}}{\frac{\frac{\Pi^{1}}{\perp}}{\exists_{c} x P x}\{2\}, \mathrm{I} \exists_{c}}}
$$

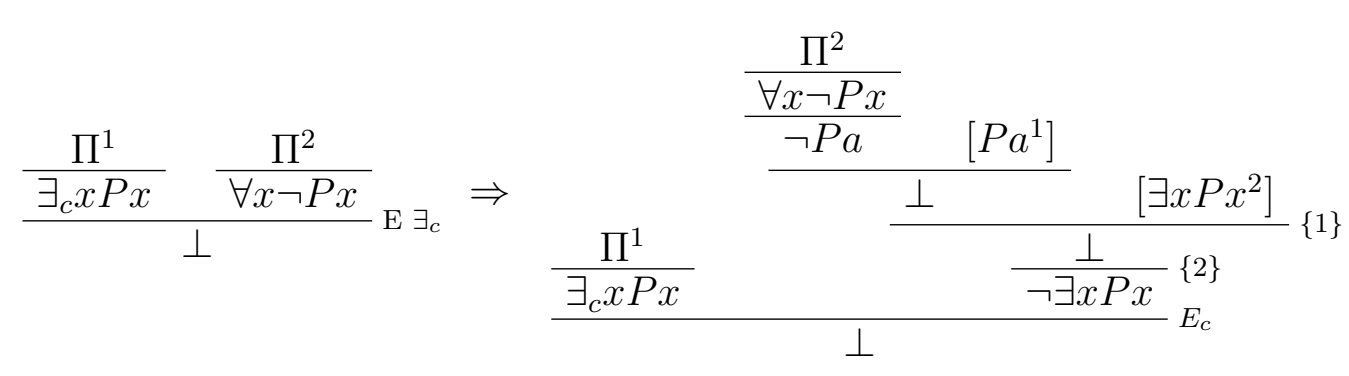

Podemos aplicar estas transformações sucessivamente se alguma das derivações $\Pi$ contidas nas derivações originais também utilizar as regras de PE 
que não são regras de ECI. Caso П possua $n$ usos de regras não compartilhadas, a aplicação dos procedimentos a qualquer uma delas terá como resultado final uma derivação com $(n-1)$ regras não compartilhadas. Reiterando o processo uma quantidade suficiente de vezes, obteremos uma derivação que utilize apenas as regras aceitas por ECI. Como todas as fórmulas clássicas que ocorrerem nestas novas derivações também serão do tipo $\left(A \vee_{c} B\right),\left(A \rightarrow_{c} B\right)$ ou $\left(\exists_{c} x P(x)\right)$ em função tanto da linguagem restrita de PE quanto do formato das derivações obtidas pelas transformações, nós temos que todas essas derivações também são PE-aceitáveis.

$(\Leftarrow)$. Pelas definições 2.1 e 2.1.1, todas as aplicações das regras clássicas de ECI em uma derivação PE-aceitável possuem um dos seguintes formatos:

$\begin{array}{ccc}{[\neg(A \vee B)]} & {[\neg(A \rightarrow B)]} & {[\neg(\exists x P(x))]} \\ \vdots & \vdots & \vdots \\ \frac{\perp}{A \vee_{c} B} I_{c} & \frac{\perp}{A \rightarrow_{c} B} I_{c} & \frac{\perp}{\exists_{c} x P(x)} I_{c}\end{array}$

$$
\frac{A \vee_{c} B \quad \neg(A \vee B)}{\perp} E_{c} \quad \frac{A \rightarrow_{c} B \quad \neg(A \rightarrow B)}{\perp} E_{c}
$$

$$
\frac{\exists_{c} x P(x) \quad \neg \exists x P(x)}{\perp} E_{c}
$$

É importante notar também que todas as derivações em ECI obtidas no passo anterior contêm apenas aplicações da regra clássica que possuam esta mesma estrutura, de modo que a obtenção de uma nova derivação em PE também será uma prova de equivalência entre as regras clássicas de PE e regras independentes para os conectivos $\vee_{c}, \rightarrow_{c}$ e $\exists_{c}$ formuladas usando as condições de asserção acima expostas.

Em cada um destes casos, podemos realizar as seguintes transformações:

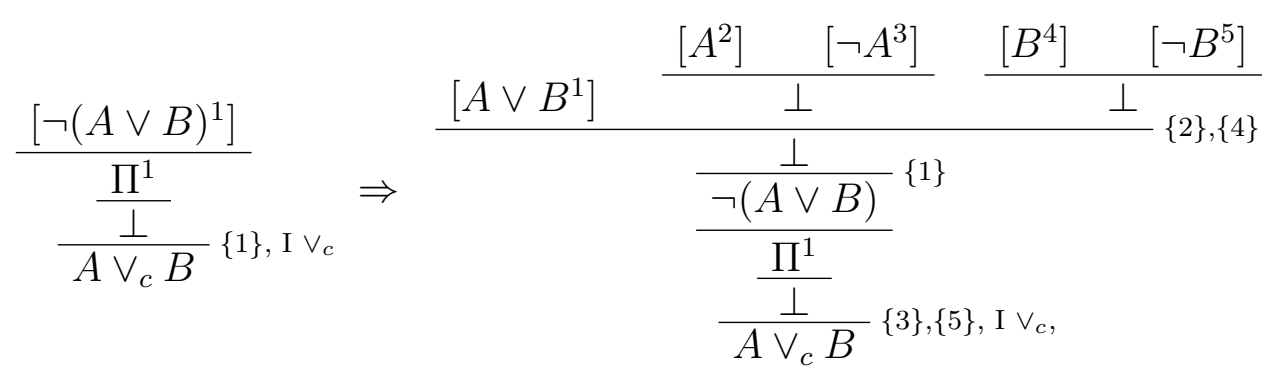



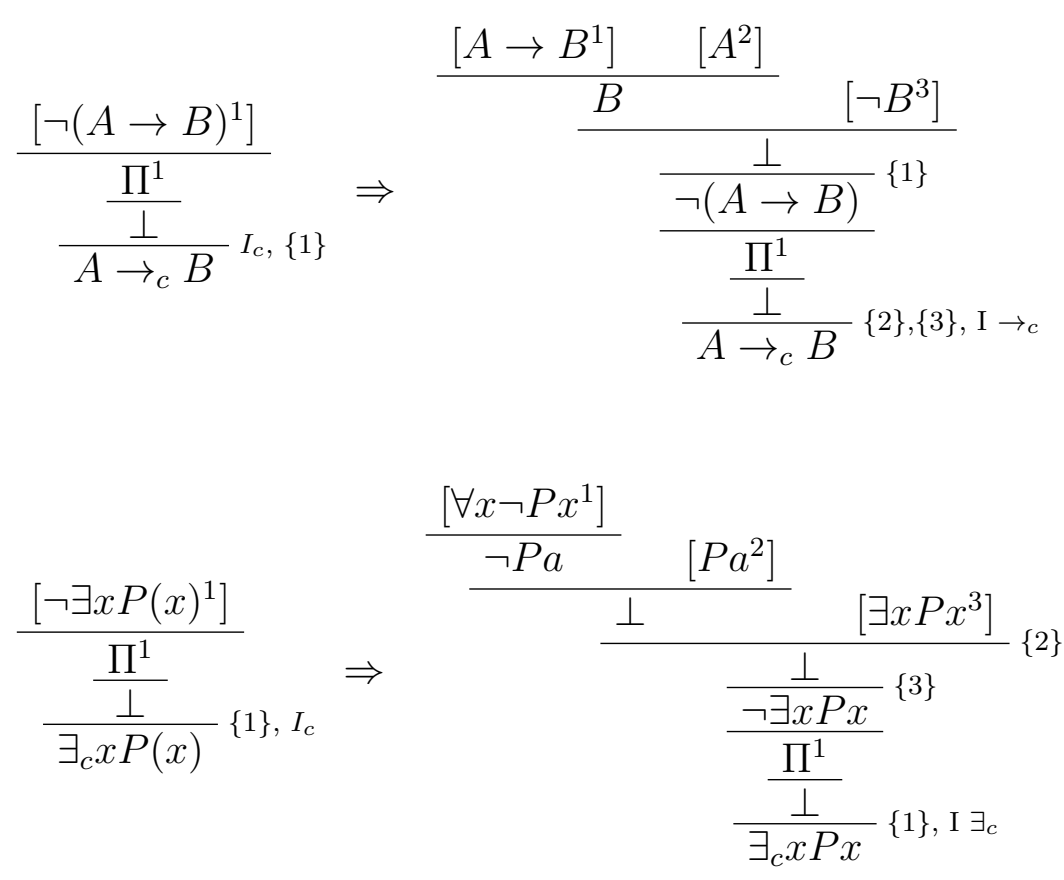

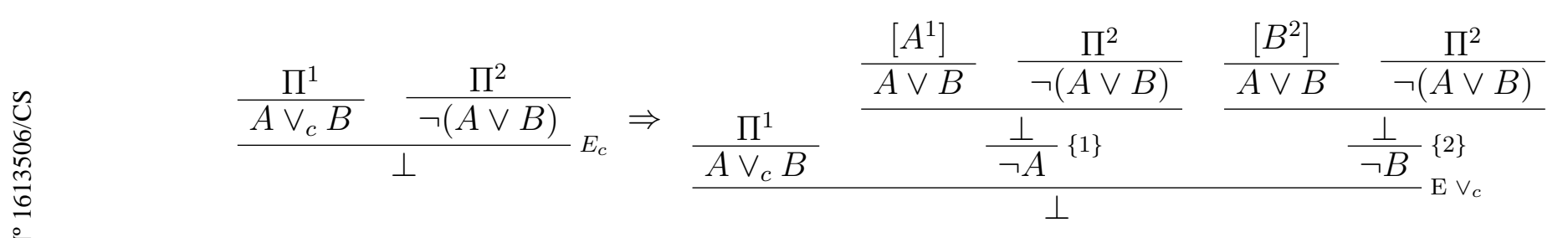

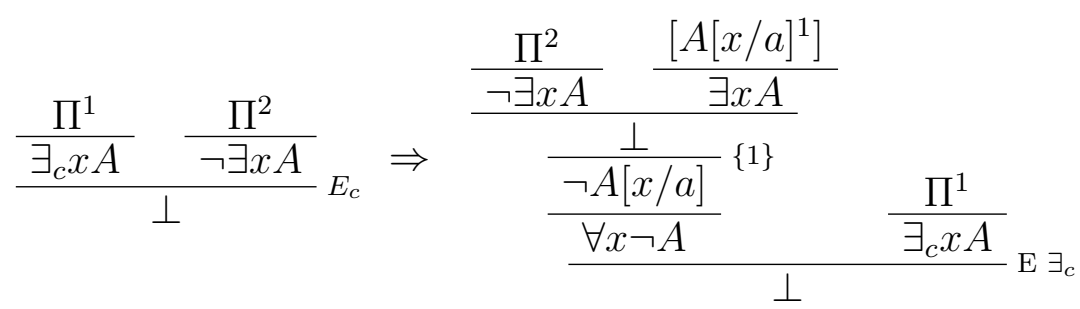

Portanto, este fragmento de ECI é equivalente a PE, e todas as regras de $\mathrm{PE}$ podem ser redefinidas de modo a adotar explicitamente o formato de uma prova por reductio ad absurdum. 
Como os dois sistemas introduzem fórmulas atômicas da mesma forma, não precisamos considerar este caso em nossos resultados, já que a prova de equivalência das derivações passa a ser trivial.

\subsubsection{1}

\section{Uma breve digressão sobre PE: regras alternativas para semântica de provas}

A criação do sistema PE por Prawitz se deu em um contexto de discussões sobre análises semânticas baseadas em teoria da prova, nas quais derivações são analisadas através de uma perspectiva inferencialista ${ }^{14}$ e têm suas propriedades semânticas definidas pelas regras de inferência permitidas no sistema. Como as propriedades semânticas de um conectivo estudado por esta ótica são ditadas diretamente pelas inferências que suas regras de introdução e eliminação autorizam, uma análise do comportamento das regras inferencialistas e dos formatos que elas podem adotar se mostraria de extrema valia para aqueles que se aproximassem da abordagem ecumênica especificamente com vistas a elaboração de análises desse tipo. No inferencialismo, uma prova de equivalência entre duas regras é uma prova de que determinado conectivo comporta mais de uma definição de suas condições de asserção - ou seja: de que as duas ou mais condições de asserção, por definirem o mesmo conectivo, possuem o mesmo valor semântico. Portanto, parece de bom tom que desviemos brevemente de nossos objetivos principais e tracemos algumas considerações sobre as regras do sistema PE.

Em primeiro lugar, precisamos chamar atenção para uma propriedade curiosa destas regras: a quantidade exata de negações à frente de cada fórmula é relativamente irrelevante, bastando que saibamos se a quantidade é par ou ímpar. Isto é trivial no caso da regra de PE para disjunção (já que fórmulas negadas são intuicionisticamente equivalentes a fórmulas triplamente negadas), mas também pode ser provado facilmente para as regras da implicação:

$$
\begin{aligned}
& {[\neg \neg A, \neg B]}
\end{aligned}
$$

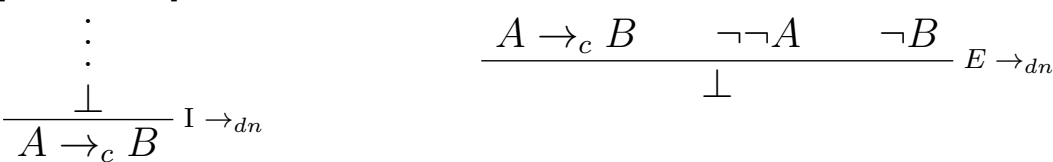

Prova de equivalência com as regras de PE para $\rightarrow_{c}$ :

\footnotetext{
${ }^{14}$ Prawitz analisa brevemente a abordagem inferencialista em (7), fornecendo um contexto para o debate e expondo algumas críticas já lançadas contra a tendência, que vem crescendo em força recentemente.
} 


$$
\begin{aligned}
& \frac{\left[A^{1}\right] \quad\left[\neg B^{2}\right]}{\frac{\frac{\Pi^{1}}{\perp}}{A \rightarrow_{c} B}\{1\},\{2\}, \mathrm{I} \rightarrow_{c}} \Rightarrow \frac{\frac{\left[A^{1}\right] \quad\left[\neg B^{2}\right]}{\frac{\frac{\Pi^{1}}{\perp}}{\neg A}\{1\} \quad\left[\neg \neg A^{3}\right]}}{\frac{\frac{\perp}{A \rightarrow_{c} B}\{2\},\{3\}, \mathrm{I} \rightarrow \rightarrow_{d n}}{\frac{}{\frac{1}{4}}}} \\
& \frac{\left[\neg \neg A^{1}\right] \quad\left[\neg B^{2}\right]}{\frac{\frac{\Pi^{1}}{\perp}}{A \rightarrow_{c} B}\{1\},\{2\}, \mathrm{I} \rightarrow_{d n}} \quad \Rightarrow \quad \frac{\frac{\left[A^{1}\right] \quad\left[\neg A^{2}\right]}{\frac{\perp}{\neg \neg}\{2\}}\left[\neg B^{3}\right]}{\frac{\frac{\Pi^{1}}{\perp}}{A \rightarrow_{c} B}\{1\},\{3\}, \mathrm{I} \rightarrow_{c}}
\end{aligned}
$$

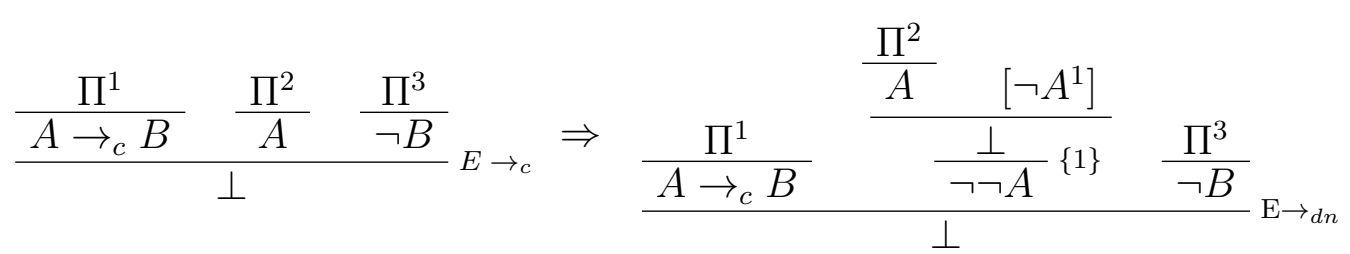

$$
\begin{aligned}
& \frac{\frac{\Pi^{1}}{A \rightarrow_{c} B} \quad \frac{\Pi^{2}}{\neg \neg A} \quad \frac{\Pi^{3}}{\neg B}}{\perp} E \rightarrow_{d n} \Rightarrow \frac{\frac{\Pi^{1}}{A \rightarrow_{c} B} \quad\left[A^{1}\right] \frac{\Pi^{3}}{\neg B}}{\frac{\frac{\perp}{\neg A}\{1\}}{\perp}} \mathrm{E \rightarrow c} \frac{\Pi^{2}}{\neg \neg A}
\end{aligned}
$$

$$
\begin{aligned}
& {[A]} \\
& \frac{\vdots}{A \rightarrow \rightarrow_{c} B} I \rightarrow 1 \quad \frac{A \rightarrow_{c} B \quad A}{\neg \neg B} E \rightarrow_{1} \\
& {[\neg \neg A]} \\
& \frac{\neg \neg B}{A \rightarrow_{c} B} I \rightarrow_{2} \quad \frac{A \rightarrow_{c} B \quad \neg \neg A}{\neg \neg B} E \rightarrow_{2}
\end{aligned}
$$




$$
\begin{aligned}
& {[\neg B]} \\
& \vdots \\
& \frac{\neg A}{A \rightarrow_{c} B} I \rightarrow_{3} \quad \frac{A \rightarrow_{c} B \quad \neg B}{\neg A} E \rightarrow_{3}
\end{aligned}
$$

Para provar a equivalência de todas estas regras de maneira econômica, demonstraremos que a regra de introdução (e a de eliminação) para a implicação clássica em PE pode ser transformada em uma aplicação da primeira regra desta lista, demonstrando logo em seguida que cada regra pode ser transformada em uma aplicação da regra seguinte e, por fim, que a última regra pode ser transformada em uma aplicação da regra de PE:

\section{Regras de introdução}

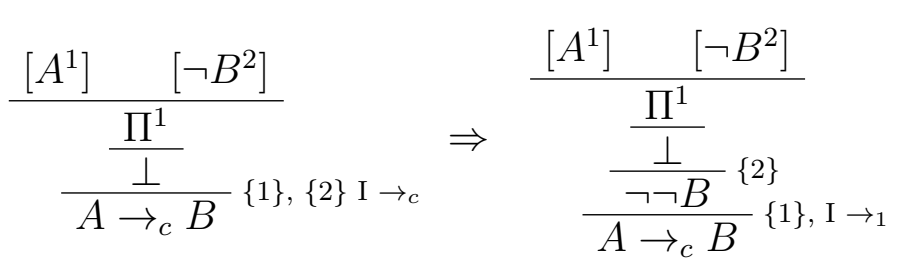

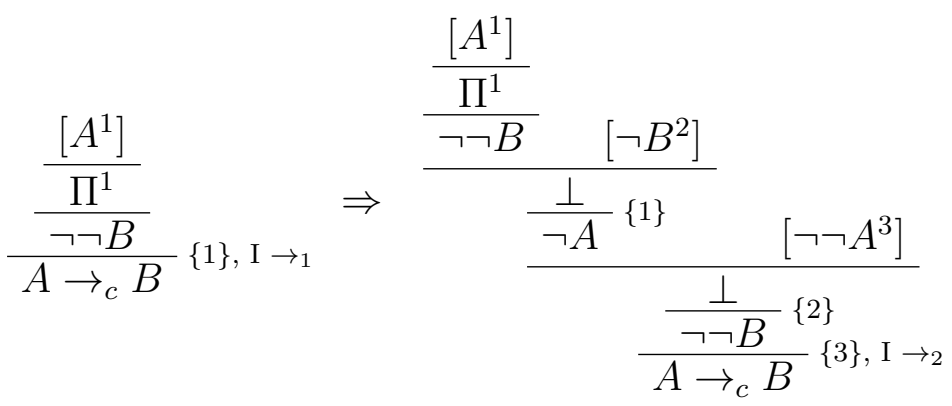

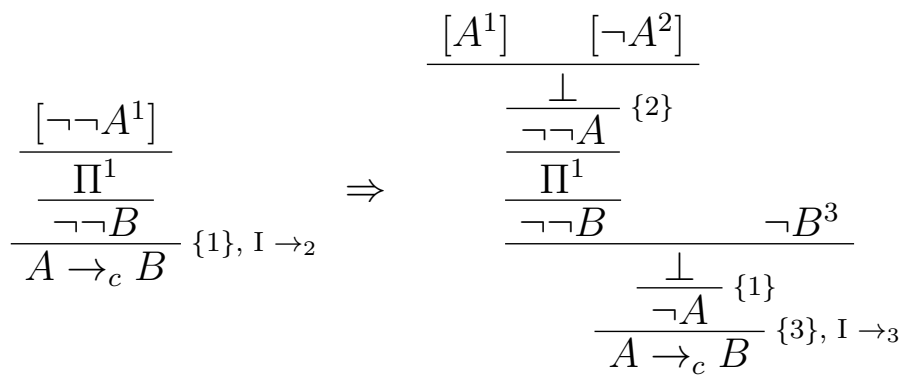




$$
\frac{\frac{\left[\neg B^{1}\right]}{\Pi^{2}}}{\frac{\neg A}{A \rightarrow_{c} B}\{1\}, \mathrm{I} \rightarrow_{3}} \Rightarrow \frac{\frac{\left[\neg B^{1}\right]}{\Pi^{1}}}{\frac{\neg A}{\frac{\perp}{A \rightarrow_{c} B}}\{1\},\{2\}, \mathrm{I} \rightarrow_{c}}
$$

\section{Regras de eliminação}

$$
\frac{\frac{\Pi^{1}}{A \rightarrow_{c} B} \frac{\Pi^{2}}{A} \quad \frac{\Pi^{3}}{\neg B}}{\perp} \mathrm{E} \rightarrow \rightarrow_{c} \Rightarrow \frac{\frac{\Pi^{1}}{A \rightarrow_{c} B} \quad \frac{\Pi^{2}}{A}}{\frac{\neg \neg B}{\perp} \rightarrow_{1} \frac{\Pi^{3}}{\neg B}}
$$

$$
\begin{aligned}
& \frac{\frac{\Pi^{1}}{A \rightarrow_{c} B}}{\neg \neg B} \frac{\Pi^{2}}{A}{ }_{\mathrm{E} \rightarrow 1} \Rightarrow{\frac{\Pi^{1}}{\frac{A \rightarrow_{c} B}{\neg \neg B}}}_{\frac{\frac{\Pi^{2}}{A}}{\neg \neg A}\{1\}}^{\frac{\perp}{\mathrm{E} \rightarrow 2}}
\end{aligned}
$$

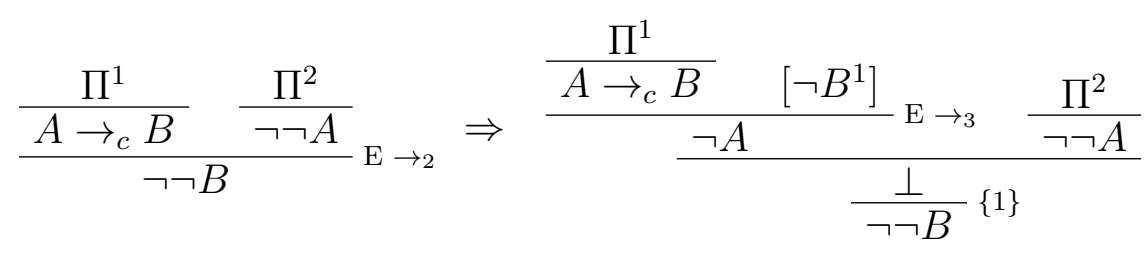

$$
\begin{aligned}
& \frac{\frac{\Pi^{1}}{A \rightarrow_{c} B} \quad \frac{\Pi^{2}}{\neg B}}{\neg A} \mathrm{E} \rightarrow \rightarrow_{3} \Rightarrow \frac{\frac{\Pi^{1}}{A \rightarrow_{c} B} \quad\left[A^{1}\right] \quad \frac{\Pi^{2}}{\neg B}}{\frac{\perp}{\neg A}\{1\}} \mathrm{E} \rightarrow \rightarrow_{c}
\end{aligned}
$$

Estas regras alternativas são interessantes não só por substituírem o formato de reductio da regra de PE por um formato mais próximo da regra de introdução para a implicação intuicionista, mas também por demonstrar que, de uma perspectiva baseada em teoria da prova, o funcionamento da implicação clássica é estritamente dependente do funcionamento da negação 
nos sistemas de dedução natural formulados por Prawitz ${ }^{15}$. Curiosamente, a equivalência intuicionista entre negação e tripla negação também faz com que a implicação clássica seja equivalente à afirmação do condicional com base em uma inferência do tipo modus tollens, conforme demonstra a terceira regra.

A regra de PE para a disjunção clássica, por sua vez, é demonstravelmente equivalente às seguintes regras:

$$
\begin{array}{ll}
{[\neg A]} & \\
\vdots & \\
\frac{\neg \neg B}{A \vee_{c} B} I \rightarrow_{1} & \\
& \\
{[\neg B]} & \\
\vdots & \frac{A \vee_{c} B \quad \neg A}{\neg \neg B} E \rightarrow_{1} \\
\frac{\neg \neg A}{A \vee_{c} B} I \rightarrow_{1} & \neg \neg A \\
&
\end{array}
$$

\section{Regras de introdução}

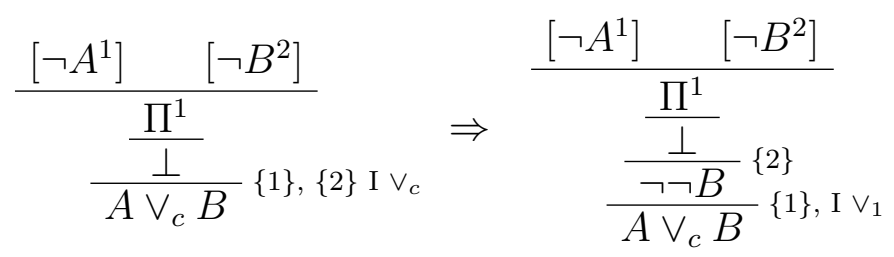

\footnotetext{
${ }^{15} \mathrm{O}$ mesmo já foi observado em (3) em relação à disjunção. No entanto, estas considerações precisam ser limitadas à caracterização específica que demos para os conectivos clássicos, intuicionistas e minimais nos sistemas de dedução natural apresentados, já que também é possível diferenciar as implicações das três lógicas sem o uso da negação em outros contextos (usando a Lei de Peirce para diferenciar a implicação clássica de implicações construtivas em um sistema axiomático, por exemplo).
} 


$$
\frac{\frac{\left[\neg A^{1}\right]}{\Pi^{1}}}{\frac{\neg \neg B}{A \vee_{c} B}\{1\} \mathrm{I} \vee_{1}} \Rightarrow \frac{\frac{\left[\neg A^{1}\right]}{\Pi^{1}}}{\frac{\neg B}{\frac{\perp}{\neg \neg A}\{1\}}[2\}, \mathrm{I} \vee_{2}}
$$

$$
\frac{\frac{\left[\neg B^{1}\right]}{\Pi^{1}}}{\frac{\neg \neg A}{A \vee_{c} B}\{1\} \mathrm{I}_{2} \vee_{2}} \quad \Rightarrow \frac{\frac{\left[\neg B^{1}\right]}{\Pi^{1}}}{\frac{\neg \neg A}{\left.\frac{\perp}{A \vee_{c} B}\{1\},\{2\}, I A^{2}\right]}}
$$

\section{Regras de eliminação}

$$
\frac{\frac{\Pi^{1}}{A \vee_{c} B} \quad \frac{\Pi^{2}}{\neg A} \quad \frac{\Pi^{3}}{\neg B}}{\perp} \mathrm{E}_{\vee_{c}} \Rightarrow \frac{\frac{\Pi^{1}}{A \vee_{c} B} \frac{\Pi^{2}}{\neg A}}{\frac{\neg \neg B}{\perp} \vee_{1} \quad \frac{\Pi^{3}}{\neg B}}
$$

$$
\begin{aligned}
& \frac{\frac{\Pi^{1}}{A \vee_{c} B} \frac{\Pi^{2}}{\neg A}}{\neg \neg B} \vee_{\vee_{1}} \Rightarrow \frac{\frac{\Pi^{1}}{A \vee_{c} B}\left[\neg B^{1}\right]}{\frac{\neg \neg A}{\frac{\perp}{\neg \neg B}\{1\}}} \vee_{2} \frac{\Pi^{3}}{\neg A}
\end{aligned}
$$

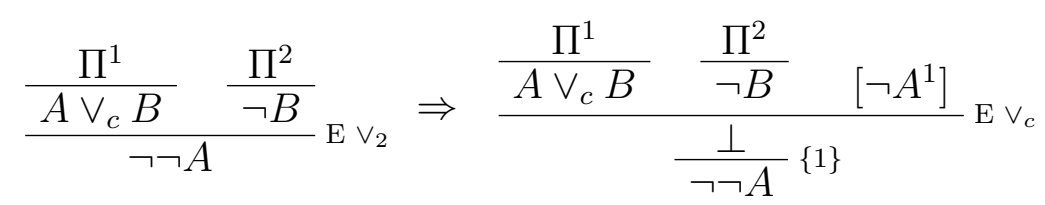

Assim como no caso da implicação clássica, a disjunção também é equivalente a regras que permitem o descarte de fórmulas. Embora evidencie a já conhecida força probatória da disjunção na lógica clássica, esta observação pode gerar um certo estranhamento para a tradição inferencialista, já que a disjunção não costuma ser pensada como um conectivo inferencialmente dependente de hipóteses. Como se não bastasse, estas equivalências mais uma vez evidenciam que os conectivos clássicos dependem da negação para ter o sentido que normalmente lhes é atribuído, mostrando que a negação possui um papel ordenador e uniformizador essencial no seio das práticas inferenciais clássicas. 


\subsection{2}

\section{Normalização, princípio de subfórmula e outros teoremas}

A estratégia empregada por Prawitz em suas provas do teorema de normalização para o sistema de dedução natural clássico (18) depende fortemente da existência de uma diferença de complexidade entre as premissas e a conclusão de cada regra (com exceção da disjunção), bem como da existência de uma certa simetria entre regras de introdução e eliminação, sendo esta última usualmente garantida pelo princípio da inversão ${ }^{16}$.

No sistema clássico, os casos problemáticos da disjunção e do existencial (que podem introduzir fórmulas mais complexas do que o conectivo objeto de eliminação) podem ser desconsiderados sem prejuízo algum, já que todo o sistema pode ser definido utilizando apenas as regras para conjunção, implicação, quantificador universal e das regras para $\perp$. No entanto, a regra $\perp_{c}$ se mostra especialmente problemática porque, não obstante não poder ser removida ou substituída e, ainda, não satisfazer o princípio de inversão, efetivamente permite que introduzamos como conclusão fórmulas menos complexas do que as utilizadas como premissas. Prawitz evita complicações estruturais geradas por esta regra utilizando reduções para demonstrar que podemos considerar apenas derivações nas quais as consequências da regra $\perp_{c}$ são atômicas, deste modo atenuando os efeitos "perturbadores" que a regra possui nos demais casos.

Esta técnica, no entanto, não pode ser utilizada na lógica ECI, porquanto a distinção sintática entre átomos clássicos e intuicionistas cria uma espécie de registro de cada aplicação da regra $I_{c}$ nas próprias fórmulas às quais a regra é aplicada. A marca deixada pela regra clássica em um átomo " $A$ " após a sua transformação em " $A_{c}$ " só pode ser eliminada da derivação por aplicações posteriores da regra $E_{c}$, e não mais podemos usar os átomos e conclusões atômicas do processo de reductio indistintamente. Isto acaba tornando o produto final de uma derivação (especialmente de uma derivação normal) estritamente dependente da etapa na qual a regra clássica veio a ser aplicada, de modo que aplicações com consequências mais complexas não podem ser reduzidas a derivações com aplicações que possuem como consequência átomos ecumênicos.

Para exemplificar, vejamos como a redução de Prawitz para fórmulas conjuntivas funcionaria em ECI:

\footnotetext{
16 "Let $\alpha$ be an application of an elimination rule that has $\mathrm{B}$ as a consequence. Then, deductions that satisfy the sufficient condition (in the list above) for deriving the major premiss of $\alpha$, when combined with deductions of the minor premiss of $\alpha$ (if any), already "contain" a deduction of $\mathrm{B}$; the deduction of $\mathrm{B}$ is thus obtainable directly from the given deductions without the addition of $\alpha . "(18, \mathrm{pg} .33)$
} 


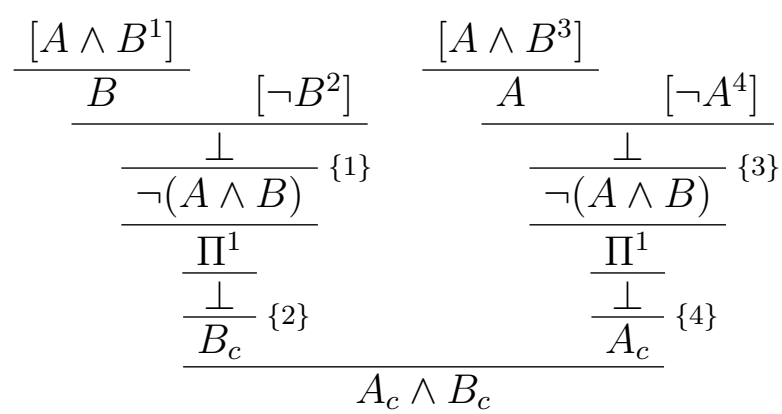

A aplicação da regra clássica a átomos gera uma fórmula distinta daquela obtida com a aplicação da mesma regra a outros tipos de fórmula. A introdução da fórmula $A \wedge_{c} B$ pela regra $I_{c}$ só pode ser realizada através do descarte direto da fórmula $\neg(A \wedge B)$, de modo que a aplicação desta regra a átomos faz com que tenhamos lembretes permanentes do caráter clássico de algum fragmento das subderivações.

Felizmente, a introdução de uma distinção sintática entre átomos simples e ecumênicos também nos permite introduzir uma métrica de complexidade diferenciada para ambos, o que inclusive pode ser utilizado para minimizar o comportamento errático da regra $\perp_{c}$ e torná-la bem mais palatável para aqueles que lidam com teoria da prova. Neste sentido, utilizando a mesma estratégia que PEREIRA, L. e RODRIGUEZ, R. (3), podemos substituir a noção tradicional do "grau" de uma fórmula, definida em termos da quantidade de conectivos lógicos que ela comporta, por uma métrica que efetivamente reflita a carga de complexidade introjetada nas fórmulas pela aplicação da regra clássica no decorrer de uma derivação:

5. Definição. O grau ecumênico ge de uma fórmula é calculado da seguinte forma:

[5.1] $g e(\mathrm{~A})=0$, para A atômico;

$[5.2] g e(\perp)=0$;

[5.3] $g e(A \circ B)=g e(\mathrm{~A})+g e(\mathrm{~B})+1$, para $\circ \in\{\wedge, \vee, \rightarrow\}$;

[5.4] $g e(\neg A)=g e(A \rightarrow \perp)=g e(\mathrm{~A})+1$;

$[5.5] g e(\circ P x)=g e(\mathrm{Px})+1$, para $\circ \in\{\exists, \forall\}$;

[5.6] $g e\left(A_{c}\right)=g e(\mathrm{~A})+2$.

Nesta nova métrica, as regras clássicas de ECI passam a preservar a relação desejada entre o grau de complexidade das premissas e o grau de 
complexidade da conclusão. Com isto, podemos definir a seguinte redução para eliminar fórmulas maximais clássicas ${ }^{17}$ :

$$
\frac{\frac{\frac{\neg A}{\Pi^{1}}}{\frac{\perp}{A_{c}}} \quad \frac{\Pi^{2}}{\neg A}}{\perp} \Rightarrow \frac{\frac{\Pi^{2}}{\frac{\neg A}{\Pi^{1}}}}{\frac{1}{\perp}}
$$

Utilizando lemas expostos em (3), podemos demonstrar que as fórmulas maximais originadas por esta redução terão um grau ecumênico menor que o grau ecumênico de $A_{c}$, viabilizando a aplicação desta estratégia na elaboração de provas de normalização para a lógica ECI.

Além da viabilização desta nova estratégia de prova, o formato específico desta redução sugere uma abordagem mais simples e abrangente para a prova deste tipo de resultado. Uma vez que as reduções para $I_{c}$ e $E_{c}$ possuem o mesmo formato que as reduções para $I \rightarrow$ e $E \rightarrow(18$, pg 37), podemos extrair nossos resultados diretamente dos resultados já estabelecidos para a lógica intuicionista ao remover as regras clássicas introduzidas em ECI e representar as fórmulas ecumênicas na lógica intuicionista por meio da seguinte tradução:

6. Definição. $E C I\left[A_{c}\right]:=\neg \neg A$

Esta transformação faz com que voltemos a lidar diretamente com a lógica intuicionista, e as regras de introdução e eliminação para $A_{c}$ passam a ser vistas como instâncias particulares das regras de introdução e eliminação da implicação intuicionista ${ }^{18}$ :

$$
\begin{gathered}
{[\neg A]} \\
\vdots \\
\frac{\perp}{A_{c}} I_{c}
\end{gathered} \quad \Leftrightarrow \quad \begin{gathered}
{[\neg A]} \\
\end{gathered}
$$

\footnotetext{
${ }^{17}$ Embora não tenha sido objeto de definição, "fórmulas maximais" está sendo usado aqui no sentido usual da literatura, como uma fórmula que é conclusão de uma regra de introdução e premissa maior de uma regra de eliminação ou, de maneira mais simples, como uma fórmula que é introduzida e imediatamente eliminada em algum momento da derivação.

${ }^{18}$ Expediente similar foi adotado por Prawitz em sua definição da negação, na qual as definições de Gentzen passaram a ser vistas como casos especiais da implicação (18, pg. 21)
} 
É importante ressaltar que esta definição não faz com que as fórmulas ecumênicas sejam estritamente equivalentes a fórmulas clássicas, ao menos caso entendamos "equivalência estrita" como $\vdash_{c} A \Longleftrightarrow \vdash_{e c i} E C I\left[A_{c}\right]$. Uma prova desta equivalência com a definição apresentada nos permitiria obter imediatamente uma prova dos dois teoremas de Glivenko para a lógica intuicionista de predicados, o que é comprovadamente impossível devido à existência de contraexemplos para o segundo. Esta definição tem por objetivo apenas demonstrar a possibilidade de representação das fórmulas ecumênicas no sistema intuicionista de dedução natural, o que nos permitiria concluir pela possibilidade de interpretação direta de ECI na lógica intuicionista.

Com esta definição, uma vez que as fórmulas do tipo $A_{c}$ se tornam casos especiais da negação e que a negação intuicionista pode ser visualizada como um caso especial da implicação, as regras $I_{c}$ e $E_{c}$ se tornam, transitivamente, casos especiais da implicação, sem nenhuma perda de generalidade. Ademais, como a regra de introdução para $A_{c}$ é transformada em uma regra de introdução e a regra de eliminação é transformada em uma regra de eliminação, nós imediatamente obtemos que, caso definamos que uma derivação é normal se e somente se nenhum conectivo for introduzido e imediatamente eliminado ${ }^{19}$ durante a derivação, então temos que o teorema de normalização para ECI se segue diretamente do teorema de normalização para a lógica intuicionista, já que podemos transformar derivações de ECI em derivações intuicionistas, normalizar estas derivações e realizar as transformações inversas para a obtenção de derivações normais em $\mathrm{ECI}^{20}$.

Já que todas as derivações normalizadas passam a utilizar apenas as regras intuicionistas originais, isto faz com que possamos estender a ECI todos os resultados já estabelecidos para a lógica intuicionista, inclusive os de normalização forte (23) e confluência $(24)^{21}$.

Também podemos estabelecer os mesmos resultados para PE com esta

${ }^{19} \mathrm{O}$ conceito de fórmula maximal é apresentado informalmente nestes termos em $(20$, pg. 187), mas não recebe caracterização informal similar em (18). Nos dois casos, a definição formal indica que uma derivação é normal se e somente se não contiver fórmulas maximais, definidas como aquelas que são introduzidas por uma regra e utilizadas como premissa maior de outra.

${ }^{20}$ É importante que usemos alguma espécie de marcador ou sinal gráfico em todas as duplas negações obtidas a partir de fórmulas do tipo $A_{c}$ por este procedimento; caso contrário, seremos incapazes de distinguir, na derivação intuicionista, duplas negações que foram obtidas através da transformação de fórmulas clássicas de duplas negações que já estavam na derivaçaõ original em ECI. Caso realizemos um controle de quais duplas negações devem ser reconvertidas após a normalização, no entanto, o procedimento não parece gerar maiores dificuldades.

${ }^{21}$ Ao que tudo indica, talvez seja possível generalizar esta abordagem de modo a permitir que visualizemos a regra do absurdo clássico como uma caso especial da regra de introdução da implicação, o que indicaria que a prova de resultados estruturais para a lógica clássica também é um caso especial dos mesmos resultados estruturais para a lógica intuicionista. 
técnica, bastando que novamente eliminemos as regras para conectivos clássicos do sistema e os reintroduzamos por meio de traduções. De acordo com as equivalências provadas no Teorema 4, a tradução que se segue seria adequada para este propósito:

\section{Definições.}

$$
\begin{aligned}
& \text { [7.1] } P E\left[A \vee_{c} B\right]:=\neg \neg(A \vee B), \\
& \text { [7.2]PE[A } \left.\rightarrow_{c} B\right]:=\neg \neg(A \rightarrow B) \\
& \text { [7.3]PE[ } \left.\exists_{c} x P c\right]:=\neg \neg \exists x P x
\end{aligned}
$$

Exemplo:

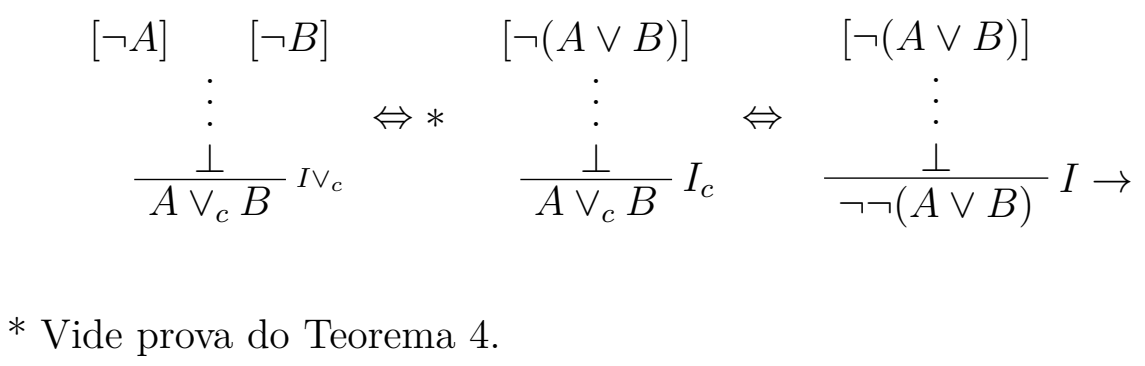

Estas definições também nos permitem resgatar o princípio de subfórmula para sistemas contendo fórmulas ecumênicas, respondendo a mais uma das questões expostas ao final de $(3)^{22}$. Isto significa que, mesmo desconsiderando estas definições e reintroduzindo no sistema as regras ecumênicas para conectivos e fórmulas clássicas, nós podemos criar versões modificadas do conceito de subfórmula que sejam satisfeitas por PE e ECI, bastando para tal que este novo conceito preserve as definições usuais de subfórmula e, adicionalmente, determine que $\neg \neg A$ (bem como todas as suas subfórmulas) também sejam subfórmulas de $A_{c}$.

\footnotetext{
${ }^{22}$ Também é interessante notar que estas definições equivalem à tradução entre as lógicas clássica e intuicionista usada por Kolmogorov.
} 


\subsection{3}

\section{Representação de derivações clássicas}

As seguintes derivações são válidas em ECI, onde $A \Longleftrightarrow B$ é tomado como abreviação para $((A \rightarrow B) \wedge(B \rightarrow A))$ (provas no apêndice):

A1. $A \vdash A_{c}$

A2. $\vdash A_{c} \Longleftrightarrow A_{c c}$

A3. $\vdash \perp_{c} \Longleftrightarrow \perp$

A4. $\vdash \neg A \Longleftrightarrow \neg{ }_{c} A$

A5. $A \wedge_{c} B \vdash A_{c}$

A6. $A \wedge_{c} B \vdash B_{c}$

A7. $A_{c}, B_{c} \vdash A \wedge_{c} B$

A8. $A_{c} \vdash B_{c} \Rightarrow \vdash A \rightarrow_{c} B$

A9. $A_{c}, A \rightarrow{ }_{c} B \vdash B_{c}$

A10. $\forall_{c} x P_{c} A \vdash P_{c} A[x / a]$, para qualquer "a", onde "A" representa os $n$ parâmetros e variáveis individuais escritas após o predicado n-ário " $\mathrm{P}$ ". A11. $\Gamma \vdash P_{c} A[x / a] \Rightarrow \Gamma \vdash \forall_{c} x P_{c} A[a / x]$, onde "a" satisfaz os requisitos de $I \forall$ e "A" está representando os $n$ parâmetros e variáveis individuais escritas após o predicado n-ário "P".

A12. $\perp \vdash A_{c}$

A13. $\neg{ }_{c} A \vdash \perp \Rightarrow \vdash A_{c}$

Podemos utilizar estas derivações para provar um resultado interessante entre as lógicas ECI e clássica:

- Teorema 5. Se existe uma derivação $\Gamma \vdash_{c} A$, então existe uma derivação $\Gamma_{c} \vdash_{e c i} A^{c}$, onde $\Gamma_{c}$ e $A^{c}$ são obtidos a partir de $\Gamma$ e $A$ por meio da substituição de ao menos uma subfórmula de alguma fórmula de $\Gamma$ e de $A$ por subfórmulas com subscrito clássico em ECI.

\section{Prova:}

Conforme indicado por Prawitz (18, pg. 39), para toda derivação clássica $\Gamma \vdash A$, existe uma derivação equivalente de $A^{\prime}$ a partir de $\Gamma^{\prime}$ na lógica $C^{\prime}$, composta por todas as regras do sistema clássico menos as regras relativas à disjunção e ao quantificador existencial. Consideraremos apenas derivações realizadas em C' em nossas transformações.

Se substituirmos todas as subfórmulas de todas as fórmulas de uma derivação por suas versões clássicas, a estrutura resultante permitirá que usemos as equivalências apontadas para imediatamente obter uma derivação válida em ECI. Isto pode ser visualizado na derivação abaixo, onde cada inferência é justificada ou por uma regra de ECI ou pelas derivações já 
estabelecidas em A1-A12, além de possuir a mesma estrutura inferencial que uma das regras de C':

$$
\begin{aligned}
& \frac{\left[P_{c} a^{1}\right] \quad P_{c} b^{2}}{\frac{\Pi^{A 7}}{P a \wedge_{c} P b}} \\
& \frac{\left[P a^{1}\right] \quad P b^{2}}{P a \wedge P b} \quad \frac{\frac{P a \wedge_{c} P b}{\Pi^{A 6}}}{P_{c} b} \\
& \frac{\frac{P b}{\frac{\frac{1}{P c}}{\forall x P x}}}{\frac{\frac{\forall b^{3}}{P d}}{P a \rightarrow P d}\{1\}} \Rightarrow \\
& \begin{array}{c}
\frac{\frac{1 P_{c} b}{\Pi^{A 12}}}{\frac{P_{c} c}{\Pi^{A 11}}} \\
\frac{\frac{\forall_{c} x P_{c} x}{\Pi^{A 10}}}{\frac{P_{c} d}{\Pi^{A 8}}}\{1\} \\
\frac{P a \rightarrow_{c} P d}{}
\end{array}
\end{aligned}
$$

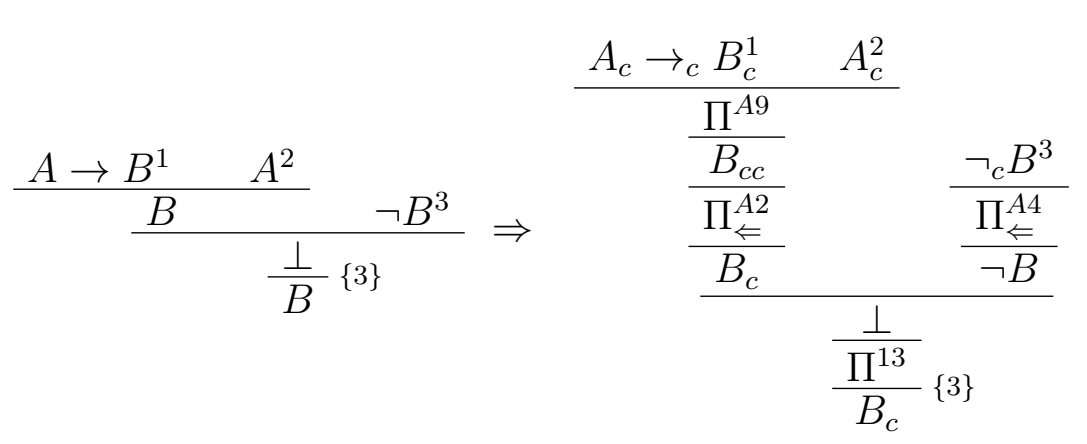

Este procedimento pode ser utilizado para substituir, por exemplo, todas as aplicações de $I \wedge$ com premissas $A$ e $B$ por derivações de $A \wedge_{c} B$ com premissas $A_{c}$ e $B_{c}$. Repetindo este processo para todas as demais regras de C', obteremos uma derivação válida em ECI com o formato desejado. Por último, caso as subfórmulas das fórmulas clássicas também sejam clássicas, podemos eliminar todos os subscritos duplicados (Ex: podemos usar uma fórmula $A_{c} \wedge_{c} B_{c}$ para obter $A_{c c}$ e usar $A 2 \Leftarrow$ para obter $A_{c}$ ), de modo que sempre é possível obter uma derivação clássica com o formato desejado, não importando se as subfórmulas possuem subscritos ou não.

Intuitivamente, a prova demonstra que uma derivação em ECI na qual são utilizadas apenas fórmulas clássicas é equivalente a uma derivação na lógica clássica, uma vez que as relações A1-A12 nos permitem criar regras derivadas que, muito embora lidem apenas com premissas e conclusões clássicas, possuem o mesmo formato das regras originais do sistema. 
Por razões estruturais, a regra de introdução para o quantificador universal se destaca das demais regras, não possuindo uma equivalente clássica similar às provadas nas relações A1-A9. Não podemos utilizar uma derivação de $P_{c} a$ para introduzir a fórmula $\forall_{c} P x$, muito embora possamos introduzir $\forall x P_{c} x$ e $\forall_{c} x P_{c} x$. De certo modo, os predicados ficam "marcados" por aplicações da regra $I_{c}$, e esta marca, que desaparece nas demais regras, é preservada por aplicações da regra $I \forall$.

Isto parece explicar tanto o formato específico da tradução definida por Kuroda quanto a impossibilidade de generalização dos resultados de Glivenko para a lógica intuicionista de predicados, já que algumas derivações classicamente válidas e intuicionistamente inválidas necessariamente contém aplicações internas da regra $I_{c}$ que precedem a introdução de quantificadores universais. Um exemplo disso é a derivação tradicional de $\vdash_{c} \forall x(P x \vee \neg P x)$, que possui o seguinte formato:

$$
\begin{gathered}
\frac{\left[P a a^{1}\right]}{P a \vee P a} \quad\left[\neg(P a \vee \neg P a)^{2}\right] \\
\frac{\frac{\perp}{P P a}\{1\}}{\frac{P a \vee \neg P a}{}} \quad\left[\neg(P a \vee \neg P a)^{2}\right] \\
\frac{\frac{\perp}{P a \vee \neg P a} \perp_{c},\{2\}}{\forall x(P x \vee \neg P x)}
\end{gathered}
$$

Não é possível reformular esta derivação de modo que a introdução do quantificador universal ocorra após a aplicação da regra $\perp_{c}$, o que faz com que possamos estabelecer $\vdash_{e} \forall x\left(P x \vee_{c} \neg P x\right)$ e $\vdash_{e} \forall_{c} x\left(P x \vee_{c} \neg P x\right)$, mas não $\vdash_{e} \forall_{c} x(P x \vee \neg P x)$. Com isso, caso interpretemos $A_{c}$ como $\neg \neg A$, uma vez que estas aplicações internas fazem com que a dupla negação permaneça dentro do escopo do quantificador universal após sua introdução, precisamos introduzir uma nova dupla negação - desta vez externa - para que a fórmula passe a apresentar o mesmo comportamento clássico já estabelecido pelo teorema de Glivenko, assim como todas as demais fórmulas duplamente negadas intuicionistas. 


\section{Sistemas formais ecumênicos: lógicas intuicionista e minimal}

\section{1}

\section{Os sistemas PEM e EMI}

Assim como no caso intuicionista, a lógica minimal admite tanto uma abordagem generalista quanto uma abordagem inferencialista, ambas com inspiração nas funções de tradução definidas entre as duas lógicas e nas caracterizações da posição de Heyting por Johansson em (17, pg. 8). Uma codificação possível do sistema inferencialista, que chamaremos de PEM, pode ser obtida a partir do uso da linguagem $L_{i} 1$ e da adoção das definições feitas no capítulo anterior e das seguintes regras, além das já aceitas pela lógica minimal:

Regras inferencialistas para o condicional intuicionista:

$$
\begin{aligned}
& \text { [A] } \\
& \frac{\vdots}{\frac{B \vee \perp}{A \rightarrow_{i} B} \mathrm{I} \rightarrow_{i}} \quad \frac{A \rightarrow_{i} B \quad A}{B \vee \perp} E \rightarrow_{i}
\end{aligned}
$$

Regras inferencialistas para o quantificador universal intuicionista:

$$
\frac{A \vee \perp}{\forall_{i} x A[a / x]} I \forall_{i} \quad \frac{\forall_{i} x A}{(A \vee \perp)[x / a]} E \forall_{i}
$$

Restrições sobre a regra $\mathrm{I}{ }_{i}$ : o parâmetro individual "a" não ocorre em nenhuma hipótese da qual " $(A \vee \perp)$ " depende.

Infelizmente, o uso da disjunção para determinar as condições de asserção do condicional intuicionista é uma complicação difícil de se contornar. Em um primeiro momento, podemos imaginar que a implicação seja definível em 
termos de duas regras com formato similar ao da implicação, tais como as que seguem:

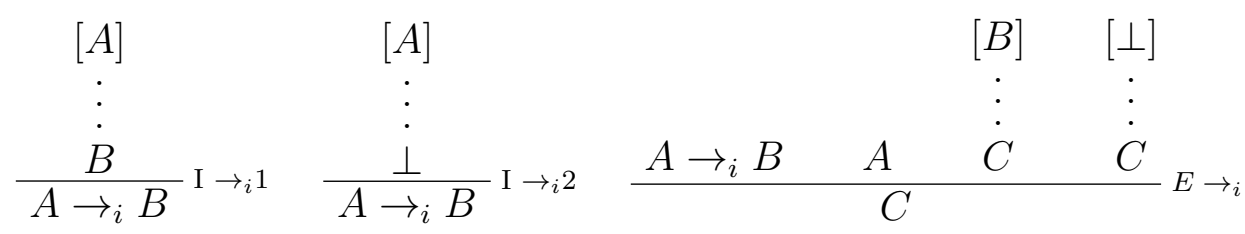

Estas regras definem a primeira equivalência usada por Johansson para caracterizar a posição de Heyting (17, pg. 8). Consequentemente, ao tornar a implicação intuicionista $\left(A \rightarrow_{i} B\right)$ equivalente a $(A \rightarrow B) \vee(A \rightarrow \perp)^{1}$, a definição do condicional nestes termos não é equivalente à definição anterior, já que $(A \rightarrow B) \vee(A \rightarrow \perp)$ não é equivalente a $(A \rightarrow(B \vee \perp))$ na lógica minimal. Portanto, estas definições esbarram exatamente nas mesmas complicações encontradas por Johansson em suas cartas: $\left(A \wedge\left(A \rightarrow_{i} B\right) \rightarrow_{i} B\right)$, assim como $\left(\left(A \rightarrow_{i} C\right) \wedge\left(B \rightarrow_{i} C\right)\right) \rightarrow_{i}\left((A \vee B) \rightarrow_{i} C\right)$, deixam de ser fórmulas que podem ser derivadas no sistema sem depender de nenhuma hipótese no sistema.

A definição do condicional intuicionista nestes termos também faz com que o operador não satisfaça modus ponens; uma prova de $A$ em conjunto com uma prova de $A \rightarrow_{i} B$ não necessariamente nos levaria a uma prova de $B$, podendo nos levar apenas a uma prova de $\perp$. Para que sempre pudessemos obter uma prova de $B$ a partir de uma prova de $B \vee \perp$ (e, portanto, uma prova de $B$, obtida a partir de uma prova de $A$ e uma prova de $A \rightarrow_{i} B$ ), precisaríamos de uma regra que codificasse o princípio ex falso sequitur quodlibet (EFQ), expressamente rejeitado pela lógica minimal.

Isto exemplifica e esclarece os apontamentos de Johansson no sentido de que, sob uma perspectiva minimal, o funcionamento da implicação no formato imaginado pelos intuicionistas está condicionado à ausência de derivações de $\perp$ no interior do sistema. Na ausência da regra EFQ, só podemos demonstrar a possibilidade de utilização das fórmulas $A$ e $A \rightarrow_{i} B$ para a obtenção de $B$ caso tivéssemos alguma garantia da impossibilidade de se derivar $\perp$ em qualquer hipótese. Caso efetivamente não exista nenhuma derivação de $\perp$ no sistema, como uma derivação de $B \vee \perp$ corresponde construtivamente a uma derivação de $B$ ou a uma derivação de $\perp$, nós podemos usar a implicação e o antecedente diretamente para obtenção de $B$, eis que esse passaria a ser o único disjunto passível de obtenção após nossa restrição inicial. Na ausência de restrições

${ }^{1}$ A prova de equivalência é simples, mas foge ao escopo da presente discussão. 
deste tipo, nada nos garantiria que, ao invés de termos um procedimento que realize transformações significativas de uma prova de $A$ em uma prova de $B$, nós tivéssemos apenas uma prova da impossibilidade de $A$, de modo que provas do tipo $B$ só pudessem ser obtidas através de aplicações da regra $E F Q$.

Muito embora não satisfaça modus ponens, assim como no caso dos operadores clássicos para a lógica intuicionista, a implicação ecumênica intuicionista satisfaz a inferência modus tollens, o que apenas reforça a proximidade das três lógicas no fragmento da linguagem onde todas as fórmulas são antecedidas por uma negação:

$$
\frac{\frac{A \rightarrow_{i} B^{1} \quad A^{2}}{B \vee \perp}}{\frac{\perp}{\neg A}\{2\}} \quad \frac{B^{3} \neg B^{4}}{\perp} \perp^{5}\{3\},\{5\}
$$

Não obstante, nós temos que a regra nos permite obter uma prova simples e imediata de $\left(A \rightarrow_{i}\left(\neg A \rightarrow_{i} B\right)\right)$, o único axioma intuicionista que precisa ser rejeitado para que cheguemos a uma formulação hillbertiana da lógica minimal:

$$
\frac{\frac{A^{1} \neg A^{2}}{\frac{\perp}{B \vee \perp}}\{2\}}{\frac{\neg A \rightarrow_{i} B}{\left(\neg A \rightarrow_{i} B\right) \vee \perp}}\{1\}
$$

Também seria possível introduzir $\left(A \rightarrow\left(\neg A \rightarrow_{i} B\right)\right)$ descartando a hipótese "A" logo após a derivação de $\left(\neg A \rightarrow_{i} B\right)$, de modo que apenas a segunda implicação necessariamente precisa receber o subscrito "i".

As regras generalistas, por sua vez, são inspiradas tanto no formato inferencial da regra $I \perp$ quanto na observação de que a lógica minimal é um subsistema da lógica intuicionista. Podemos obter o sistema ecumênico generalista EMI para estas lógicas por meio da adoção da linguagem $L_{i} 2$ e da adição das seguintes regras à lógica minimal: 
Regras generalistas:

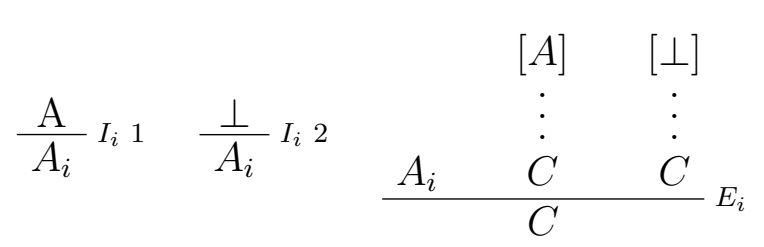

Também usaremos a mesma convenção adotada para o subscrito clássico, escrevendo, por exemplo, fórmulas do tipo $\left((A)_{i} \wedge B\right)_{i} \operatorname{cmo}\left(A_{i} \wedge_{i} B_{i}\right)$.

A rigor, precisaríamos apenas da regra que tem por premissa $\perp$ para criar um sistema ecumênico minimal-intuicionista. No entanto, isto faria com que $A_{i}$ representasse apenas as fórmulas que são intuicionistamente válidas e que não são minimalmente válidas, e não a totalidade de fórmulas intuicionistas válidas. Portanto, esta definição ampliada parece ser mais adequada para as finalidades deste trabalho.

\subsection{1}

\section{Representações assimétricas nos sistemas EMI e PEM}

Diferentemente do que ocorre entre os sistemas PE e ECI, as fórmulas ecumênicas definidas em EMI e PEM não são diretamente equivalentes, muito embora ainda possamos transformar todas as inferências com o formato das regras ecumênicas de PEM em derivações com formato similar e que contêm fórmulas intuicionistas em EMI e, conversamente, todas as inferências ecumênicas em EMI que introduzam implicações intuicionistas em derivações com formato similar em PEM.

- Teorema 6. Toda inferência com o formato da regra $I \rightarrow_{i}$ em PEM que introduza uma fórmula $A \rightarrow_{i} B$ pode ser transformada em uma inferência de EMI com conclusão $A \rightarrow B_{i}$, e a conclusão da regra $E \rightarrow_{i}$ pode ser introduzida em EMI usando como premissas as fórmulas $A$ e $A \rightarrow B_{i}$.

Prova:

$$
\frac{\frac{\left[A^{1}\right]}{\Pi^{1}}}{\frac{B \vee \perp}{A \rightarrow_{i} B}\{1\}, \mathrm{I} \rightarrow_{i} 1} \Rightarrow \frac{\frac{\frac{\left[A^{1}\right]}{\Pi^{1}}}{B \vee \perp} \frac{\left[B^{2}\right]}{B_{i}} I_{i} 1 \frac{\left[\perp^{3}\right]}{B_{i}} I_{i} 2}{\frac{B_{i}}{A \rightarrow B_{i}}\{1\}}\{2\},\{3\}
$$




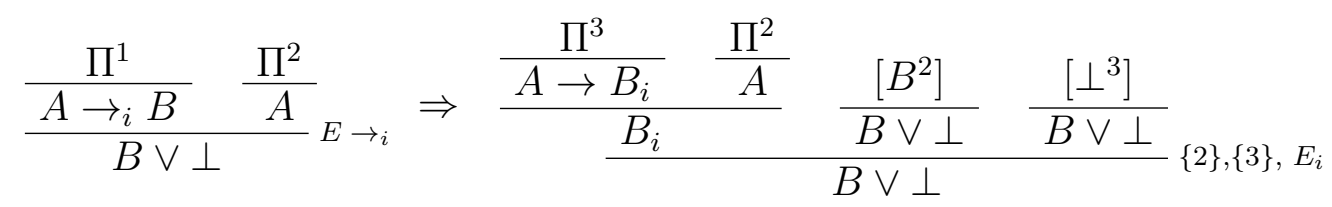

Para provar teoremas na outra direção, assim como no caso clássico, precisamos nos restringir ao fragmento da linguagem compartilhado pelos dois sistemas:

\section{- Definições - EMI}

1. Se $A_{i}$ é uma subfórmula de $B$, então $A$ é uma subfórmula de $B$.

2. Se $A_{i}$ é uma subfórmula de $B$, então $A_{i}$ é uma subfórmula intuicionista de $B$.

2.1 Se $\left(A \vee_{i} B\right)$ ou $\left(A \rightarrow_{i} B\right)$ são subfórmulas de $C$, então, respectivamente em cada um destes casos, chamaremos $\left(A \vee_{i} B\right)$ e $\left(A \rightarrow_{i} B\right)$ de $P E M$ subfórmulas de $C$.

2.1.1. Uma derivação em EMI é PEM-aceitável se e somente se toda subfórmula intuicionista de qualquer fórmula que ocorra na derivação também for uma PEM-subfórmula.

- Teorema 7. Toda inferência PEM-aceitável com o formato da regra $I_{i}$ em EMI que introduza uma fórmula $A \rightarrow_{i} B$ pode ser transformada em uma inferência de PEM com conclusão $A \rightarrow_{i} B$.

Prova:

$$
\begin{aligned}
& \frac{\Pi^{1}}{A \rightarrow B} I_{i} \Rightarrow \frac{\frac{\Pi^{1}}{A \rightarrow B}\left[A^{1}\right]}{\frac{B}{B \rightarrow_{i} B}}\{1\}, I \rightarrow_{i} \\
& \frac{\frac{\Pi^{1}}{\perp}}{A \rightarrow_{i} B} I_{i} \Rightarrow \frac{\frac{\Pi^{1}}{\frac{\perp}{B \perp}}\left[A^{1}\right]}{A \rightarrow_{i} B}\{1\}, I \rightarrow_{i}
\end{aligned}
$$

A representação da regra de eliminação de EMI em PEM é especialmente problemática, já que, além das limitações que decorrem das diferenças de 
linguagem entre as duas lógicas, também precisamos lidar com a assimetria na representação de uma regra por outra, assim como no caso da regra de introdução no Teorema 7 (que não precisa lidar com as diferenças linguísticas porque a linguagem $L_{I} 2$ contém a linguagem $L_{I} 1$ ). Não podemos substituir a fórmula inferencialista $A \rightarrow_{i} B$ pelo seu equivalente generalista $A \rightarrow B_{i}$, já que $B$ pode ser uma fórmula que não admita subscrito na linguagem de PEM (atômica ou conjuntiva, por exemplo).

Estas complicações podem ser resolvidas caso $B \vee \perp$ passe a adotar o mesmo papel que $B_{i}$ na substituição anterior - o que, como veremos, pode ser justificado em função da equivalência das fórmulas ecumênicas generalistas $B_{i}$ com fórmulas minimais do tipo $B \vee \perp$.

- Lema 1. Em EMI, uma derivação de $A_{i}$ sempre pode ser transformada em uma derivação de $A \vee \perp$, e vice-versa.

Prova:

$$
\begin{aligned}
& \frac{\Pi^{1}}{A_{i}} \Rightarrow \frac{\frac{\Pi^{1}}{A_{i}} \quad \frac{\left[A^{1}\right]}{A \vee \perp} \frac{\left[\perp^{2}\right]}{A \vee \perp}}{A \vee \perp}\{1\},\{2\}, E_{i} \\
& \frac{\Pi^{1}}{A \vee \perp} \Rightarrow \frac{\Pi^{1}}{\frac{A \vee \perp}{A_{i}}} \frac{\left[A^{1}\right]}{A_{i}} \frac{\left[\perp^{2}\right]}{A_{i}}
\end{aligned}
$$

- Teorema 8. Toda inferência em EMI com o formato de $E_{i}$ que elimine $A \rightarrow_{i} B^{2}$ em uma derivação PEM-aceitável pode ser representada como uma derivação de $C$ que utilize como premissa uma derivação de $B \vee \perp$ a partir de $A$.

\footnotetext{
${ }^{2} \mathrm{Na}$ ausência do conceito de "premissa maior", podemos dizer que "premissas" são as fórmulas imediatamente acima do traço horizontal correspondente à inferência e que uma fórmula é eliminada por essa regra se e somente se as três premissas forem iguais e a fórmula tiver o mesmo formato das três ou se a fórmula for a única premissa diferente das demais. No entanto, o contexto parece tornar o termo "eliminação" claro o bastante para ser utilizado informalmente.
} 


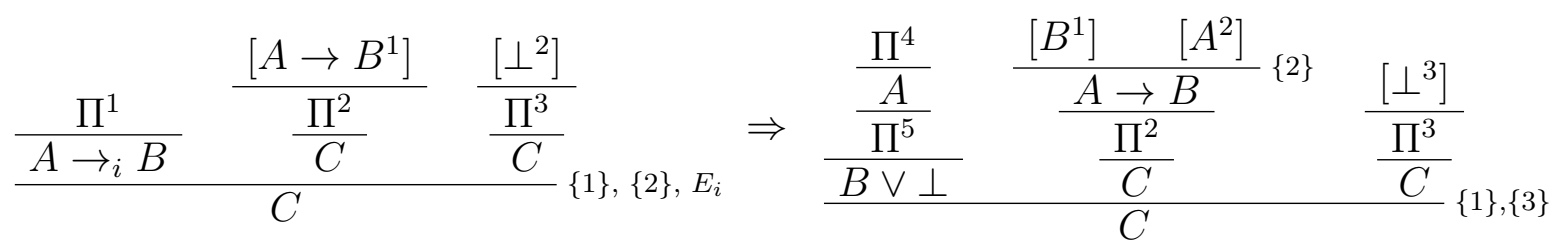

Tudo isso parece sugerir uma conexão estreita entre a definição de $A \rightarrow_{i} B$ em PEM e as condições de asserção de $A \rightarrow B_{i}$ em EMI. E, de fato, utilizando a equivalência provada pelo Lema 1, podemos definir um conectivo em EMI equivalente à implicação intuicionista de PEM utilizando as condições de asserção de $A \rightarrow B_{i}$ :

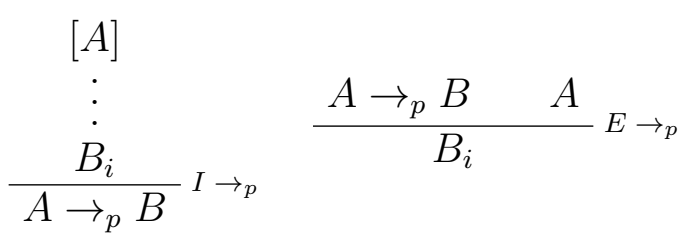

A prova de equivalência entre as duas formulações é imediata, bastando que substituamos $B_{i}$ por $B \vee \perp$ (o que resultará em uma regra equivalente, de acordo com o Lema 1 e nossa definição de equivalência) e observemos que as condições de asserção passam a ser as mesmas de $A \rightarrow_{i} B$ em PEM.

Muito embora tenhamos tratado apenas da implicação até o presente momento, todas as considerações que acabamos de realizar também se aplicam ao quantificador universal intuicionista das duas lógicas, eis que fórmulas de PEM com o formato $\forall_{i} x A$ não são equivalentes a fórmulas de EMI com o mesmo formato, muito embora tenham as mesmas condições de asserção de $\forall x A_{i}$ e $\forall x(A \vee \perp)$, como podemos ver na seguinte comparação:

$$
\frac{A_{i}}{\forall x A_{i}[a / x]} I \forall \Leftrightarrow \frac{(A \vee \perp)^{*}}{\forall x(A \vee \perp)[a / x]} I \forall \Leftrightarrow \frac{A \vee \perp}{\forall_{i} x A[a / x]} I \forall_{i}
$$

Restrições sobre as inferências: o parâmetro individual "a" não ocorre em nenhuma hipótese da qual " $A_{i}$ " ou $(A \vee \perp)$ dependam. 
Portanto, muito embora as definições dadas para $A \rightarrow_{i} B$ e $\forall_{i} x P x$ em PEM e EMI não coincidam, caso adiramos ao entendimento de que o sentido de um conectivo é determinado exclusivamente por suas condições de prova/asserção - algo comum tanto em teoria da prova quanto na obra de diversos defensores proeminentes do construtivismo, tais como Dummett (25, pg. 8) -, podemos dizer que $A \rightarrow B_{i}$ possui o mesmo sentido em EMI que $A \rightarrow_{i} B$ possui em PEM, assim como $\forall x P_{i} x$ possui o mesmo sentido em EMI que $\forall_{i} x P$ possui em EMI, de modo que, assim como no caso clássico, a abordagem generalista, mais ampla, é perfeitamente capaz de representar as inferências adotadas na abordagem inferencialista, mais restrita.

\subsection{2}

\section{Normalização e outros teoremas}

Alguns resultados importantes podem ser estabelecidos para estes dois sistemas por meio de traduções, assim como no caso dos sistemas clássicos. Para tanto, basta que interpretemos as fórmulas próprias de EMI e PEM em derivações minimais por meio das seguintes traduções:

\section{Definição.}

[8.1] $\operatorname{EMI}\left[A_{i}\right]:=A \vee \perp$

[8.2] $P E M\left[A \rightarrow_{i} B\right]:=A \rightarrow(B \vee \perp)$

[8.3] $\operatorname{PEM}\left[\forall_{i} x A\right]:=\forall x(A \vee \perp)$

Repetindo as transformações do caso clássico, podemos transformar derivações neste sistema nas seguintes derivações minimais, onde $\Pi_{m}$ é obtido a partir de П pela aplicação das mesmas transformações a regras ecumênicas porventura presentes em $\Pi$ :

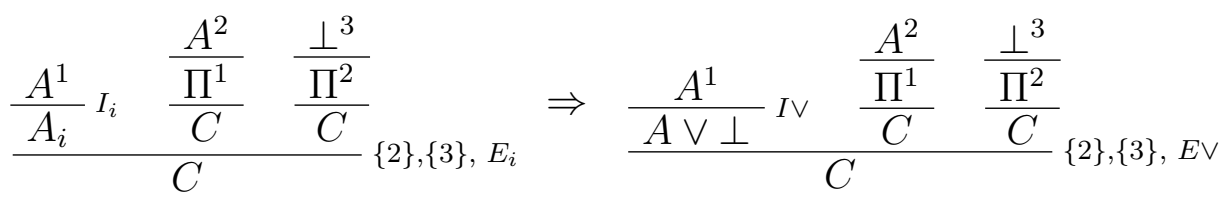

$$
\begin{aligned}
& {\left[A^{1}\right] \quad\left[A^{1}\right]} \\
& \text { : } \\
& \frac{\frac{B \vee \perp}{A \rightarrow_{i} B}\{1\}, I_{i} \quad A^{2}}{B \vee \perp} E_{i} \\
& \Rightarrow \frac{\frac{\dot{B} \vee \perp}{A \rightarrow(B \vee \perp)}\{1\}, I \rightarrow \quad A^{2}}{B \vee \perp} E \rightarrow
\end{aligned}
$$




$$
\frac{\frac{A^{*} \vee \perp}{\forall_{i} x A[a / x]}}{A[x / b]} I_{i} \forall_{i} \Rightarrow \frac{A^{*} \vee \perp}{\forall x(A \vee \perp)[a / x]}{ }^{\forall \vee} E \forall
$$

Onde $A *$ precisa satisfazer as restrições previstas para a regra $I \forall$.

Como toda regra de introdução é interpretada como uma regra de introdução e toda regra de eliminação é interpretada como regra de eliminação, após a transformação, podemos usar o teorema de normalização para a lógica minimal e obter uma derivação normal com o segundo formato, contanto que mantenhamos um registro de quais fórmulas devem ser reconvertidas após a normalização da derivação transformada ${ }^{3}$. Esta derivação normal pode ser transformada em uma derivação ecumênica por meio da inversão das transformações (com o mesmo preocedimento usado na inversão das transformações clássicas), e o resultado será uma derivação normal em EMI ou em PEM, já que a ordem das regras de introdução e eliminação continua a mesma - ou seja, nenhuma fórmula é introduzida e eliminada logo em seguida. E, mais uma vez, como estamos normalizando derivações minimais, isto faz com que possamos afirmar que, caso a lógica minimal seja fortemente normalizável e confluente, as lógicas EMI e PEM também o são.

\subsection{3}

\section{Representação de derivações intuicionistas}

Assim como no caso clássico, todas as regras intuicionistas podem ser simuladas no sistema generalista caso substituamos fórmulas comuns por fórmulas intuicionistas de EMI. No entanto, a não interdefinibilidade dos conectivos intuicionistas faz com que não mais possamos considerar um fragmento restrito da linguagem, sendo necessária a representação de todos os conectivos individualmente. Além disso, as complexidades do sistema minimal sugerem que provemos uma versão mais simples do Teorema 5, mas também mais fraca:

- Teorema 9. Se existe uma derivação $\Gamma \vdash_{i} A$, então existe uma derivação $\Gamma_{i} \vdash_{e m i} A^{i}$, onde $\Gamma_{i}$ e $A^{i}$ são obtidos a partir de $\Gamma$ e $A$ por meio da substituição de todas as subfórmulas intuicionistas de todas as fórmulas por subfórmulas de mesmo formato com subscritos intuicionistas.

Prova:

${ }^{3}$ Vide rodapé da prova relativa ao caso clássico. 
Mais uma vez, nós precisamos provar que cada regra intuicionista pode ser representada por uma inferência contendo fórmulas com subscrito, o que pode ser feito com facilidade após o estabelecimento dos seguintes resultados ${ }^{4}$ :

A14. $A \vdash A_{i}$

A15. $\vdash A_{i} \Longleftrightarrow A_{i i}$

A16. $\vdash \perp_{i} \Longleftrightarrow \perp$

A17. $\vdash \neg A \Longleftrightarrow \neg_{i} A$

A18. $A_{i} \wedge_{i} B_{i} \vdash A_{i}$

A19. $A_{i} \wedge_{i} B_{i} \vdash B_{i}$

A20. $A_{i}, B_{i} \vdash A_{i} \wedge_{i} B_{i}$

A21. $A_{i} \vdash B_{i} \Rightarrow A_{i} \rightarrow_{i} B_{i}$

A22. $A_{i}, A_{i} \rightarrow_{i} B_{i} \vdash B_{i}$

A23. $A_{i} \vdash A_{i} \vee_{i} B_{i}$

A24. $B_{i} \vdash A_{i} \vee_{i} B_{i}$

A25. $\left\{\Gamma \vdash A_{i} \vee_{i} B_{i}\right\}+\left\{A_{i} \vdash C_{i}\right\}+\left\{B_{i} \vdash C_{i}\right\} \Rightarrow \Gamma \vdash C_{i}$

A26. $P_{i} a \vdash \exists_{i} x P_{i} x$.

A27. $\left\{\Gamma \vdash \exists_{i} x P_{i} x\right\}+\left\{P_{i} a \vdash C_{i}\right\} \Rightarrow \Gamma \vdash C_{i}$, onde "Pa" satisfaz os requisitos de $E \exists$.

A28. $\Gamma \vdash P_{i} a \Rightarrow \Gamma \vdash \forall_{i} x P_{i} x$, caso "a" satisfaça os requisitos de $I \forall$.

A29. $\forall_{i} x P_{i} x \vdash P_{i} a$, para qualquer "a".

A30. $\perp \vdash A_{i}$

Estabelecidos estes resultados, basta que substituamos as regras intuicionistas por inferências ecumênicas correspondentes. As substituições devem ser feitas de acordo com os exemplos abaixo, onde $\Pi_{i}$ é uma derivação obtida a partir de $\Pi$ pelos mesmos procedimentos:

$$
\frac{A \quad B}{\frac{A \wedge B}{B}} \Rightarrow \frac{\frac{A_{i} B_{i}}{\Pi^{A 20}}}{\frac{A_{i} \wedge_{i} B_{i}}{\Pi^{A 19}}}
$$

${ }^{4}$ Como ressaltado no início do trabalho, todos os resultados são válidos para predicados de qualquer aridade. No entanto, por razões de simplicidade, apenas predicados unários serão utilizados nas derivações do apêndice. 


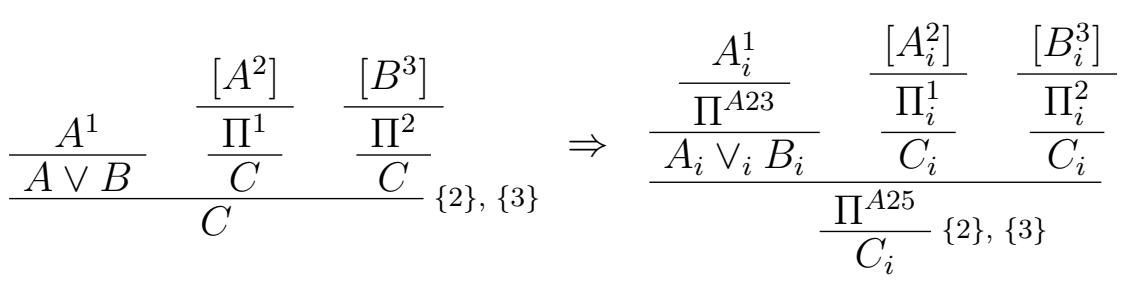

Após substituir todas as inferências da derivação clássica por inferências com fórmulas com subfórmulas contendo o subscrito intuicionista, obteremos uma derivação do formato desejado.

\section{2 \\ Perda e recuperação de alguns resultados no ecumenismo clássico- intuicionista-minimal}

As definições anteriores podem ser estendidas e adaptadas de maneira simples para a obtenção de sistemas ecumênicos que combinem a lógicas clássica diretamente com a minimal ou que combinem as três lógicas: basta que adicionemos as definições de $L_{c} 1$ e as regras próprias de PE ao sistema minimal ou a PEM para que obtenhamos, respectivamente, um sistema clássico-minimal $(\mathrm{PECM}){ }^{5}$ e um sistema clássico-intuicionista-minimal (PECIM) inferencialista, e basta que adicionemos as definições de $L_{i} 1$ e as regras próprias de ECI ao sistema minimal ou a EMI para que obtenhamos, respectivamente, um sistema clássico-minimal (ECM $)^{6}$ e um sistema clássico-intuicionista-minimal (ECIM) generalista.

Já que estes novos sistemas também utilizam a lógica minimal como base, todos os resultados que provamos sobre as relações entre EMI e PEM também valem entre PECIM e ECIM, assim como todos os resultados provados entre PE e ECI sem o auxílio da regra $E F Q$ continuam válidos tanto entre PECIM e ECIM quanto entre PECM e ECM. Como a regra EFQ é usada na prova dos teoremas 4 e 5 , no entanto, estes teoremas não são válidos para sistemas ecumênicos que tomam por base a lógica minimal.

No entanto, muito embora o Teorema 5 utilize a regra EFQ na prova de A8 e o Teorema 4 o utilize em uma única derivação durante a prova de equivalência dos condicionais clássicos, como a prova de ambos é desenvolvida com base na lógica intuicionista e esta, por sua vez, pode ter suas inferências

\footnotetext{
${ }^{5}$ Isto não é surpreendente; como indicado por Prawitz e Mälmnas, a tradução que embasa nossas definições funciona tanto para a lógica minimal quanto para a lógica intuicionista(4, pg. 218). Esta, aliás, é uma propriedade geral de alguns tipos específicos de tradução, conforme demonstrado recentemente em (26).

${ }^{6}$ É interessante notar que, como a regra EFQ pode ser vista como um caso especial da regra do absurdo clássico, a inferência $\perp \vdash A_{c}$ continua sendo válida nesse sistema.
} 
representadas em sistemas ecumênicos generalistas com fórmulas intuicionistas por meio de derivações nas quais todas as proposições só contenham conectivos e átomos intuicionistas (Teorema 9), nós podemos substituir todas as subfórmulas nas provas de A1 a A13 e nas derivações do Teorema 4 por subfórmulas com o subscrito intuicionista (Exemplo: $A \wedge_{c} B \vdash B$ se transforma em $\left.A_{i} \wedge_{i c} B_{i} \vdash B_{i}\right)$, o que nos permite derivar como corolário imediato uma versão modificada dos dois teorema para todos estes sistemas: no Teorema $4, \Gamma$ e $A$ passam a ser $\Gamma_{i}$ e $A^{i}$, obtidos a partir de $\Gamma$ e $A$ por meio da substituição de todas as fórmulas e subfórmulas da derivação por fórmulas de mesmo formato com subscrito intuicionista, e, no Teorema $5, \Gamma_{c}$ e $A^{c}$ são obtidos a partir de $\Gamma_{i}$ e $A^{i}$ por meio do acréscimo do subscrito clássico a algumas fórmulas, não obstante a relação de consequência clássica deva ser substituída pela relação de consequência da lógica para a qual o resultado está sendo estendido.

Após a transformação, o único fragmento problemático do Teorema 4, por exemplo, fica com o seguinte formato, onde as inferências são justificadas pelas derivações e equivalências expostas em A14-A30:

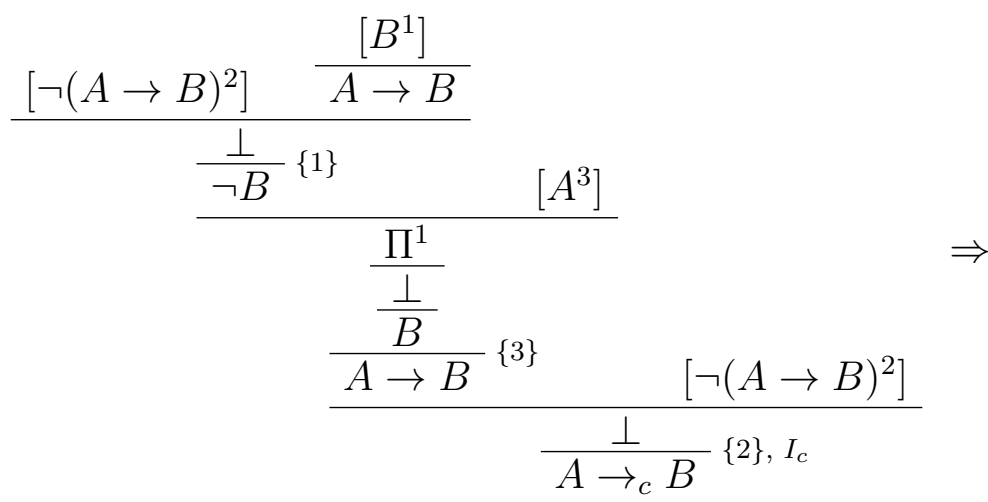

$$
\begin{aligned}
& \frac{\frac{\left[B_{i}^{1}\right] \quad\left[A_{i}^{4}\right]}{\Pi^{A 21}}}{\frac{\left[\neg\left(A_{i} \rightarrow_{i} B_{i}\right)^{2}\right]}{\frac{\perp}{A_{i} \rightarrow_{i} B_{i}}}\{4\}} \\
& \frac{\frac{\Pi_{i}^{1}}{\perp_{i}}}{\frac{\prod_{\Rightarrow}^{A 16}}{\perp}} \frac{\frac{\Pi^{A 30}}{B_{i}}}{\Pi^{A 21}} \\
& \frac{\frac{\frac{B_{i}}{\prod^{A 21}}}{A_{i} \rightarrow_{i} B_{i}}\{3\} \frac{\perp}{\frac{\perp}{A_{i} \rightarrow_{i c} B_{i}}}\{2\}, I_{c}}{}
\end{aligned}
$$


No entanto, boa parte destas transformações são completamente desnecessárias e devem ser incluídas apenas para garantir a uniformidades das transformações, já que o uso da regra $E F Q$ nas derivações inválidas só se dá para a obtenção de fórmulas que são posteriormente usadas como o consequente de algum condicional.

Em termos pragmáticos, a única diferença entre sistemas ecumênicos com base minimal e intuicionista parece residir no fato de que a assimetria das representações minimais também passa a se estender a algumas representações do condicional clássico, de modo que uma asserção inferencialista de $A \rightarrow_{c} B$ deve passar a ser vista como equivalente a uma asserção generalista de $A \rightarrow_{c} B_{i}$ ou $A \rightarrow_{c}(B \vee \perp)$, enquanto a inferência clássica $(A \vdash B \Rightarrow \vdash A \rightarrow B)$, por exemplo, deve passar a ser representada não mais por $\left(A_{c} \vdash B_{c} \Rightarrow \vdash A \rightarrow_{c} B\right)$, mas sim por $\left(A_{c} \vdash B_{c} \Rightarrow \vdash A \rightarrow_{c} B_{i}\right)$ ou $\left(A_{c} \vdash B_{c} \Rightarrow \vdash A \rightarrow_{c} B \vee \perp\right)$. 


\section{Uma reinterpretação ecumênica da Lógica Matemática}

\section{1 \\ A significância da diferença entre o ecumenismo inferencialista e o generalista}

Muito embora as diferenças entre as abordagens inferencialista e generalista tenham sido preliminarmente delineadas no começo do Capítulo 2, os resultados obtidos em partes posteriores do Capítulo e no Capítulo 3 permitem que passemos a apontar diferenças mais marcantes entre as duas abordagens, bem como que discutamos mais a fundo a razão de ser de cada uma e de que forma elas podem se inter-relacionar.

O inferencialismo surge no contexto ecumênico com uma proposta bem específica: oferecer condições de assertabilidade aceitáveis para os operadores de determinado sistema lógico em um sistema lógico no qual eles não são aceitos, o que permitiria que estes operadores, antes rejeitados, fossem reinterpretados e passassem a ser e aceitos sob a nova roupagem inferencial. No contexto do conflito entre clássicos e intuicionistas, isto equivaleria a definir condições de assertabilidade para operadores clássicos no interior da lógica intuicionista, o que de fato é feito por Prawitz em (7). Portanto, a principal tarefa do inferencialista é criar conectivos ecumênicos que, através das condições de assertabilidade expostas em suas regras inferenciais, possam representar os conectivos aceitos por uma das lógicas e rejeitado pelas outras no interior do ambiente ecumênico.

Por sua vez, o generalismo, abordagem original deste trabalho, busca criar novas regras inferenciais que possam representar diretamente no interior do ambiente ecumênico as inferências aceitas por uma lógica e rejeitadas por outras. O foco do generalismo está não na preservação de conectivos ou outras fórmulas de especial relevância, mas sim na preservação da estrutura inferencial originária da derivação, o que é feito por meio de uma reinterpretação direta das inferências controversas (ex: as regras gerais do reductio ad absurdum e do ex falso sequitur quodlibet). E, caso nos filiemos a teorias segundo as quais a caracterização dos diferentes sistemas de lógica deve ser feita através da observação de quais inferências são aceitas ou rejeitadas por cada sistema 
(o que é o cerne das propostas semânticas baseadas em teoria da prova), a recuperação dos conectivos rejeitados será, naturalmente, obtida indiretamente após a recuperação das formas inferenciais.

Este último ponto fica bem claro quando contrastamos as relações existentes entre as lógicas ECI e PE e entre as lógicas ECIM e PEM. Como visto anteriormente, enquanto os conectivos $\left(A \rightarrow_{c} B\right),\left(A \vee_{c} B\right)$ e $\left(\exists_{c} x A\right)$ possuem as mesmas condições de asserção em PE e ECI, as proposições $\left(A \rightarrow_{i} B\right)$ e $\left(\forall_{i} x A\right)$ possuem as mesmas condições de asserção em PEM que, respectivamente, as proposições $\left(A \rightarrow B_{i}\right)$ e $\left(\forall x A_{i}\right)$ em ECIM, não sendo equivalentes às proposições $\left(A \rightarrow_{i} B\right)$ e $\left(\forall_{i} x A\right)$. Aplicações da inferência $E F Q$ tendem a ser mais dispersas do que aplicações do reductio, o que faz com que os subscritos frequentemente precisem ser distribuídos entre as subfórmulas da conclusão de uma derivação. Por esse mesmo motivo usamos o vocabúlo "relações de representação" em nossos resultados, e não mais "relações de equivalência"; as similaridades fortuitas na distribuição inferencial desaparecem quando saimos do caso clássico.

A explicação para essa divergência é bem simples e esclarece um pouco mais de que forma as duas abordagens se inter-relacionam. Quando nos focamos na recuperação dos operadores perdidos durante a transição entre lógicas, nós estamos condensando todas as restrições a que suas condições de asserção estão submetidas na própria definição do conectivo, o que faz com que eventuais operações realizadas exclusivamente sobre "A" ou exclusivamente sobre "B" durante a asserção de um conectivo $\left(A \rightarrow_{c} B\right)$ desaparecem após a introdução do conectivo. Ao revés, quando nos focamos na recuperação das inferências e esta recuperação de conectivos se dá apenas de forma indireta, eventuais operações ou restrições que precisem ser realizadas sobre determinadas fórmulas deixarão sua marca, que só poderá ser removida caso a própria operação se prove supérflua (ou seja: se eliminarmos o subscrito e provarmos que a derivação prescinde dessa inferência específica). Todas as aplicação de inferências controversas, portanto, refletirão direta e especificamente no resultado final da derivação, tornando evidente a influência das inferências controversas sobre cada subfórmula de cada conectivo específico ao final da derivação.

No caso dos sistemas ecumênicos intuicionista/minimais, por exemplo, a inferência $E F Q$ precisa ser aplicada especificamente sobre o consequente durante a asserção da implicação intuicionista (por isso a implicação intuicionista de PEM é equivalente a $\left(A \rightarrow B_{i}\right)$ em ECIM, e não a $\left.\left(A \rightarrow_{i} B\right)\right)$, uma nuance que é perdida no sistema inferencialista. O mesmo seria verdade para o sistema clássico/intuicionista caso definíssemos um quantificador $\left(\forall_{c} x A\right)$ adequadamente e nos termos da abordagem inferencialista; caso ele seja definido 
de modo a corresponder diretamente ao quantificador clássico (no sentido de que $\vdash_{c} \forall x A \Longleftrightarrow \vdash_{p e} \forall_{c} x A$ ), uma vez que algumas asserções universais clássicas depende de uma aplicação "interna" do reductio ad absurdum que torne clássicos os conectivos ou predicados antes da introdução do quantificador, é provável que o equivalente inferencialista desta fórmula fossem as fórmulas equivalentes $\left(\forall_{c} x A_{c}\right)$ e $\left(\forall x A_{c}\right)$, e não a fórmula $\forall_{c} x A$.

Em defesa do sistema inferencialista, nós podemos apontar que as definições de PE e PEM são mais claras e sucintas em sua representação dos conectivos de outras lógicas, além de serem visualmente mais agradáveis (eis que econômicas com subscritos) e inferencialmente mais econômicas. E, de fato, estas qualidades precisam ser reconhecidas; o inferencialismo perde em nuances, mas ganha em simplicidade e praticidade. Dessarte, parece ideal que as duas abordagens sejam avançadas em conjunto e, quando possível, sejam mescladas no interior de um mesmo ambiente ecumênico, o que permitirá que desfrutemos das vantagens de uma sem precisar abdicar das vantagens de outra.

\section{2 \\ Estado da arte}

Conforme apontado na seção 1.2, existem (ou pelo menos nos são conhecidos) cinco autores cujos trabalhos podem ser de alguma forma relacionados à proposta ecumênica: Prawitz, Pereira, Krauss, Girard e Dowek. Antes de concluir nosso trabalho, exporemos o atual estado da arte em maior detalhe.

O artigo escrito por Prawitz(7), no qual o autor definiu pela primeira vez os conectivos pertencentes à lógica que convencionamos chamar de $\mathrm{PE}$, possui um cunho predominantemente filosófico, objetivando a discussão das relações existentes entre as lógicas clássica e intuicionista. Considerações mais técnicas são reservadas para o final do artigo, e o autor dedica poucas páginas à exploração dos conectivos que define.

Ao comentar as diferenças de significado entre os conectivos clássicos e intuicionistas, Prawitz afirma o seguinte:

"Having seen that the classical as well as the intuitionistic codification of deductive practice is fully justified on the basis of different meanings attached to the involved expressions, a choice between the codifications should reasonably depend on what one wants to say with one's sentences. For instance, if one is interested in the computational content of an inferred existential sentence $\exists x A(x)$ and wants it to say that an assertible instance $A(t)$ can be found, then one should choose the intuitionistic codification. If one does 
not care about this and is satisfied with the weaker existential assertion provided by the classical codification, one can still choose the intuitionistic codification since this assertion is also available there by using the sentence $\neg \forall x \neg A(x)$, but one may as well choose the classical codification as more convenient."(pg. 28)

O trecho transcrito sugere que Prawitz possui objetivos típicos da abordagem que chamamos de inferencialista. Em seu exemplo, o autor busca contrastar o sentido assertivo do existencial intuicionista com o sentido assertivo do existencial clássico, indicando que este último seria equivalente a uma asserção intuicionista de $\neg \forall x \neg A$. Isto reflete uma preocupação maior com o sentido conferido às constantes lógicas pelos dois sistemas, e não com o sentido da inferência reductio ad absurdum.

Ao discorrer sobre o caráter ecumênico do sistema PE, o autor continua:

"In their own speech, a classical logician and an intuitionist can both adopt the present mixed system, and the intuitionist must then agree that $A \vee_{c} \neg A$ is trivially provable for any sentence $A$, even when it contains intuitionistic constants, and the classical logician must admit that he has no ground for universally asserting $A \vee_{i} \neg A$, even when A contains only classical constants. That would require a general method for finding for any $A$ a canonical proof of $A \vee_{i} \neg A$ whose immediate sub-proof must be either a proof of $A$ or a proof of $\neg A$, and we do not know any such method.

In the case of the classical form of reductio, the situation is somewhat different. The only constants explicitly involved here are negation and falsehood, understood in the same way classically and intuitionistically, so the classical and intuitionistic logicians are now speaking about the same thing. The intuitionist must agree to such an inference when the inferred sentence contains only classical constants. The classical logician, who initially endorses the inference schema as universally correct, must retract when he realizes that the inferred sentence A may contain one of the particular intuitionistic constants that is not common with the classical ones. Although he is still speaking about the common negation, he now agrees that when $A$ contains an intuitionistic constant, he cannot always infer A after having derived $\perp$ from $\neg A . "$ pg. 30)

A primeira observação mais uma vez ressalta os objetivos inferencialistas de Prawitz, e a segunda nos remete a uma diferença prática entre sistemas 
generalistas e inferencialista: ao usar um sistema clássico-intuicionista inferencialista, o lógico clássico precisaria vigiar a quais fórmulas a regra do reductio estaria sendo aplicada, já que apenas fórmulas contendo constantes clássicas admitiriam tal inferência. Por sua vez, o sistema generalista permite a aplicação do reductio a qualquer forma, intuicionista ou clássica, já que todas as fórmulas do sistema passam a ter uma versão clássica. O lógico classico não mais precisaria retrair seu endosso universal da inferência, muito embora seja obrigado a concluir que sua conclusão, $A_{c}$, possui natureza distinta de fórmulas similares do tipo "A", que só admitiriam provas construtivas. Em outras palavras: o clássico pode continuar a usar o reductio para qualquer fórmula, contanto que reconheça a distinção semântica entre $A_{c}$ e " $A$ ".

As considerações técnicas contidas no artigo de Prawitz, como dito, são bem limitadas; no entanto, Pereira e Rodriguez publicaram recentemente resultados de normalização, soundness e completude para PE (3). Além disso, em um artigo curto que examina o conceito de negação (8), ao comentar a comportamento da implicação clássica de PE e complementar as observações de Prawitz com relação à identidade entre a negação e o absurdo nas lógicas clássicas e intuicionista (o que também subsiste na abordagem inferencialista, já que $\perp_{c}$ é equivalente a $\perp \mathrm{e} \neg_{c} A$ é equivalente a $\neg A$ ), Pereira indica o seguinte:

"It has been objected that the ecumenical classical implication is not an implication at all, since it does not satisfy modus ponens. The idea is that any reasonable concept of conditional/hypothetical proposition/judgement should satisfy modus ponens: given that the antecedent implies the consequent and given that the antecedent is given, then we must have the consequent. This is not so for the ecumenical classical implication. Thus, we can assert an ecumenical classical implication and we can assert the antecedent of this implication, but we are not committed to assert its consequent. We observe that we cannot denied it either, for we can assert the negation of the negation of the consequent (or deny its negation). But we can easily explain why classical implication does not in general satisfy modus ponens: the assertability conditions for classical implication are weaker that those of intuitionistic implication; the assertability conditions for classical implication clearly depend on the meaning of negation, and unless we assume from the very beginning that negation satisfies the classical reductio, there is no reason to accept the general validity of modus ponens in the case of classical implication. As we saw, in the ecumenical system there is just one negation, and this negation is constructive." (pgs.8-9) 
As equivalências examinadas na seção 2.3.1.1. corroboram isso, especialmente em função da equivalência entre as condições de assertabilidade da implicação clássica de PE e a seguinte regra:

$$
\begin{aligned}
& {[A]} \\
& \frac{\neg \neg B}{A \rightarrow_{c} B} I \rightarrow_{1} \quad \frac{A \rightarrow_{c} B \quad A}{\neg \neg B} E \rightarrow 1
\end{aligned}
$$

Usaremos estas condições de asserção no lugar das previstas para PE quando caracterizarmos nosso sistema ecumênico final na próxima seção, já que seu formato parece refletir de maneira mais clara o significado intuitivo da implicação ecumênica clássica.

Ante o exposto, podemos concluir que Pereira e Prawitz abordam o ecumenismo lógico a partir de uma perspectiva exclusivamente inferencialista. Dowek (10) e Krauss (5), no entanto, parecem ter abordado indiretamente alguns aspectos generalistas em suas considerações; o primeiro sob uma luz negativa, rejeitando o generalismo em favor do inferencialismo, e o segundo sob uma luz positiva, adotando alguns aspectos generalistas em seu inferencialismo.

Dowek inicia seu artigo, publicado no mesmo livro que o artigo do Prawitz, com a seguinte caracterização de seus objetivos:

"The idea that the meaning of connectives and quantifiers is expressed by the deduction rules leads to propose a logic containing all the constructive and classical connectives and quantifiers and deduction rules such that a proposition containing only constructive connectives and quantifiers has a proof in this logic if and only if it has a proof in constructive logic and a proposition containing only classical connectives and quantifiers has a proof in this logic if and only if it has a proof in classical logic. Such a logic containing classical, constructive, and also linear, connectives and quantifiers has been proposed by J.-Y. Girard (Girard, 1993). This logic is a sequent calculus with unified sequents that contain a linear zone and a classical zone and rules treating differently propositions depending on the zone they belong.

Our goal in this paper is slightly different, as we want to define the meaning of a small set of primitive connectives and quantifiers with deduction rules and define the others explicitly, in the same way the exclusive or is explicitly defined in terms of conjunction, disjunction and negation: $A \oplus B=(A \wedge \neg B) \vee(\neg A \wedge B)$. A 
first step in this direction has been made by Gödel (Gödel, 1932) who defined a translation of constructive logic into classical logic, and Kolmogorov (Kolmogorov, 1925), Gödel (Gödel, 1933), and Gentzen (Gentzen, 1969) who defined a translation of classical logic into constructive logic. As the first translation requires a modal operator, we shall focus on the second. This leads to consider constructive connectives and quantifiers as primitive and search for definitions of the classical ones." (pg. 229)

Esta caracterização é nitidamente inferencialista, e os objetivos de Dowek parecem alinhados com os de Pereira e Prawitz. Diferentemente de Prawitz e Pereira, no entanto, o autor chega a cogitar uma mudança da abordagem inferencialista para a generalista, mas imediatamente a rejeita:

"Thus, to view Kolmogorov-Gödel-Gentzen translation as a definition, we would need also to introduce a proposition symbol $P^{c}$ defined by $P^{c}=\neg \neg P$. But this would lead us too far: we want to introduce constructive and classical versions of the logical symbols - the connectives and the quantifiers - but not of the non logical ones, such as the predicate symbols." (pg. 231)

Dowek parece rejeitar não só a abordagem generalista, mas também a determinação de Prawitz de que a regra do absurdo clássico também possa ser aplicada a predicados, medida necessária para que também possamos realizar quantificações universais à moda clássica. No entanto, as razões oferecidas por Dowek para um abandono dos elementos não-lógicos clássicos podem ser contornadas facilmente: basta que visualizemos o subscrito clássico não como denotador de um elemento não-lógico diferenciado, mas sim como uma espécie de qualificação assertiva da proposição - ou seja, como um conectivo unário aplicado à proposição original. Assim como $(\neg P a)$ é uma asserção diferenciada sobre os objetos extralógicos " $P$ " e " $a$ " (já que afirma a falsidade ou impossibilidade de "Pa" $),\left(P_{c} a\right)$ e $\left(P_{i} a\right)$ também podem ser visualizados como asserções sobre objetos extralógicos " $P^{\prime \prime}$ e " $a$ ", e não como asserções sobre objetos extralógicos diferenciados do tipo " $P_{c}$ " e " $P_{i}$ ".

De modo a evidenciar a adoção desta perspectiva, caracterizaremos os subscritos "c" e "i" no sistema da próxima seção por meio dos conectivos unários $\square$ e $\oslash$, substituindo asserções do tipo $A_{c}$ e $A_{i}$ por asserções do tipo $\square A$ e $\oslash$ A. Não restará dúvida, portanto, de que as objeções de Dowek não se aplicam a esse sistema.

No aspecto técnico, Dowek diverge de Prawitz e Pereira ao determinar, em suas definições, que conectivos clássicos devem ser construídos a partir 
de operadores intuicionistas contendo subfórmulas duplamente negadas, e não mais da dupla negação de conectivos intuicionistas. A disjunção clássica, por exemplo, é definida como equivalente à disjunção intuicionista $(\neg \neg A \vee \neg \neg B)$, e não como equivalente a $\neg \neg(A \vee B)$. Para diversos conectivos, o resultado prático acaba sendo o mesmo; no entanto, como $(\neg \neg A \vee \neg \neg B)$ e $\neg \neg(A \vee B)$ não são intuicionistamente equivalentes, a análise de Dowek possui divergências menores com as análises de Pereira e Prawitz.

Krauss(5), por sua vez, parece ter uma preocupação específica com a preservação da estrutura inferencial de derivações clássicas, sendo o único autor que realmente se aproxima do generalismo. O autor chega até mesmo a provar um resultado que, por sua forma, talvez possa ser considerado uma versão inferencialista do nosso Teorema 5 (5, pg. 13). Isto ocorre a despeito de suas finalidades declaradamente inferencialistas, já que o principal objetivo do autor é promover um "refinamento" do cálculo de sequentes clássico por meio da adoção de constantes que representariam provas construtivas.

O objetivo de seu texto, que infelizmente nunca chegou a ser publicado, é resumido da seguinte forma:

"The purpose of this part is to provide for a formal framework in which the intuitive reasoning in Part II can be justified. This formal framework has two essential features:

(1) All proofs are constructively valid.

(2) Classical proofs may be incorporated preserving their familiar structure.

The basic idea rests on the observation that classical mathematics uses the logical operator

and, or, if-then, for all, there exists

with two different meaning. One meaning is constructive and is determined by the rules of intuitionistic logic. The other meaning involves proofs by contradiction and becomes non-constructive through the elimination of double negation. Such proofs are usually called indirect. These two meanings can only be separated as long as one abstains from eliminating double negations. With elimination of double negation the two meanings fuse and the proof loses its constructive validity." (pg.1)

Como apontamos anteriormente, o problema levantado no final deste trecho é resolvido pela provisão generalista de separar asserções clássicas de asserção intuicionistas, de forma a permitir o colapso entre asserções simples 
e asserções duplamente negadas apenas para as fórmulas clássicas. Contanto que o lógico clássico se comprometa a diferenciar asserções não construtivas $\left(A_{c}\right)$ de asserções construtivas $(A)$, o uso do reductio deixa de ser problemático no contexto da separação de provas construtivas e não construtivas.

Ainda sobre os efeitos indesejados da eliminação da dupla negação para sistemas que distinguam entre provas construtivas e não construtivas, Kraus afirma que:

"The indiscriminate use of elimination of double negation extinguishes all finer distinctions in classical proofs. This makes it impossible to trace constructively valid parts of classical reasoning. For most pursuits in classical mathematics this appears to be irrelevant. However, as soon as the classical mathematician is interested in an algorithmic interpretation of his results, he ought to locate the places where he uses elimination of double negation because at those places the possibility of an algorithmic interpretation definitely gets lost."(pg. 10).

Mais uma vez, as pretensões de Krauss são plenamente satisfeitas pela abordagem generalista; os subscritos generalistas possuem um caráter "local" e permitem que observemos imediatamente quais trechos de nossa derivação são problemáticos, já que fórmulas e subfórmulas às quais é aplicado o reductio são diferenciadas das demais pelo subscrito clássico.

O autor também oferece versões clássicas de todos os conectivos usuais, à exceção da negação (5, pg. 11). A disjunção e o existencial clássicos são definidos diretamente em termos da dupla negação dos respectivos conectivos intuicionistas, mas a conjunção clássica é definida como sendo equivalente a uma conjunção intuicionista na qual os dois conjuntos estão duplamente negados, se assemelhando às definição de Dowek. O quantificador universal clássico é definido em termos de uma quantificação universal intuicionista na qual o predicado está duplamente negado, corroborando as conjecturas sobre o comportamento de quantificadores universais ecumênicos clássicos que traçamos ao final da seção 4.1.. E a implicação clássica, surpreendentemente, é definida de maneira similar às regras alternativas do tipo $\rightarrow_{1}$ para PE.

Muito embora Krauss tenha definido todos os operadores de maneira autônoma, tudo indica que os conectivos de implicação, disjunção e quantificação existencial poderiam ter sido definidos a partir de um único par de regras, tendo em vista nossas provas de equivalência entre regras de dedução natural análogas a estas regras do cálculo de sequentes de Krauss e nossas regras generalistas para a asserção de fórmulas clássicas em geral. O uso de todas 
estas regras autônomas talvez constitua uma complicação desnecessária, e a adoção do sistema generalista puro ou deste inferencialismo simplificado parece obter os mesmos resultados de forma mais econômica. Deste modo, parece que as regras de Krauss para estes três conectivos poderiam ser substituídas por um par de regras que recuperasse a inferência do reductio, seja para todas as fórmulas (o que configuraria um cálculo de sequentes generalista), seja especificamente para a disjunção, a implicação e o existencial, o que poderia ser feito por meio de restrições sobre a aplicação da regra para que ela só introduza fórmulas clássicas disjuntivas, implicativas ou existenciais (o que preservaria o caráter inferencialista do sistema).

Próximo ao final do texto, o autor retoma sua discussão sobre a importância de diferenciação entre provas construtivas e não construtivas nos seguintes termos:

"We should rather like to persuade classical mathematicians to carry out their proofs distinguishing between inuitionistic (sic) ans classical logic operators depending on what they actually prove. This way they may abstain from eliminating double negations without leaving their familiar traditional tracks of reasoning. Moreover, this way their reasoning stays constructively valid and therefore preserves the possibility of computational interpretation. For this more cautious form of classical reasoning we are proposing a formal framework presenting our system of first-order logic.

Of course, to distinguish between two different kinds of logical operators requires some additional effort. However, this effort is only notational. It does not require new techniques of reasoning. Familiar classical reasoning just amounts to abolishing this distinction by permitting elimination of double negation. The price for this notational simplification is to abandon the possibility of a computational interpretation. In "pure abstract"mathematics this might not be of any concern. However, in computational mathematics attempting to take advantage of such "pure abstract" results it is of considerable interest to trace their origin in search of a computational interpretation. Our system of first-order logic is a simple practicable tool to do exactly this: It is a constructively valid refinement of classical reasoning "(pg. 17)

A abordagem generalista parece, mais uma vez, ser a mais adequada para os objetivos de Krauss. A reinterpretação construtiva do reductio e a inclusão de subscritos/operadores em fórmulas às quais são aplicadas a inferência 
clássicas introduz no sistema uma diferença notacional simples que permite a diferenciação de provas construtivas e não construtivas.

Diante de todas estas semelhanças, podemos concluir que Krauss é o único autor cujas preocupações parecem ser alinhar mais com o generalismo do que com o inferencialismo, ainda que o próprio autor tenha conduzido seus estudos de forma similar aos autores inferencialistas.

Por fim, para encerrar a presente exposição, precisamos mencionar brevemente um artigo com conotações ecumênicas escrito por Girard (9), no início do qual o autor afirma o seguinte:

By the turn of this century the situation concerning logic was quite simple: there was basically one logic (classical logic) which could be used (by changing the set of proper axioms) in various situations. Logic was about pure reasoning. Brouwer's criticism destroyed this dream of unity: classial logic was not suited for constructive features and therefore it lost its universality. Now by the end of the century we are faced with an incredible number of logics-some of them only named 'logic' by antiphrasis, some of them introduced on serious grounds. Is logic still about pure reasoning? In other words, could there by a way to reunify logical systems-let us say those systems with a good sequent calculus- into a single sequent calculus ? Is it possible to handle the (legitimate) distinction classical/intuitionistic not through a change of system, but through a change of formulas? Is it possible to obtain classical effects by a restriction to classical formulas? Etc."(pgs.1-2)

Os objetivos sugeridos nas perguntas finais evidenciam o caráter ecumênico da proposta de Girard. Infelizmente, os aspectos técnicos deste artigo predominantemente formal fogem ao escopo do presente trabalho, eis que o autor cria seu cálculo de sequentes com base no sistema da Lógica Linear, que não é abordada em nosso estudo. Portanto, deixaremos de expor a posição do autor, reservando tal tarefa a estudos futuros que analisem sistemas ecumênicos nos quais também estejam inclusos elementos típicos do sistema linear.

\section{3}

\section{Uma nova lógica}

Podemos usar as definições e provas de equivalência dos Capítulos 2 e 3 para criar uma nova lógica que, além de organizar todas as informações já 
obtidas de maneira clara e intuitiva, possua tanto as vantagens da abordagem inferencialista quanto as vantagens da abordagem generalista. Para isto, usaremos as seguintes regras inferenciais:

$$
\begin{aligned}
& \frac{A \quad B}{A \wedge B} \mathrm{I} \wedge \quad \frac{A \wedge B}{A} \mathrm{E} \wedge_{e} \quad \frac{A \wedge B}{B} \mathrm{E} \wedge_{d} \\
& {\left[A^{n}\right] \quad\left[B^{m}\right]}
\end{aligned}
$$

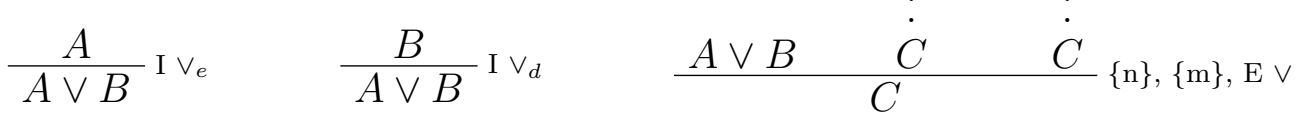

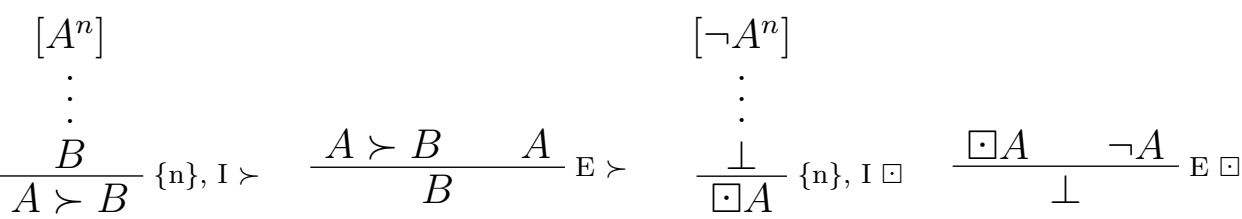

$$
\begin{aligned}
& \frac{\perp}{\oslash A} \mathrm{I} \oslash \quad \frac{A}{\oslash A} \mathrm{I} \oslash \\
& {\left[A^{n}\right] \quad\left[A^{n}\right]} \\
& \frac{\oslash B}{A \rightarrow B}\{\mathrm{n}\}, \mathrm{I} \rightarrow \frac{A \rightarrow B \quad A}{\oslash B} \mathrm{E} \rightarrow \frac{\square B}{A \supset B}\{\mathrm{n}\}, \mathrm{I} \supset \frac{A \supset B \quad A}{\square B} \mathrm{E} \supset \\
& {\left[\neg A^{n}\right] \quad\left[\neg B^{n}\right]}
\end{aligned}
$$

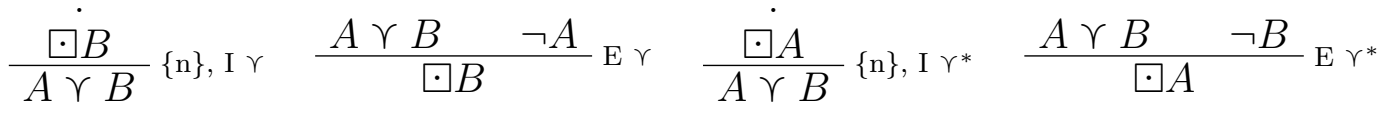

$$
\begin{aligned}
& {\left[A[x / a]^{n}\right]} \\
& \frac{A}{\forall x A[a / x]} \mathrm{I} \forall \quad \frac{\forall x A}{A[x / a]} \mathrm{E} \forall \quad \frac{A}{\exists x A[a / x]} \mathrm{I} \exists \quad \frac{\exists x A}{B}\{\mathrm{n}\}, \mathrm{E} \exists \\
& \frac{\oslash A}{\bigwedge x A[a / x]} \mathrm{I} \wedge \quad \frac{\bigwedge x A}{\oslash A[x / a]} \mathrm{E} \wedge \quad \frac{\square \exists x A}{\bigvee x A} \mathrm{I} \bigvee \quad \frac{\bigvee x A}{\square \exists x A} \mathrm{E} \bigvee
\end{aligned}
$$

Restrições sobre as regras I $\forall$ e i $\bigwedge$ : o parâmetro individual "a" não ocorre em nenhuma hipótese da qual "A" depende. 
Restrições sobre a regra $\mathrm{E}$ ヨ: o parâmetro individual "a" não ocorre em $\exists x A$, em $B$ e nem em nenhuma hipótese da qual $A[x / a]$ dependa, com exceção da própria fórmula $A[x / a]$.

Nova definição para a negação: $\neg A:=A \succ \perp^{1}$.

Passamos a interpretar fórmulas que comportam aplicações de métodos inferenciais clássicos como asserções diferenciadas do tipo $\square A$, e a aplicação de métodos inferenciais intuicionistas faz com que nossas asserções precisem adotar o formato $\oslash A^{2}$. Do mesmo modo, a implicação minimal passa a ser representada como $A \succ B$; a implicação intuicionista passa a ser representada como $A \rightarrow B$; a implicação clássica passa a ser representada como $A \supset B$; a disjunção minimal passa a ser representada como $A \vee B$; a disjunção clássica passa a ser representada como $A \curlyvee B$; o quantificador universal minimal passa a ser representado como $\forall x A$; o quantificador universal intuicionista passa a ser representado como $\wedge x A$; o quantificador existencial minimal passa a ser representado por $\exists x A$ e, por fim, o quantificador existencial clássico passa a ser representado como $\bigvee x A$. As demais constantes são consideradas compartilhadas, muito embora ainda possam ser asseridas de forma diferente usando as regras para $\oslash$ e $\square$.

As regras para $\curlyvee$ marcadas com * são derivadas, mas sua previsão explícita parece ser interessante por criar um certo paralelo com a disjunção minimal em termos de simetria. A derivação segue os moldes da prova de equivalência entre as duas novas formulações da regra para a disjunção clássica em PE (vide seção 2.3.1.1). A adição de regras para os conectivo clássicos, apesar de interessante, também é opcional, já que estes são equivalentes à asserção do implicativo intuicionista ou dos conectivos compartilhados antecedido pelo conectivo $\square$. Mas a remoção dos conectivos intuicionistas seria genuinamente prejudicial, já que as relações entre $\oslash, \rightarrow$ e $\bigwedge$ não são tão simples.

Também poderíamos definir as três implicação de uma forma alternativa bem interessante caso prevêssemos, como condição de asserção, a possibilidade de derivação de uma asserção específica daquela lógica a partir de outra asserção específica daquela lógica:

\footnotetext{
${ }^{1}$ A escolha da implicação a ser usada para a definição da negação é irrelevante mesmo com a inclusão de uma implicação minimal, tornando ainda mais amplas as observações de Pereira em (8). Poderíamos definir a negação como $A \supset \perp$ ou $A \rightarrow \perp$ e obter os mesmos resultados.

${ }^{2} \mathrm{Um}$ aspecto interessante de $\square$ é a sua capacidade de simular, ao mesmo tempo, aplicações do reductio e de $E F Q$, já que a regra $E F Q$ pode ser vista como um caso especial do reductio, conforme observado por Prawitz em (18) e reiterado por nossa prova de que $\perp \vdash A_{c}$. Isto evita que precisemos definir asserções clássicas a partir de premissas intuicionistas, já que as regras para $\square$ felizmente já cobrem todas as inferências necessárias para a caracterização da lógica clássica.
} 


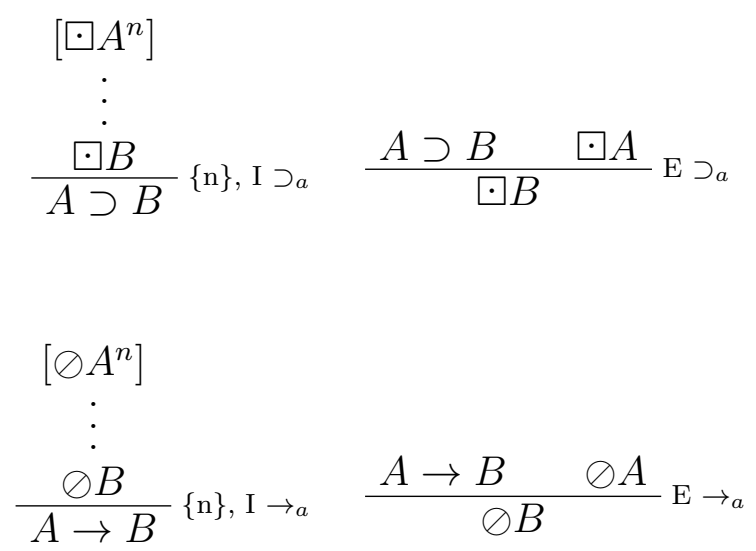

Uma prova de equivalência da nova formulação de $A \supset B$ pode ser encontrada no seção 2.3.1.1, já que está nova versão é análoga à definição das regras $\rightarrow_{2}$, equivalentes à regra $\rightarrow_{1}$. No caso da implicação intuicionista, podemos provar a equivalência de maneira breve usando diretamente este novo sistema:

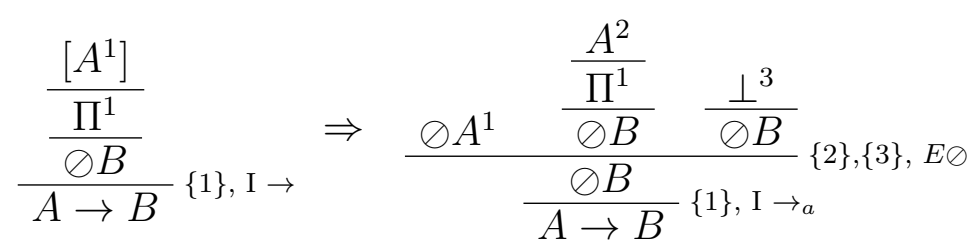

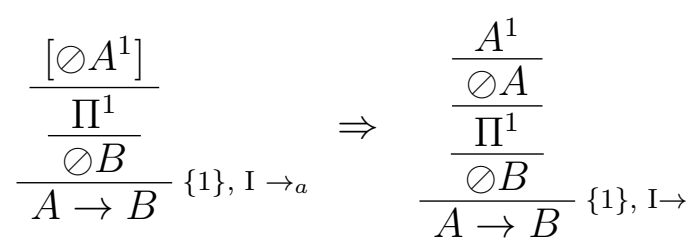

$$
\frac{\frac{\Pi^{1}}{A \rightarrow B} \quad \frac{\Pi^{2}}{A}}{\oslash B} \mathrm{E} \rightarrow \frac{\frac{\Pi}{1}_{\frac{\Pi^{2}}{A}} \frac{\frac{\Pi^{2}}{\oslash A}}{\oslash B}}{\mathrm{E} \rightarrow a}
$$

$$
\frac{\frac{\Pi^{1}}{A \rightarrow B}}{\oslash B}{\frac{\Pi^{2}}{\oslash A}}_{\mathrm{E} \rightarrow a} \Rightarrow \frac{\Pi^{2}}{\oslash A} \frac{\frac{\Pi^{1}}{A \rightarrow B} A^{1}}{\oslash B} E \rightarrow{\frac{\perp^{2}}{\oslash B}}_{\{1\},\{2\}}^{\oslash B}
$$


Estas equivalências evidenciam relações bem interessantes entre os conectivos inferencialistas de uma lógica e suas afirmações generalistas, especialmente em função do formato adotado pelas regras de introdução e eliminação das diferentes implicações. Nós não só podemos realizar afirmações enfraquecidas do consequente usando implicações clássicas com antecedentes construtivos, conforme apontado por Pereira em (8), mas também obter estes consequentes enfraquecidos usando implicações ecumênicas em conjunto com afirmações enfraquecidas do antecedente, tanto no caso clássico quanto no intuicionista. De certo modo, estas novas regras podem nos levar a concluir que existem, em verdade, três modalidades distintas de modus ponens: o modus ponens clássico $(\square A, A \supset B \vdash \boxminus B)$, o modus ponens intuicionista $(\oslash A, A \rightarrow B \vdash \oslash B)$ e o modus ponens minimal $(A, A \succ B \vdash B)$.

Existem pelo menos duas formas de caracterizar esta nova lógica. A primeira é feita através da perspectiva clássica, e consiste em visualizá-la como uma versão refinada do sistema de dedução natural para o a lógica clássica, similar ao refinamento construtivo do cálculo de sequentes clássico feitos por Krauss (5). Esta interpretação é justificada porque, como vimos, todas as derivações clássicas podem ser representadas em termos de derivações contendo apenas asserções do tipo $\square A$, de modo que asserções do tipo $\oslash A$ e $A$ poderiam ser vistas simplesmente como formas específicas (construtivas) de asserir o mesmo resultado $\square A$. E é claro, esta redefinição de conectivos estaria sendo feito apenas para que pudéssemos fazer uma distinção sintática entre a qualidade das provas; não estaríamos "redefinindo" as constantes clássicas, conforme sugerido por Quine, mas sim propondo constantes alternativas distintas das clássicas para a descrição do mesmo fenômeno. Esta parece ser uma proposta produtiva e aceitável para os defensores do pensamento clássico, eis que este novo sistema parece descrever as formas de raciocínio clássico de uma maneira semanticamente mais rica do que o próprio formalismo clássico, que é incapaz de diferenciar entre provas construtivas e não construtivas ${ }^{3}$.

\footnotetext{
${ }^{3} \mathrm{O}$ valor de uma empreitada deste tipo talvez fosse reconhecida pelo próprio Quine, que chega a afirmar o seguinte ao final de seu livro: "Intuitionism is one school of constructivism. More generally, constructivism in mathematics is intolerance of methods that lead to affirming the existence of things of some sort without showing how to find one. This is not a sharp definition of constructivism; there is none, or no unique one. My vague word 'find' could mean 'compute' in the case of a number, and 'construct', in some sense, in the case of a geometric figure or a set. Now constructivism, in some such sense, is congenial and admirable. Adherence to constructivist restraints makes for enhanced understanding of what we manage to accomplish within those restraints. Moreover, the paradoxes of set theory put an added premium on constructivism; for what we accomlplish within its restraints is pretty clearly immune to the threat of contradiction that lingers outside. Even mathematicians who tolerate and use non-constructive methods recognize that a step forward has been made when a constructive proof is found for a theorem that had been proved non-constructively."(11, pgs. $87-88$, grifo nosso)
} 
A segunda forma de caracterização é feita através da perspectiva intuicionista, consistindo tanto em uma reinterpretação construtiva das formas de raciocínio clássico quanto em um refinamento das próprias constantes do intuicionismo no sistema de Heyting. As distinções entre o sistemas intuicionistas de de Heyting e Johansson passam a ser incluídos diretamente no sistema formal, de modo que possamos diferenciar, por exemplo, quando uma implicação $A \rightarrow B$ está sendo usada no sentido de "A é impossível ou é possível obter uma prova de B a partir de A" (Heyting) ou no sentido literal de "É possível obter uma prova de $\mathrm{B}$ a partir de $\mathrm{A}$, independentemente da possibilidade ou impossibilidade de A" (Johansson). No primeiro caso, usamos $A \rightarrow B$; no segundo, usamos $A \succ B$.

Mas a mudança mais radical é feita pela reinterpretação construtiva da lógica clássica. O próprio Heyting parecia já ter previsto esta possibilidade, indicando que a matemática clássica talvez pudesse ser aceita por intuicionistas caso seu sentido fosse esclarecido:

"FORM. Our discussion has assumed the form of a discussion of values. I gather from your words that you are ready to acknowledge the value of other conceptions of mathematics, but that you claim for your conception a value of its own. Is that right?

INT. Indeed, the only positive contention in the foundation of mathematics which I oppose is that classical mathematics has a clear sense; I must confess that I do not understand that. But even those who maintain that they do understand it might still be able to grasp our point of view and to value our work."(15, pg. 11)

A solução, prevista de maneira implícita nos resultados de tradução entre as lógicas intuicionista e clássica e de maneira explícita no presente trabalho, é fazer com que intuicionistas visualizem qualquer asserção clássica (ou seja: não construtiva) de $A$ como uma asserção intuicionista de $\neg \neg A$, evitando confusões ao realizar a distinção semântica correspondente.

Os matemáticos clássicos, diferentemente dos intuicionistas, usam o termo "prova" para caracterizar de um mesmo modo duas asserções construtivamente distintas: sua lógica considera como "prova" tanta as "provas construtivas", que são construções de objetos matemáticos, quanto as "provas não construtivas", que são construções demonstrando a possibilidade a priori de construção do mesmo objeto matemático. Isto a despeito do próprio reconhecimento pelos clássicos de que "provas construtivas" são mais interessantes do que "provas não construtivas", o que sugeriria alguma distinção de natureza 
semântica entre as duas. O intuicionista, ao revés, usa o termo "prova" apenas para se referir ao primeiro tipo de asserção, não possuindo um vocábulo próprio para esta "prova de possibilidade". Ainda assim, este novo conceito é perfeitamente definível a partir da perspectiva intuicionista como uma "prova de impossibilidade da impossibilidade", eis que o reductio nada mais é do que a demonstração de que a negação de uma fórmula é impossível.

Portanto, basta que os dois lados reconheçam esta diferença semântica e tenham ciência do sentido em que o termo "prova" está sendo usado para que o convívio volte a se tornar possível, já que o clássico poderá admitir que as considerações intuicionistas são corretas quando o termo "prova" é interpretado no sentido restrito (ainda que a restrição seja considerada desnecessária ou indevida, já que o clássico se contenta com os dois tipos de asserção) e o intuicionista poderá admitir que as considerações clássicas são corretas quando o termo "prova" é interpretado neste sentido mais amplo (ainda que a ampliação seja desnecessária ou indevida, já que não mais corresponderá ao sentido intuitivo e restrito que o termo possui para os intruicionistas).

\section{4}

\section{Possíveis estudos futuros}

O presente trabalho se dedicou especificamente à análise da abordagem ecumênica aplicada às lógicas clássica, intuicionista e minimal em um nível sintático, o que naturalmente sugere a futura continuação do estudo a partir de uma perspectiva mais focado no aspecto semântico. Não obstante, parece que a nova lógica definida na seção anterior admite uma interpretação intuitiva e bem simples que usa como base a semântica de Kripke para a lógica minimal, algo que também poderia vir a ser analisado futuramente.

Além disso, futuros estudos também poderão abordar sistemas ecumênicos destinados à conciliação de outras lógicas, conforme sugerido em nossa exposição do estado da arte em relação à Lógica Linear de Girard. A aplicação do ecumenismo a diferentes sistemas possivelmente nos trará ainda mais informações sobre a abordagem ecumênica em geral, do mesmo modo que a distinção entre as abordagens inferencialista e generalista nos levou a conclusões que não poderiam ter sido obtidas apenas a partir da primeira.

Por fim, futuros trabalhos também poderão abordar o último sistema apresentado a partir de uma perspectiva mais filosófica e menos formal, o que permitirá que analisemos de forma mais aprofundada os novos conectivos lógicos apresentados e que depuremos os sentidos exatos em que estas novas constantes podem ser compreendidas. 


\section{5 \\ Conclusão}

Muito embora seja uma abordagem recente e ainda bastante dispersa na literatura, o ecumenismo lógico parece ter especial relevância em um contexto onde o pluralismo conquista cada vez mais espaço nos estudos sobre a lógica matemática. O desenvolvimento das múltiplas lógicas atualmente existentes naturalmente nos conduzirá ao desenvolvimento de análises comparativas entre esses diferentes sistemas, e o ecumenismo poderá ser usado tanto para o esclarecimento dos pontos de contato e divergência entre cada uma destas lógicas quanto para o uso das informações obtidas para a criação de novos sistemas lógicos integrados.

Buscando aprofundar um pouco mais a literatura sobre o tema, este trabalho indicou como a abordagem usada por Prawitz para a integração das lógicas clássica e intuicionista também pode ser usada para criar sistemas que integram as lógicas intuicionista e minimal, além de oferecer contribuições menores para o sistema de Prawitz ao criar regras alternativas equivalentes às já definidas para os operadores ecumênicos da disjunção e implicação. Estas duas contribuições originais para a literatura podem ser caracterizadas como extensões naturais do trabalho já iniciado por Prawitz, preservando uma certa relação de continuidade com o artigo citado em (7).

Por sua vez, nossa terceira contribuição, consistente na criação da abordagem ecumênica generalista, representa uma ruptura maior com a literatura já estabelecida, que parece sempre convergir para a abordagem ecumênica que chamamos de inferencialista. Esta mudança de foco, como visto, faz com que possamos criar sistemas ecumênicos distintos bastante característicos, já que que passamos a resgatar formas/regras gerais de inferência (em detrimento do resgate inferencialista de conectivos específicos). E, muito embora a perspectiva pela qual cada abordagem analisa o fenômeno ecumênico seja distinta, em diversos pontos as duas abordagens se aproximam ou até mesmo coincidem, conforme tentamos demonstrar nos resultados provados nos Capítulos 2 e 3 .

Por fim, nosso trabalho culmina na criação do sistema apresentado na Seção 4.3, que mescla elementos das abordagens generalista e inferencialista e os apresenta sob uma nova e distinta roupagem. Esta nova lógica ecumênica integra as lógicas clássica, intuicionista e minimal em um único ambiente e, além de apresentar vantagens tanto do inferencialismo quanto do generalismo, também possui algumas propriedades emergentes bem interessantes, já que podemos redefinir as regras para os conectivos inferencialistas ao usar os conectivos introduzidos pelas regras de caráter generalista na determinação de suas condições de asserção. 
Em que pese tenha se focado apenas na análise das interações entre as lógicas clássica, intuicionista e minimal, o presente trabalho almeja não só promover um aprofundamento nos estudos que envolvem estes três sistemas específicos, mas também conferir subsídios diversos para novos estudos que busquem ampliar ainda mais a literatura ecumênica. Assim como a análise conjunta das abordagens generalista e inferencialista permitiu que criássemos um sistema unificado que possui qualidades de ambas, talvez sua transposição para outros contextos permita que criemos novos sistemas ecumênicos que mesclam satisfatoriamente lógicas diversas usando procedimentos similares aos que empregamos.

Com isto, esperamos que as contribuições do presente trabalho não só integrem a literatura especíifica do ecumenismo envolvendo os três sistemas específicos analisados, mas também que promovam uma ampliação nos horizontes do próprio ecumenismo lógico, de modo a permitir que o campo seja cada vez mais expandido, explorado, difundido e aprofundado na literatura, o que inegavelmente consubstanciaria uma contribuição de extrema valia para o próprio desenvolvimento da lógica como campo do saber. 


\section{Referências bibliográficas}

[1] COOK, R. T.. Let a thousand flowers bloom: A tour of logical pluralism. Philosophy Compass, 5, 2010.

[2] RUSSELL, G.. Logical pluralism. In: Zalta, E. N., editor, THE STANFORD ENCYCLOPEDIA OF PHILOSOPHY. Metaphysics Research Lab, Stanford University, winter 2016 edition, 2016.

[3] PEREIRA, L.C.; RODRIGUEZ, R.. Normalization, Soundness and Completeness for the Propositional Fragment of Prawitz's Ecumenical system. Revista Portuguesa de Filosofia, 73(3/4):1153-1168, 2017.

[4] PRAWITZ, D.; MALMNÄS, P.. A survey of some connections between classical, intuitionistic and minimal logic. In: Schmidt, H. A.; Schütte, K. ; Thiele, H., editors, CONTRIBUTIONS TO MATHEMATICAL LOGIC, volumen 50 de Studies in Logic and the Foundations of Mathematics. Elsevier, 1968.

[5] KRAUSS, P.. A Constructive Refinement of Classical Logic. Não publicado, 1992.

[6] BÉZIAU, J.-Y.. 13 questions about universal logic. Bulletin of the Section of Logic, 35:2/3:133-50, 2006.

[7] PRAWITZ, D.. Classical versus intuitionistic logic. In: WHY IS THIS A PROOF?: FESTSCHRIFT FOR LUIZ CARLOS PEREIRA, número 27 em Tributes, p. 15-32. 2015.

[8] PEREIRA, L.C.. A (very) short note on classical and intuitionistic negation. Não publicado, 2018.

[9] GIRARD, J.-Y.. On the unity of logic. Annals of Pure and Applied Logic, 59, 1993.

[10] DOWEK, G.. On the definition of the classical connectives and quantifiers. In: WHY IS THIS A PROOF?: FESTSCHRIFT FOR LUIZ CARLOS PEREIRA, número 27 em Tributes, p. 228-238. 2015. 
[11] QUINE, W. V.. Philosophy of Logic. Harvard University Press, 2 edition, 1986.

[12] LUKASIEWICZ, J.. Aristotle's Syllogistic From the Standpoint of Modern Formal Logic. Oxford University Press, 2nd edition, 1957.

[13] MATES, B.. Stoic Logic. University of California Press, 2nd edition, 1961.

[14] TARSKI, A.. The concept of truth in formalized languages. In: Tarski, A., editor, LOGIC, SEMANTICS, METAMATHEMATICS, p. 152-278. Oxford University Press, 1936.

[15] HEYTING, A.. Intuitionism: An Introduction. Studies in Logic and the Foundations of Mathematics 17. Elsevier Science, 1956.

[16] JOHANSSON, I.. Der minimalkalkul, ein reduzierter intutionistischer formalismus. Compositio Mathematica, 4:119-136, 1937.

[17] VAN DER MOLEN, T.. The Johansson/Heyting letters and the birth of minimal logic. Technical Report X-2016-04, 2016.

[18] PRAWITZ, D.. Natural deduction: A proof-theoretical study. Dover Publications, 2006.

[19] VAN DALEN, D. Brouwer's Cambridge Lectures on Intuitionism. 1981.

[20] VAN DALEN, D.. Logic and Structure. Universitext. Springer, 5th edition, 2013.

[21] GLIVENKO, V. Sur quelques points de la logique de M. Brouwer. Bulletins de la classe des sciences, 15:183-188, 1929.

[22] FERREIRA, G.; OLIVA, P.. On various negative translations. In: PROCEEDINGS THIRD INTERNATIONAL WORKSHOP ON CLASSICAL LOGIC AND COMPUTATION, CL\&C 2010, BRNO, CZECH REPUBLIC, 21-22 AUGUST 2010., p. 21-33, 2010.

[23] DE GROOTE, P.. On the strong normalisation of intuitionistic natural deduction with permutation-conversions. Information and Computation, 178, 2002.

[24] ZIMMERMANN, E.. Decomposition of reduction. In: Pereira, L. C.; Haeusler, E. H. ; de Paiva, V., editors, ADVANCES IN NATURAL DEDUCTION: A CELEBRATION OF DAG PRAWITZ'S WORK, p. 242-267. Springer Netherlands, 2014. 
[25] DUMMETT, M.. Elements of Intuitionism. Oxford Logic Guides 39. Oxford University Press, USA, 2nd edition, 2000.

[26] HAEUSLER, E. H.; PEREIRA, L. C.. Two basic results on translations between logics. O que nos faz pensar, 25(39), 2016. 
A

\section{Provas adicionais}

A1.

$$
\frac{A^{1} \quad\left[\neg A^{2}\right]}{\frac{\perp}{A_{c}}\{2\}}
$$

A2.

$$
\Rightarrow \frac{\left[A_{c}^{1}\right] \quad\left[\neg A_{c}^{2}\right]}{\frac{\frac{\perp}{A_{c c}}\{2\}}{A_{c} \rightarrow A_{c c}}\{1\}}
$$

$$
\Leftarrow \frac{\left[A_{c c}^{3}\right] \frac{\left[A^{1}\right]\left[A_{c}^{2}\right]}{\frac{\perp}{\neg A_{c}}}\{2\}}{\frac{\frac{\perp}{A_{c}}\{1\}}{A_{c c} \rightarrow A_{c}}\{3\}}
$$

A3.

$$
\Rightarrow \frac{\left[\perp_{c}^{2}\right] \frac{\left[\perp^{1}\right]}{\neg \perp}}{\frac{\perp}{\perp_{c} \rightarrow \perp}\{2\}} \quad \Leftarrow \frac{\frac{\left[\perp^{1}\right]}{\perp_{c}}}{\perp \rightarrow \perp_{c}}\{1\}
$$

A4.

$$
\Rightarrow \frac{\left[\neg A^{1}\right] \quad\left[\neg \neg A^{2}\right]}{\frac{\frac{\perp}{\neg_{c} A}\{2\}}{\neg A \rightarrow \neg_{c} A}\{1\}}
$$

$$
\Leftarrow \frac{\left[A^{1}\right] \quad\left[\neg A^{2}\right]}{\frac{\frac{\perp}{\neg \neg A}\{2\}}{\frac{\frac{\perp}{\neg A}}{\neg_{c} A \rightarrow \neg A}\{1\}}\{3\}}
$$

A5.

$$
\begin{array}{cl}
A \wedge_{c} B^{3} \quad \frac{\left[\neg A^{2}\right] \quad \frac{\left[A \wedge B^{1}\right]}{A}}{\neg(A \wedge B)}\{1\} \\
\frac{\perp}{A_{c}}\{2\}
\end{array}
$$


A6.

$$
\begin{array}{cl}
A \wedge_{c} B^{3} \quad \frac{\left[\neg B^{2}\right] \frac{\left[A \wedge B^{1}\right]}{B}}{\frac{\perp}{\neg(A \wedge B)}\{1\}} \\
\frac{\perp}{B_{c}}\{2\}
\end{array}
$$

A7.

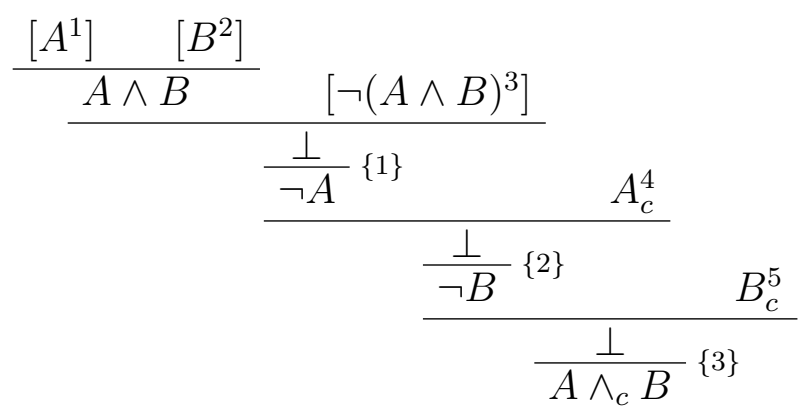

A8.

$$
\begin{aligned}
& \begin{array}{cccc}
\frac{\left[B^{1}\right]}{A \rightarrow B} & {\left[\neg(A \rightarrow B)^{2}\right]} & \frac{\left[A_{c}^{3}\right]}{\Pi^{1}} & \\
& \frac{\frac{\perp}{B_{c}}}{\neg B} & \frac{\left[A^{4}\right]}{\Pi^{A 1}} \\
\cline { 2 - 4 } & \frac{\perp}{\neg A_{c}}\{3\} & \frac{A_{c}}{n}
\end{array} \\
& \frac{\frac{\frac{\perp}{B}}{A \rightarrow B}\{4\} \quad\left[\neg(A \rightarrow B)^{2}\right]}{\frac{\perp}{A \rightarrow{ }_{c} B}\{2\}}
\end{aligned}
$$

A9.

$$
\begin{array}{cl}
\frac{\left[A \rightarrow B^{1}\right] \quad\left[A^{2}\right]}{B \quad} \quad\left[\neg B^{3}\right] \\
\frac{\frac{\perp}{\neg A}\{2\} \quad}{\frac{\perp}{\neg(A \rightarrow B)}\{1\}} \quad A \rightarrow_{c}^{4} B^{5} \\
\frac{\frac{\perp}{B_{c}}\{3\}}{}
\end{array}
$$


A10.

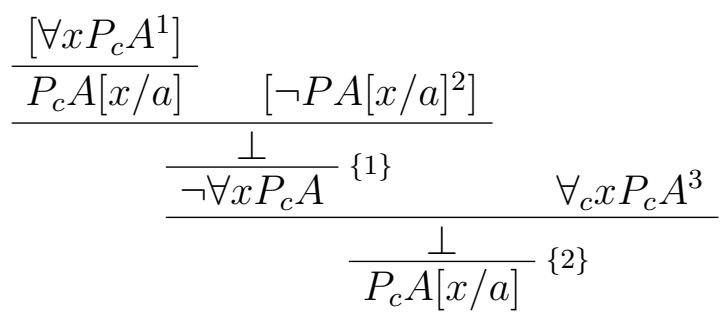

A11.

$$
\frac{\frac{\frac{\Gamma}{\prod_{\forall}^{a}}}{\frac{\forall x P_{c} A}{\left.P_{c} A x / a\right]}} \quad\left[\neg \forall x P_{c} A^{2}\right]}{\frac{\perp}{\forall_{c} x P_{c} A}\{2\}}
$$

A12.

$$
\frac{\perp^{1} \quad\left[\neg A^{2}\right]}{A_{c}}\{2\}
$$

A13.

$$
\frac{\frac{\frac{\left[\neg_{c} A^{1}\right]}{\Pi^{1}}}{\perp}\left\{\frac{\neg^{2}}{\left.\prod_{\Rightarrow}^{A 4} A\right)}\{1\} \quad \frac{\neg_{c}^{A} A}{\neg_{c}}\right.}{\frac{\perp}{A_{c}}\{2\}}
$$

A14.

$$
\frac{A^{1}}{A_{i}} I_{i}
$$

A15.

$$
\Rightarrow \frac{\frac{\left[A_{i}^{1}\right]}{A_{i i}} I_{i}}{A_{i} \rightarrow A_{i i}}\{1\} \quad \Leftarrow \frac{\left[A_{i i}^{1}\right] \quad\left[A_{i}^{2}\right] \frac{\left[\perp^{3}\right]}{A_{i}} I_{i}}{\frac{A_{i}}{A_{i i} \rightarrow A_{i}}\{1\}}\{2\},\{3\}, E_{i}
$$

A16.

$$
\Rightarrow \frac{\left[\perp_{i}^{1}\right] \quad\left[\perp^{2}\right] \quad\left[\perp^{3}\right]}{\frac{\perp}{\perp_{i} \rightarrow \perp}\{1\}}\{2\},\{3\}, E_{i} \quad \Leftarrow \frac{\frac{\left[\perp^{1}\right]}{\perp_{i}} I_{i}}{\perp \rightarrow \perp_{i}}\{1\}
$$


A17.

$\Rightarrow \frac{\frac{\left[\neg A^{1}\right]}{\neg \neg_{i} A} I_{i}}{\neg A \rightarrow \neg_{i} A}\{1\}$

$\Leftarrow \frac{\left[\neg_{i} A^{1}\right] \quad\left[\neg A^{2}\right] \quad \frac{\left[\perp^{3}\right]}{\neg A}}{\frac{\neg A}{\neg_{i} A \rightarrow \neg A}\{1\}}\{2\},\{3\}, E_{i}$

A18.

$$
\frac{A_{i} \wedge_{i} B_{i}^{1} \quad \frac{\left[A_{i} \wedge B_{i}\right]^{2}}{A_{i}} \quad \frac{[\perp]^{3}}{A_{i}}}{A_{i}}\{2\},\{3\}, E_{i}
$$

A19.

$$
\frac{A_{i} \wedge_{i} B_{i}^{1} \quad \frac{\left[A_{i} \wedge B_{i}\right]^{2}}{B_{i}} \quad \frac{[\perp]^{3}}{B_{i}}}{B_{i}}\{2\},\{3\}, E_{i}
$$

A20.

$$
\frac{A_{i}^{1} B_{i}^{2}}{\frac{A_{i} \wedge B_{i}}{A_{i} \wedge_{i} B_{i}}}
$$

A21.

$$
\frac{\frac{\left[A_{i}^{1}\right]}{\Pi^{2}}}{\frac{B_{i}}{A_{i} \rightarrow B_{i}}}\{1\}
$$

A22.

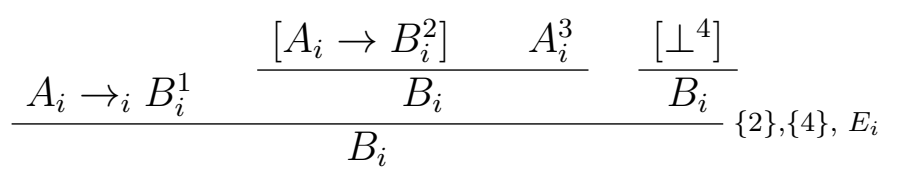

A23.

$$
\frac{\frac{A_{i}}{A_{i} \vee B_{i}}}{A_{i} \vee_{i} B_{i}} I_{i}
$$


A24.

$$
\frac{\frac{B_{i}}{A_{i} \vee B_{i}}}{A_{i} \vee_{i} B_{i}} I_{i}
$$

A25.

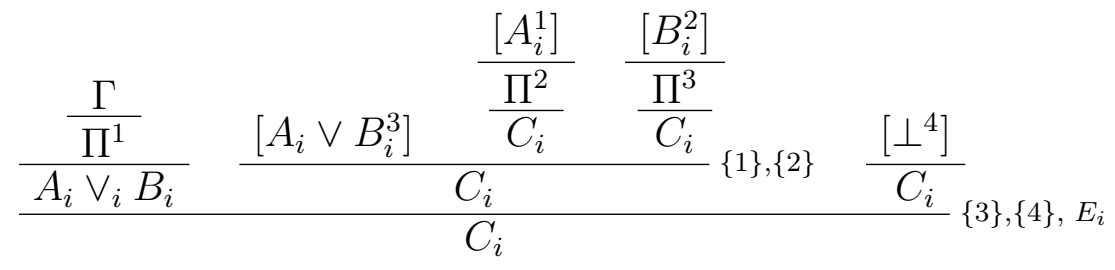

A26.

$$
\frac{\frac{P_{i} a}{\exists x P_{i} x}}{\exists_{i} x P_{i} x} I_{i}
$$

A27.

$$
\begin{array}{ccc}
\frac{\Gamma}{\frac{\left.\Gamma P_{i} a^{1}\right]}{\Pi^{2}}} & \\
\frac{\exists_{i} x P_{i} x}{\frac{\left[\exists x P_{i} x^{2}\right]}{C_{i}}}\{1\} & \frac{\left[\perp^{3}\right]}{C_{i}} I_{i} \\
C_{i} & &
\end{array}
$$

A28.

$$
\frac{\frac{\Gamma}{\Pi^{1}}}{\frac{\forall x P_{i} x}{\forall_{i} x P_{i} x}} I_{i}
$$

A29.

$$
\frac{\forall_{i} x P_{i} x^{1} \quad \frac{\left[\forall x P_{i} x^{2}\right]}{P_{i} a} \quad \frac{\left[\perp^{3}\right]}{P_{i} a}}{P_{i} a}\{2\},\{3\}, E_{i}
$$

A30.

$$
\frac{\perp}{A_{i}} I_{i}
$$

